\title{
Chlamydia trachomatis antibody testing in screening for tubal factor subfertility : clinical application and the pathogenesis paradigm
}

Citation for published version (APA):

Gijsen, A. P. (2006). Chlamydia trachomatis antibody testing in screening for tubal factor subfertility: clinical application and the pathogenesis paradigm. [Doctoral Thesis, Maastricht University]. Universitaire Pers Maastricht. https://doi.org/10.26481/dis.20060310ag

Document status and date:

Published: 01/01/2006

DOI:

10.26481/dis.20060310ag

Document Version:

Publisher's PDF, also known as Version of record

Please check the document version of this publication:

- A submitted manuscript is the version of the article upon submission and before peer-review. There can be important differences between the submitted version and the official published version of record.

People interested in the research are advised to contact the author for the final version of the publication, or visit the DOI to the publisher's website.

- The final author version and the galley proof are versions of the publication after peer review.

- The final published version features the final layout of the paper including the volume, issue and page numbers.

Link to publication

\footnotetext{
General rights rights.

- You may freely distribute the URL identifying the publication in the public portal. please follow below link for the End User Agreement:

www.umlib.nl/taverne-license

Take down policy

If you believe that this document breaches copyright please contact us at:

repository@maastrichtuniversity.nl

providing details and we will investigate your claim.
}

Copyright and moral rights for the publications made accessible in the public portal are retained by the authors and/or other copyright owners and it is a condition of accessing publications that users recognise and abide by the legal requirements associated with these

- Users may download and print one copy of any publication from the public portal for the purpose of private study or research.

- You may not further distribute the material or use it for any profit-making activity or commercial gain

If the publication is distributed under the terms of Article $25 \mathrm{fa}$ of the Dutch Copyright Act, indicated by the "Taverne" license above, 
Chlamydia trachomatis antibody testing in screening for tubal factor subfertility

Clinical application and the pathogenesis paradigm 
Copyright $\bigcirc$ Tanja Gijsen, Mastricht 2006

ISBN-10: 90-5278-514-7

ISBN-13: 978-90-5278-514-1

Vormgeving en druk: Datawyse | Universitaire Pers Maastricht 


\title{
Chlamydia trachomatis antibody testing in screening for tubal factor subfertility
}

Clinical application and the pathogenesis paradigm

\author{
Proefschrift \\ ter verkrijging van de graad van doctor \\ aan de Universiteit Maastricht, \\ op gezag van de Rector Magnificus, \\ Prof. mr. G.P.M.F. Mols, \\ volgens het besluit van het College van Decanen, \\ in het openbaar te verdedigen \\ op vrijdlag 10 maart 2006 on 12:00 uur \\ door

\section{Anna Peter Gijsen} \\ geboren 8 november 1971 te Nederweert
}

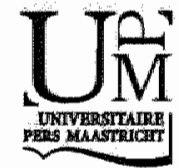


Promotores:

Prof. dr. J.L.H. Evers

Prof. dr. C.A. Bruggeman

Copromotor:

Dr. IA, Land

Beoordelingscommissie:

Prof dr. P.M. Stejlen (voorzitter)

Prof, dr. H. ten Cate

Dr. P. Groothuis

Prof. Dr. J. de Haan

Dr. S.A. Morré (Vrije Universiteit Medisch Centrum, Amsterdam)

The studies presented in this thesis were financially supported by the Profileringstonds, ZonMw and Organon Nederland N.V.

Finamciall support for publication of this thesis has kndly been provided by Organon Nederland B.V. and Ferring B.V. 


\section{Contents}

ABBREVIATIONS

CHAPTER 1

General introduction

Preface

Microorganism

C. trachowatis infection

Pathogenesis of C. Tachomatis infection

Immune response and immunopathology of $C$. trachomatis genital tract infection

Chinical aspects of female $C$. trachomatis genital tract infection

Diagnostic tests

Serologic screening for tubal factor subfertility

Outline of the thesis and aims of the study

CHAPTER 2

Chamydia antibody testing in screening for tubal factor subfertility:

The significance of IgG antibody titre decline over time

CHAPTER 3

Chanydia pnewmoniae and screening for tubal factor subfertility

CHAPTER 4

Performance of five serological Chlamydia antibody tests in subfertile women

CHAPTER 5

Chlamydia trachomatis in subfertile women undergoing uterine instrumentation: Screen or treat? 
CHPTER 6

A mouse model for genital tract pathology by Chlamydia trachomatis

CHAPTER ?

Detection of Chlamydia and mouse hsp 60 antibodies in murine serum following Chamydia trachomatis or Chlamydia pnewnonia infection

CHAPTER 8

General Discussion

SUMMARY

SAMENVATTING

DANKWOORD 


\section{Abbreviations}

$\begin{array}{ll}\text { C } & \text { Chlamydia } \\ \text { CI } & \text { confidence interval } \\ \text { CAT } & \text { Chlamydia antibody testing } \\ \text { Chsp } & \text { Chlamydia heat shock protein } \\ \text { CO value } & \text { cut-off value } \\ \text { EB } & \text { elementary body } \\ \text { ELISA } & \text { enzyme-linked immunosorbent assay } \\ \text { IFU } & \text { inclusion forming units } \\ \text { FITC } & \text { fluorescein-isothiocyanate-conjugate } \\ \text { Hhsp } & \text { human heat shock protein } \\ \text { HSG } & \text { hysterosalpingography } \\ \text { Ig } & \text { immunoglobulin } \\ \text { K } & \text { kappa } \\ \text { LCR } & \text { ligase chain reaction } \\ \text { LGV } & \text { lymphogranuloma venereum } \\ \text { LPS } & \text { lipopolysaccharide } \\ \text { LR } & \text { likelihood ratio } \\ \text { Mhsp } & \text { mouse heat shock protein } \\ \text { MIF } & \text { micro-immunofluorescence } \\ \text { Min } & \text { minutes } \\ \text { MOMP } & \text { major outer membrane protein } \\ \text { MoPn } & \text { mouse pneumonitis } \\ \text { NPV } & \text { negative predictive value } \\ \text { OR } & \text { odds ratio } \\ \text { PBS } & \text { phosphate-based saline } \\ \text { PCR } & \text { polymerase chain reaction } \\ \text { PID } & \text { pelvic inflammatory disease } \\ \text { PPV } & \text { positive predictive value } \\ \text { RB } & \text { reticulate body } \\ \text { SCI } & \text { signal to cut-off index } \\ \text { S/CO value } & \text { signal to cut-off value } \\ \text { SEM } & \text { standard error of mean } \\ \text { STD } & \text { sexually transmitted disease } \\ \text { TP } & \text { tubal pathology } \\ \text { TWAR } & \text { TaiWan Acute Respiratory disease } \\ & \end{array}$


i

, 


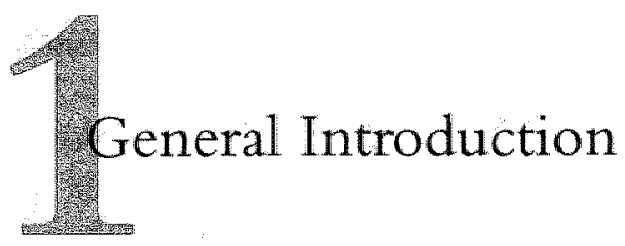

\section{Preface}

Chlamydia (C.) trachomatis is the most common sexually transmitted disease worldwide. In up to $80 \%$ of female patients $C$. trachomatis infection remains asymptomatic. These asymptomatic infections remain undetected and consequently untreated. The untreated women are at risk of developing late sequelae such as periadnexal adhesions and tubal occlusion. They may present at fertility clinics many years after the infection. For the evaluation of pelvic pathology as a cause of the subfertility, laparoscopy with dye testing is considered the gold standard. Laparoscopy is an invasive and costly procedure. Since a correlation between the level of $C$. trachomatis antibodies and the presence of tubal factor subfertility has been established, C. trachomatis antibody testing (CAT) is incorporated in the fertility work-up as a simple and inexpensive screening method for tubal factor subfertility. However, the predictive value of CAT is limited. For clinical practice the availability of a reliable screening method for tubal factor subfertility is important. Adequately estimating a patients' risk for tubal factor subfertility will prevent loss of time by unjustified expectant management, or the institution of ineffective medical treatment. Furthermore, an adequate screening test will minimise the number of unnecessarily performed laparoscopies in patients without tubal pathology.

The thesis will focus on the value of CAT in predicting tubal factor subfertility. At first, the literature on the microorganism $C$. trachomatis and the way infection is induced will be reviewed. Then the pathogenesis, the immune response and its role in the development of tubal pathology will be described. Subsequently the epidemiology, the clinical manifestations of $C$. trachomatis female genital infection and the need for screening programmes will be discussed. Then an overview of the available diagnostic tests will be given and screening for tubal factor subfertility up to now will be reviewed. The chapter ends with an outline of the present thesis and the aims of the study. 
10 Chapter 1

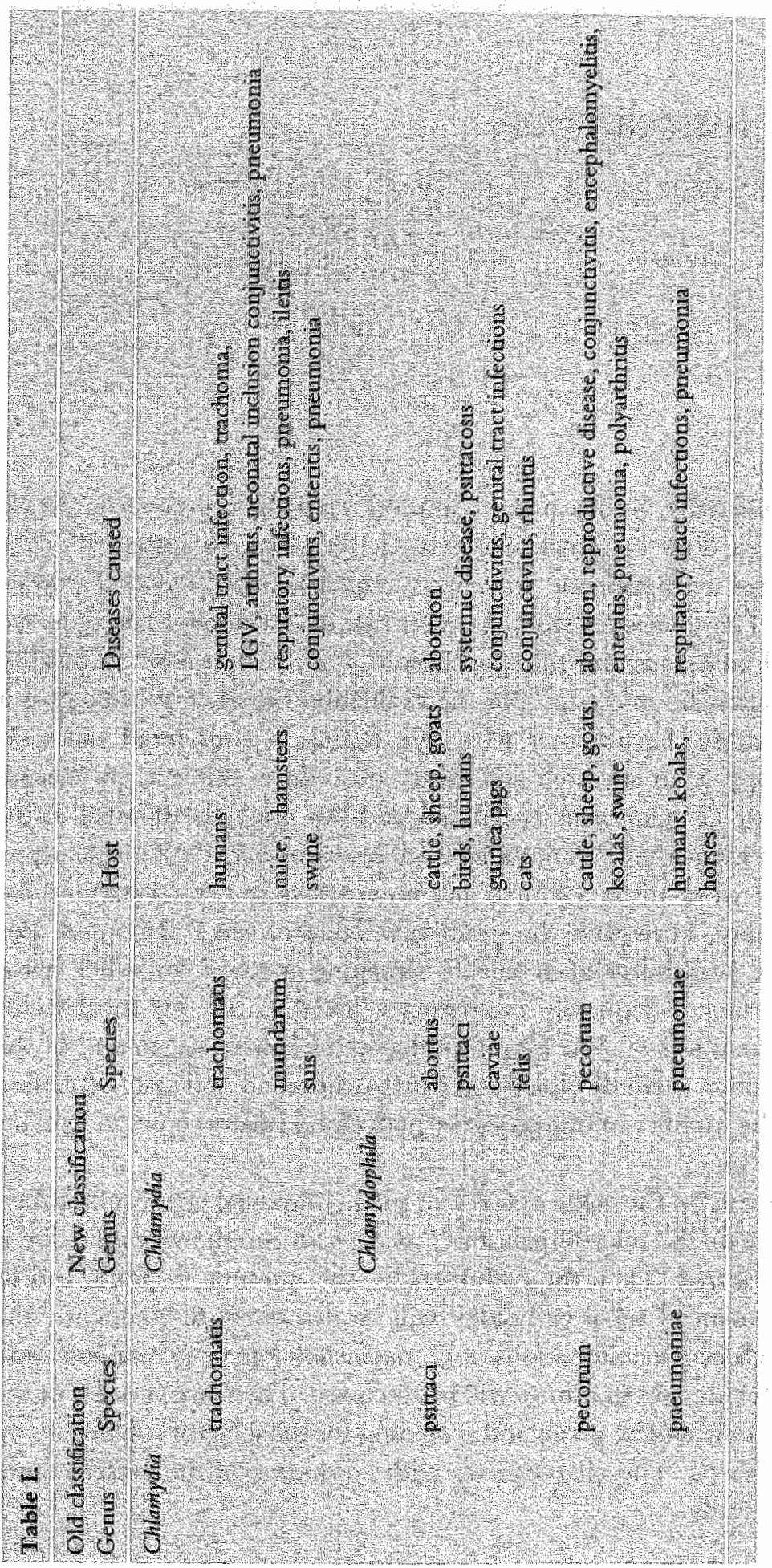




\section{Microorganism}

Chlamydia is a Gram-negative coccoid microorganism that has a unique obligatory intracellular development cycle. Until recently, the classification of Chlamydia was based on phenotypic, morphologic and limited genetic criteria. The family contained a single genus, Chlamydia. The genus Chlamydia was subdivided into four species: C. peconm, C. psittaci, C. pneumonine or TWAR (TaiWan Acute Respiratory disease) and C. trachomatis. However, phylogenetic analysis has progressed and more obligatory intracellular organisms that have a Chlamydia-like developmental cycle of replication were identified. Based on these developments, Everett et al. (1999) proposed a reclassification. The reclassification would replace the genus Chlamydia and its four species, with two genera, Chlanydia and Chlamydophila, and nine species. The genus Chamydia contains $C$. trachomatis. The mouse and swine strains that were previously grouped with $C$. trachomatis belong to separate species (C. muridarum and C. suis respectively). Chlamydophila assimilates the current species C. pecomm, C. pneumoniae and C. psittaci to form Chlanydophila peconm, Chlamydophila pneumoniae and Chlanydophila psiftaci. Three new Chlamydophila species are derived from C. psittaci: Chlamydophila felis, caviae and abortus. Chlamydophila pecorum, felis, caviae and abortus are not pathogenic in humans. However, Schachter and other Chlamydia researchers, have objected to the proposed reclassification. They object because the reclassification is based on minor sequence differences for genus or species differentiation, instead of important biological properties. Furthermore, according to them, there is not sufficient sequence difference that compels a division of the genus into two genera (Schachter et al., 2001).

C. psittaci primarily infects birds and domestic mammals, while in humans infections are rare. C. preuthoniae is a respiratory pathogen infecting lung (Kuo of al., 1995; Hammerschlag, 2000; Hahn et al., 2002) and has also been found in vessels, brain and joints (Saikku et al., 1988; Campbell et al., 1998; Grayston, 2000; Kuo and Campbell, 2000; Taylor-Robinson et al., 2000; Dugan et al., 2002; Leinonen and Saikku, 2002; Ngeh er al.; 2002). C. trachomatis has been isolated from humans and consists of two human biovars (i.e. biologic variants: genetically identical organisms with affinity for different sources) that are transmitted by sexual or other direct contact. The two biovars have been further subdivided in 19 serovars (i.e. serologic variants based on antigenic differences). The biovar trachoma consists of 15. serovars and the remaining 4 serovars are in the biovar lymphogranuloma venereum. (LGV). Serovars in both $C$. trachomatis biovars can cause trachoma (Daniell and Taylor, 1997; Mabey and Fraser-Hurt, 2004; Tabbara, 2001), sexually transmitted disease (Sciarto, 1997; Guaschino and De Seta, 2000), some forms of arthritis (Inman et al., 2000; Ishii et al., 2005; Villareal et al., 2002) and neonatal 
conjunctivitis (Deschenes et al., 1990; Di Bartolomeo et al., 2001) and pneumonia (Griffin et al., 1990; Hess, 1993; Colarizi et al., 1996; Monno et al., 2002). Table I summarises the old and new classification.

\section{C. trachomatis infection}

Chlamydiae are microorganisms, which may exist in two different forms: an infectious form adapted for extra cellular survival and attachment to new host cells (ellementary body (EB)), and an intracellular, metabolically active, non-transnissible form (reticulate body (RB)) (Moulder, 1991; Peeling and Brunham, 1996). C. trachomatis infection is initiated by the extra cellular EB, which attaches to epithelial cells at mucosal surfaces. The EB is ingested and in the cell an endocytic vesicle will be formed containing the $\mathrm{EB}$. Fusion of different $\mathrm{EB}$ containing vesicles takes place. Within 8-12 h after invasion and fusion, EBs develop into the metabolically active RBs. RBs start to divide inside an endosome derived from the host and eventually occupy a large part of the volume of the host cell cytoplasm (termed Chlamydial inclusion). RBs reorganise into EBs 18-30 hours after invasion of host cells and infected cells begin to release infectious EBs by lysis and exocytosis at $48-72 \mathrm{~h}$ after infection.

Although little is known about the pathogenicity of the bacteria and the host defense mechanisms against them, it has been established that surface structures of Chlamydiae are involved in the early steps of infection (attachment and ingestion). At the same time, these surface structures are antigens against which antibodies are raised during infection (Holst et al., 1991). The cell wall structure of the EB of Chlanydia contains both an inner and an outer bilayer membrane. The outer menbrane, which consists of a lipopolysaccharide (LPS) and outer membrane proteins (OMP), determine the antigenicity of the Chlamydia cell wall. LPS is a genus-specific antigen shared by all Chlannydiae. The OMP, including the major outer membrane protein (MOMP), contain species and subspecies serotype-specific epitopes (Brade ef al., 1990). However, regions with high inter-species homology have been identified among the OMP (Yuan et al., 1989). As a restilt, protective immunity developed during Chlamydia infection is thought to be directed against serovar-specific MOMP epitopes, but non-serovar-specific immunity might. develop as well.

During the infective cycle generating new infectious progeny, Chlamydiae express basal levels of two major antigens: MOMP and heat shock protein (hsp) 60. MOMP is the antigen that confers serovar-specific features to Chlamydiae. Protective immunity developed during Chlamydial infection is thought to be 


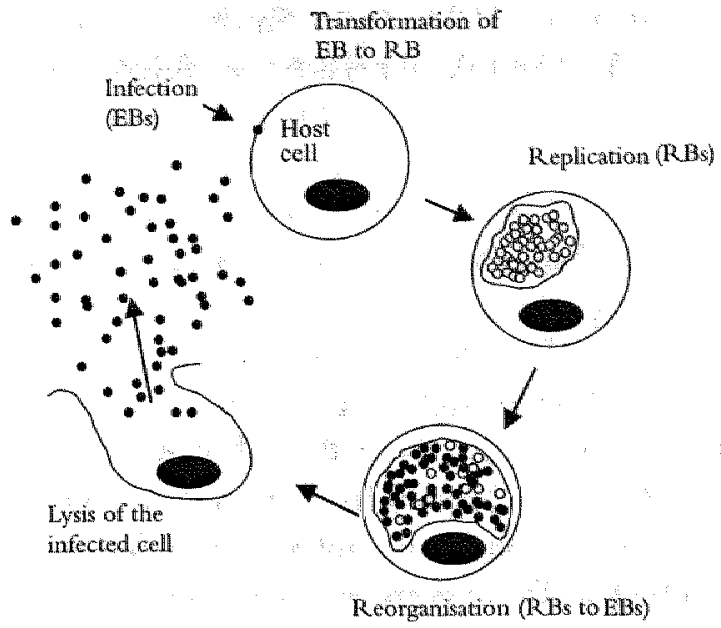

Figure I. The Chlanydia developmental cycle of infection and replication. $\mathrm{EB}$ is elementary body and $\mathrm{RB}$ is reticulate body.

directed especially towards serovar MOMP determinants (Ward, 1995; Findlay et al., 2005). Hsps are highly conserved proteins present in most prokaryotic and eukaryotic organisms (Kinnunen et al,, 2001). These proteins are highly immunogenic, which results in both humoral and cellular immunity. There are four main groups of structurally related hsps based on their molecular weights: hsp 90, hsp 70, hsp 60 and small hsps. Hsp expression is enhanced in cells undergoing stress but also in conditions such as heat shock and nutrient deprivation. Figure I summarises the life cycle of C. trachomatis.

Besides the above-mentioned acute, productive infection, a chronic infection form has been described (Beatty et al., 1994b and 1995). Although this chronic infection form is not well-defined, in vitro studies have shown that under certain circumstances, e.g. by amino acid deprivation (Coles et al., 1987 and 1993), in the presence of penicillin (Beatty et al., 1994a; Dreses Werringloer et al., 2000), or gamma interferon (IFN- $\gamma$ ) (Beatty et al., 1993; Dean et al., 2000), persistence of Chlamydiae may occur. Recently, Dean and coworkers (2001) established a persistent infection when IFN- $\gamma$ in physiologic concentrations was present. Thus, during the acute phase of infection the production of inflammatory molecules; under which IFN- $\gamma$, occurs to eradicate infection. However, IFN- $\gamma$ may also contribute to initiation of a persistent Chlamydia infection (Dean and Powers, 2001). This persistence is characterised by incomplete Chlanydia replication and the formation of atypical RBs, which are unable to differentiate into infectious progeny (Beatty et al., 1994a; Koehler et al., 1997). The chronic state of Chlamydia infection might therefore be defined as long-term intracellular persis- 
tence of non-infectious atypical Chlamydial forms (Beatty et al., 1994a; Dean et al., 2000; Peters ef al., 2005). The role of persistence of infection in vivo still. needs to be studied.

\section{Pathogenesis of C. trachomatis infection}

C. trachomatis is transmitted by direct sexual contact. The microorganism infects epithelial cells at mucosal surfaces of the genital tract. Infection is characterised by inflarmmation, but little is known about the mechanisms that initiate and sustain this infammatory response to Chamydia. In response to infection, epithelial cells at mucosal surfaces secrete chemoatractant and proinflammatory cytokines. It has been suggested that these cells act as an early warning system for cells in the underlying mucosa. This concept was studied by Rasmussen and coworkers (1997), who showed that infection of cervical epithelial cells with $C$. trachomatis induced the secretion of proinflammatory cytokines that have chemoattractant and proinflammatory functions. Not only invasion of Chlamydia, but especially its intracelJular growth is required for this epithelial cytokine response. Thus, the acute inflammatory response induced by Chlamydia infection is mediated by the local production of proinflanmatory cytokines from infected epithelial cells. The mechanisms by which $C$. trachomatis indaces inflammation that ultimately leads to tissue damage and scarring, resulting in tubal pathology and subfertility, are only partly understood. It has been suggested that the risk of subfertility increases after repeated episodes of salpingitis (Cohen and Brunham, 1999; Weström, 1980 and 1994; Lehtinen and Paavonen, 1994). Subfertility after salpingitis is due to occlusion of the frllopian tubes by fibrous scarring, adhesion formation, mucosal damage and ovarian encapsulation. Tissue damage due to $C$. trachowatis has been assumed to be immunopathologically similar to trachoma, a chronic keratoconjunctivitis due to infection with $C$. tradhomatis. In patients with trachoma, it has been demonstrated that tissue destruction and chronic sequelae are only seen in hosts repeatedly exposed to the microorganism (Grayston et al, 1972, 1985). Although the importance of repeated Chllamydia infections in the development of chronic sequelae has been established (Beatty et al, 1995), reactivation of persistent infection might also play a role in the development of these chronic sequelae.

Evidence exists that G. machomotis may persist in the fallopian tubes in a dormant but viablo state (chronic infection) for a long period. Pearce and coworkers (1994) showed that $C$. trachomatis DNA or antigens, but not infectious microorganisms, were present in tubal tissue long after the acute phase of infection. The majority of the studied patients had received antibiotic therapy suggesting a persistent infection even after antibiotic therapy. Data of in vitro 
studies support this suggestion (Beatty et al., 1994). In patients with histologically documented chronic salpingitis and bilateral tubal occlusions $C$. vrachomatis antigens in fallopian tube tissue were found in 11 out of 56 (20\%) patients (Dieterle et al., 1998). In women presenting with ectopic pregnancy, both $C$. trachomatis DNA and RNA was found in 7/10 fallopian tube biopsy samples (Gérard et al., 1998). The duration of persistence in vivo is not known, but recent evidence suggests that organisms may persist for as long as 5 years in the genital tract (Dean et al., 2000).

It remains to be studied how persistent microorganisins contribute to the development of tubal pathology. For this purpose animal models are of great value since they enable us to study several infection modalities such as acute and chronic infections, re-infections and reactivation of infection in well-defined conditions.

Most of the animal studies have been done in mice and focussed on acute infections. Differences in host (mouse strain dependency) and differences in microorganism (human versus mice $C$. trachonnatis serovars) were studied. The end-point of most of the animal studies was the development of infertility, defined as a failure to achieve pregnancy after mating with several male mice of proven fertility. De la Maza et al. (1994) studied the susceptibility to Chlamydia infection in different mouse strains. They compared $\mathrm{C} 3 \mathrm{H}, \mathrm{BALB} / \mathrm{c}$ and $\mathrm{C} 57 \mathrm{BL} / 6 \mathrm{~J}$ mice in their ability to develop salpingitis and tubal pathology after intravaginal inoculation with $3 \mathrm{x}$ $10^{7}$ inclusion forming units (IFU) C. muridarum (previously called mouse pneumonitis (MoPn)). Of these three strains of mice, $\mathrm{C} 3 \mathrm{H}$ developed the most extensive disease and had the highest rate of infertility, whereas C57BL/6J mice showed the mildest salpingitis. The duration and severity of infection was significantly increased in the C3H strain when compared to that in the C57 strain (Darville et al, 1997). In addition to differences in mouse strain susceptibility to Chlanydia genital infection also the age of the animals was shown to be important. Older animals were more resistant to infection than younger ones (Pal et al., 2001). Mice are considered to be born inmmunologically mature, but sexual maturation does not occur in most strains of mice until the animals are 6 to 10 weeks of age. In this respect progesterone and estradiol levels can have an effect on the local immune response, which could affect susceptibility to Chlamydia infection (Kaushic et al, 2000). The results suggested that sexual maturation might play a significant role in the decrease in susceptibility to a C. trachomatis upper genital tract infection.

Tuffrey et al. (1986a, 1986b) compared the C. muridarum biovar with human serovars, and showed that intravaginal inoculation of $\mathrm{C} 3 \mathrm{H}$ mice with $C$. muridarum led to hydrosalpinx formation and infertility, whereas intravaginal inoculation with human serovars resolved without tubal pathology. Human serovars caused post-infectious sequelae only when high doses were inoculated directly into the uterine horns in mice pre-treated with progesterone. Progesterone was 
given before inoculation to synchronise oestrus. It has been shown that during the follicular phase of the cycle mice are less prone to develop an upper genital tract infection than during the luteal phase (Ito et al, 1984; Pal et al., 1998). Why progesterone pre-treatment increases susceptibility to local infection needs to be investigated. One possibility is that progesterone treatment interrupts the normal reproductive cyclicity, which may enhance the attachment of Chlamydiae and establishment of infection in uterine epithelial cells. It is also possible that progesterone causes immunosuppression, decreasing innate immunity to Chlamydia infection (Tufrey et al, 1981, 1986a, 1986b, 1990; Kaushic al, 1998; Brunham and Rey-Ladino, 2005).

Pal al (1998) performed migration studies in $\mathrm{C} 3 \mathrm{H}$ mice, which were intravaginally inoculated with $C$. muridarm, and detected infectious particles in the upper genital tract within 24 hours after inoculation. To ascertain the dose needed to induce infertility, groups of $\mathrm{C} 3 \mathrm{H}$ mice were inoculated with $10^{4}, 10^{5}$, $10^{6}$ or $10^{7}$ IFU C. muridarm, of which $15 \%, 45 \%, 70 \%$ and $80 \%$ respectively became infertile (in contrast to $10 \%$ in the control group). From these dose-dependent results Pal ot al. (1998) concluded that different doses of inocula lead to different degrees of tubal disease.

Only a few animal studies have been performed on $C$. trachomats re-infection and tubal pathology. C. trachomatis reminfection has been described by Patton ef al. (1989) in macaques, using different serovars of $C$.trachomatis. Their goal was to induce extensive pathology and distal tubal obstruction, in order to develop an animal model that simulated acute pelvic inflammatory disease in women. Patton and coworkers found that re-infection with homologous and heterologous $C$. trachomatis serovars produced a comparable degree of tubal scarring and distal tubal obstruction.

Furthermore, in 1990 Patton and coworkers studied the effects of repeated cervical inoculations followed by a single direct tubal inoculation with $C$. trachomatis in macaques, to test the hypothesis that tubal inoculation after cervical priming causes more extensive disease than primary tubal inoculation alone. In conclusion, they observed the development of peritubal adhesions whether or not the animals had previously been infected in the cervix. More evidence of inflammation was seen in the upper genital tract in macaques that had cervical inoculacions prior to tubal inoculation with $C$. trachomatis, as compared to macaques that had tubal inoculations only. This suggests that repeated infections are more likely to cause extensive tissue damage after prior priming of the genital tract with $C$. trachomatis.

The susceptibility to re-infection after a primary genital tract Chlamydia infection was studied by Rank et al. (1988) in female guinea pigs. Their goal was to determine the duration of resistance to re-infection after the primary inoculation. 
The animals were infected vaginally with Chlanydophila caviat (previously called guinea pig inclusion conjunctivitis agent), and re-inoculated at different intervals. Guinea pigs were considered resistant to re-infection when no Chlamydia could be isolated any longer from cervical swabs. Thirty days after primary inoculation the majority of guinea pigs was resistant to re-infection, but after 77 days all animals could become re-infected again. The course of this re-infection was shorter and of lower intensity as compared to the response in animals after primary inoculation. In this study various immune parameters were examined: a decrease in IgA and IgG antibodies was found 30 days after primary inoculation, and cell mediated immunity (the amount of peripheral blood lymphocytes) was at its maximum 30 days after primary inoculation and decreased thereafter.

Ramsey et al. (2000) studied the disease outcome subsequent to primary and secondary urogenital infection with $C$. muridarum or $C$. trachomatis. They hypothesised that protection against infection with $C$. trachomatis is serovar-specific, and that re-infections with different serovars are responsible for pathological responses and tissue damage. To confirm this hypothesis, they studied fertility and hydrosalpinx formation in $\mathrm{C} 3 \mathrm{H}$ mice after primary vaginal inoculation and re-inoculation with $C$. muridarum and different $C$. trachomatis serovars. First, Ramsey and coworkers confirmed earlier findings by de la Maza et al. (1994) that even a single inoculation with $C$. muridarum induced infertility in $\mathrm{C} 3 \mathrm{H}$ mice. Furthermore, they observed that mice inoculated primarily with a C. trachomatis serovar and re-inoculated with a different serovar remained fertile. On the other hand, mice re-inoculated with the same $C$. trachomatis serovar became infertile. In conclusion, repeated inoculation with the same $C$. trachonatis serovar seems to induce a more profound inflammatory response as compared to repeated inoculation with different C. trachomatis serovars. Those results differ from the results of Patton and coworkers (1990) as described above.

Thus, most animal studies concerning $C$. trachomatis inoculation and re-inoculation deal with acute pelvic inflammatory disease with subsequent salpingitis. Although the studies published are heterogenous concerning the animal strains, the C. trachomatis and C. muridarum administered, the inoculation route and dose of inoculation used, some conclusions can be drawn from these animal studies: different hosts have shown different susceptibility to infection and different inoculation doses induce different degrees of tubal pathology. In mice, some biovars are more virulent than others, $C$. muridarum generally resulting in infertility after one single inoculation only. In guinea pigs a transient resistance to re-infection has been observed. In macaques cervical priming prior to tubal inoculation increased the extent of tubal pathology. In macaques re-inoculation with the same serovar as well as with different serovars induced infertility. In mice however, re-inoculation with the same serovar induced more pronounced tubal pathology whereas mice 
re-inoculated with different serovars remained fertle. Extrapolating the results of the anmal studies to the human situation remains difficult. These studies all focussed on the course of acute infections resulting in extensive pathology already after primary noculation. In women thowever, $C$, trachomatis infections nierely induce slent infections eventually leading to chronic sequelae.

\section{Immune response and immunopathology of C. trachomatis genital tract infection}

Whether $C$. trachomatis infection results in immunity and / or in disease depends on interactions between the host immune system and specific Chlamydia antigens. Up to now, from the very complex structure of $C$. trachomatis, only a limited number of antigens are serologically recognised and studied during infection. Among these, the major serologically defined antigens are the ones most abundantly accessible on the surface of the EB, i.e. MOMP, LPS and hsp antigens. The inimune response consists of both a cellular and a humoral response.

The cellular host response to a primary Chlamydia infection occurs at the mucosal surface within one to two days after infection. The cellular response is characterised by inflammation and mucosal infiltration with neutrophilic lymphocytes and small numbers of monocytes (Kuo, 1988). Neutrophilic lymphocytes are recruited and migrate in large numbers to the site of infection, where phagocytosis of Chlamydia elementary bodies is induced (Yong et al., 1986). This host response eliminates or substantially reduces the bacterial load (Rank et al, 1985; Whittum-Hudson et al., 1987; Monnickendam et al., 1980; Brunham et al., 1985).

Besides the cellular immune response a humoral response occurs. The specific interactions of Chlamydia antigens and $\mathrm{T}$ cell subsets in the endometrium during an ascending infection are merely unknown, but plasma cell and $T$ helper (Th)-cell infiltration are pathognomonic for endometritis (Paavonen et al., 1985; Lehtinen et al, 1986; Kiviat et al., 1990). Following local antigen stimulation by C. trachomatis, specific nucosal $\mathrm{T}$ cells (Th1-cells) stimulate the maturation of the plasma cells (Zeitz et al., 1990). Furthermore, plasma cell infiltration is enhanced by inhibition of cytotoxic suppressor cells in response to $C$. trathomatis antigen stimulation (Pavonen and Wolner-Hanssen, 1989; Punnonen et al., 1989). Plasma cells produce immunoglobulin (Ig) A, $\operatorname{IgM}$ and $\operatorname{IgG}$ antibodies. $\operatorname{IgA}$ provides local immunity at mucosal surfaces. IgM is the earliest antibody to appear after $C$. trachomatis antigenic stimulation, but it declines rapidly and is often succeeded by IgG production. IgM is not itself an opsonising antibody, but it activates processes which are able to induce opsonisation. Secondly, IgG antibodies are formed which are the most abundantly present Igs. IgGs are the most signifi- 
cant antibody class for neutralizing LPS and MOMP. They act by blocking the sites of the antugenic molecule that determines attachment to cell receptors, and they also enhance phagocytosis of antigens (Sherris and Ray, 1990):

Animal studies have demonstrated a role for antibodies, particularly mucosal $\operatorname{Ig} A_{n}$ in protection against (or clearance of) vaginal $C$. mowowatis infection and in this way preventing the infection to ascend to the upper genital aract. In vivo, presence of $\operatorname{IgA}$ and $\operatorname{Ig} G$ antibodies against the $C$. trachomatis MOMP reduced vaginal infection rates, reduced the level of shedding of $C$. thow mats from the vagina and reduced dissemination of infection to the upper genital tract and the associated inflammatory response (Cotter et al., 1995).

The course of $C$. trachomatis infection largely depends on the interaction and balance of cytokines secreted by activated $T$ cells. The role of this $T$ cell response has been reported in animal models (Patton et al, 1994). Th cells can be divided in Th1 and Th2 cells which each produce specific cytokines. IFN- $\gamma$, a product of Th1 cells, has been described as the single most important factor in host defence against Chlamydia, while disease susceptibility has been associated with enhanced expression of $\mathrm{LL}-10$, a marker of Th2 cell activation (Beatty et al., 1993). Disturbance of the balance between Th1 and Th2 cell mechanisms, in the favour of $T h 2$, might enable Chlamydia to survive in the host (Morrison ef al, 1989; Paavonen and Lehtinen, 1994). The Th1 response induces IFN- $\gamma$, and in vitro studies have shown that treatment of infected cells with IFN $y$ limits the replication of Chlamydia (Paavonen and Kruse, 1999). Studies in primates have shown that after a single inoculation with $C$. rachowatis, IFN- $\gamma$ is induced, suggesting that a Th1-like response predominates (Van Voorhis et al, 1996 and 1997). Furthermore, they showed that after re-infection the Th1 response continued to dominate. Since it is known that repeated infections are more likely to cause wbal pathology, one might speculate this $T h-1$ response to play a role in the induction of $C$. trachomatis induced tubal pathology.

Although the exact role of the cytokines is not fully defined, Thl-like cytokines are important for the killing of intracellular microorganisms, whereas "Th2-like cytokines are known to promote persistence of intracellular bacteria. Especially the presence of IFN- $\gamma$ has been associated with enthanced killing of microorganisms and elimination of Chlamydia infection (Beatty et al., 1993; Stambach et at, 1994; Rank et al, 1992). Interestingly, as described earlier, IFN- $\gamma$ also mediates the development of persisting atypical Chlamydia forms in vitro (Beatty et al., 1994). These data suggest that on the one hand Th1-cytokines (especially IFN-Y) may help to recover from a $C$. trachomatis infection but that on the other hand these cytokines induce the development of persistent infection.

Thus, although the host responses to infection have a protective character, i.e. aim to resolve Chlamydia infection, the immune responses might on the other 
hand also form the basis of immunopathogenesis. Especially during re-infection or reactivation of persistent infection, the immune system has already been primed and the recurent inflammatory reaction might ultimately culminate in destructive pathology of the genital tract.

Many authors have associated the development of chronic sequelae after $C$. tradiomatis infection with a host response to hsp, secreted by the microorganism (Toye et al., 1993; Witkin et al. 1993; Arno et al., 1995). Hsps are major immune targets for both cellular and humoral immune responses, and their exact role in the development of $C$. tradowatis induced tubal pathology remains an important issue. They function as an important survival mechanism to safeguard cells and microbes from conditions of stress. Although not the only inducers of hsps, infections may activate hsp expression by the release of proinflanmatory mediators or by the immune response they induce. Thus the appearance of hsps is an indication of disturbance of the local cellular environment. More specifically, the inmune response to Chlamydia hsp (Chsp) 60 may detemine the outcome of Chlamydia infection.

In humans hsp60 is found to be associated with subfertility related to tubal occlusion and ectopic pregnancy in women with pelvic inflammatory disease (PID) Brunham et al., 1985; Sziller et al, 1998; Wager et al, 1990; Ault et al., 1998; Persson et al., 1999). In salpingeal tissue of patients with tubal pathology due to PID, presence of activated Chsp 60 reactive $T$ cells suggests that these cells play a role in the pathogenesis of tissue damage in tubal pathology (Kinmunen et al., 2000 ).

Chsp 60 antibody levels have been suggested to be predictive of an enhanced risk of PID (Peeling et al., 1997). As shown by Spandorfer and coworkers (1999) not only hsp 60 but also hsp 10, another member of the hsp family, seems to be involved in tubal pathology. In this study it was shown that tubal occlusion was strongly associated with circulating antbodies to both Chlamydia structural antigens and to the Ghsp 10.

In animal models of $C$. thathowats ocular mection (Morrison et al. 1989) or salpingitis (Peeling et al, 1999) purified Chsp 60 elicits an immune response comparable to that in C. trachomatis genital infection.

In conclusion, cellulat as well as humoral immune responses play a role in the defense against $C$, trachomatis infection but also in the pathogenesis of the disease.

\section{Clinical aspects of female C. trachomatis genital tract infection}

Over the last decades the incidence of reported $C$. trachomatis infection has increased dramatically. Although this trend probably reflects improvements in screening, 
recognition of asymptomatic infection and reporting, wher than a true rise the incidence of the disease, $C$. rudhomatis is the most common sexually transmitted disease (STD) in the Netherlands (van de Lar et al, 1997 ) and other westem countries. In the United States of America an annual incidence of over 4 milhon new cases of infection is reported by the Centers for Disease Control, 10 million new infections occur in Exrope and 89 million cases occur worldwide each year (Guaschino et al, 2000; Low and Cowan, 2002; Marra et al, 1998).

To identify risk factors associated with $C$. thehomatis infection various studies in STD clinics and general practices have been conducted. A number of risk tactors are associated with $C$. trachomatis infection, including fenale sex (Matondo et al., 1996; Simms et al., 1997), young adult age (Oakeshot et al., 1998), particularly teenage ginls (Evans et al, 1993; Grun et al, 1997; Simms et al., 1997) and black ethnic origin (Evans et al, 1993; Oakeshot et al., 1998). In addition, young age is associated with increased risk of repeated infection (Hillis et al., 1994 and 1997). Sexual behaviour risk factors include an increased number of sexual partners (Evans et al., 1993; Grun et al., 1997; Oakeshot et al., 1998) and fahure to use barrier contraceptives, such as condoms (Evans et al., 1995). Gaydos and coworkers (1998) conducted a large survey among over 13.000 new fenale arny recruits to design a Chlanydia screening program for asymptomatic infection. The new recruits were screened by ligase chain reaction (LCR) for C. trachowntis in urine and information on potential risk factors was obtained. They found the following risk factors to be independently associated with Chlamydia infection: having ever had vaginal sex (odds ratio (OR) 5.9 ), being 25 years of age or less (OR 3.0), being black (OR 3.4), having had more than one sex partner (OR 1.4) or a new partner in the previous 90 days (OR 1.3), having sex without condom use in the previous 90 days (OR 1.4) and having ever had a STD (OR 1.2).

Genital C. trachomatis infection is asymptomatic in up to $80 \%$ of women (Holmes et al., 1999; Peipert, 2003), which leaves only 20\% of infected women presenting with symptoms. The most common clinical manifestation of $C$. trachomatis infection in women is mucopurulent cervicitis. The patient may present with symptoms such as vaginal discharge, post-coital vaginal bleeding, mild abdominal pain and dysuria. On examination cervicitis is characterised by a mucopurulent (green or yellow) endocervical discharge and a cervix that is erythematous, edematous, and friable (Faro, 2001). Chlamydia may ascend into the upper genital tract and cause PID. In $40 \%$ of cases of mucopurulent cervicitis, endometritis is also present (Paavonen et al., 1985). In about 10\% of patients with endometritis, Chlamydia has been shown to ascend and cause salpingitis (Cates and Wasserheit 1991). Thus, PID can be considered as an infection that started as cervicitis and progressed up to the genital tract to endometritis and eventually salpingitis. In endometritis the patient may present with only mild lower abdom- 
inal pain. More intense pain increases the possiblity to include salpingitis in the diferential diagnosis. Bimanual pelvic examination may show uterine, adnexal or cervical motion tendemess. Furthemore, an elevated erythrocyte sedmentation rate or elevated $\mathrm{C}$-reactiwe protein and a temperature greater than $38^{\circ} \mathrm{C}$ are good predictors of laparoscopically confirmed salpingitis (Westrom et al, 1984). Laparoscopy remans the gold standard for the diagnosis of acute salpingitis. The tubal surface will be hyperaemic, edematous and covered with a sticky exudate. The severity of chnical disease is unrelated to laparoscopy findings (Livengood et al. 1992).

Infection of the fallopian tubes can result in damage of the cillated columnar cels that line their imer surface. This damage prohibits the movement of the cilia, which prevents the ovum from migrating down the fallopian tube: In addition, the inflammatory response within the fallopian tube can result in the development of adhesions blocking the passage of the ovum. This might lead to an ectopic pregnancy, since the fertilized ovum is not able to travel throughout the length of the tube to enter into the uterine cavity for implantation.

The inflammatory response due to $C$. trachomatis infection may result in formation of adhesions at the distal end of the tube. The fimbriae become agglutinated, eventually resulting in occlusion of the tube. The fallopian tube fills with purulent exudate forming a pyosalpinx or abscess. The pyosalpinx can either resolve (with treatment) into a hydrosalpinx; or if closely pressed against the ovary, infect the ovary forming a tubo-ovarian abscess (Faro, 2001).

The organism can exit the fallopian tubes and cause a perihepatitis, known as the Fitz-Hugh-Curtis syndrome. The Fitz-Hugh-Curtis syndrome is an extrapelvic manifestation of PID, caused by $C$. trachomatis as well as by Neisseria (N.) gonowhoea (Lopez-Zeno ef al, 1985). It is composed of two plases, acute and chronic. In the acute phase, a perihepatitis and a focal peritonitis result from the transport of inflammatory peritoneal fluid either directly or by lymphatics to the subphrenic and subdiaphragmatic space. Laparoscopically, those patients have a purulent exudate on the liver capsule. The chronic phase is characterised by violin-string adhesions between the anterior surface of the liver and the abdominal wall. Fitz-Hugh-Curtis syndrome tends to be an incidental finding in patients with a clinical diagnosis of PID because their pelvic symptoms are usually more evident (Wolner-Hanssen et al., 1980 and 1982).

Adequate treatment in order to eradicate C. trachomatis is very important in preventing the development of long-term sequelae such as ectopic pregnancy or tubal factor subfertility. Tubal factor subfertility has been found to occur in about $11 \%$ of women after a single episode of symptomatic PID, and the risk of ectopic pregnancy is increased six- to sevenfold (Weström et al, 1981). 
Treatment of $C$. trachowatis genital infection should be instituted prior to the return of confirmatory diagnostic test results to prevent damage of the fallopian tubes. Mucopurulent cervicitis can be effectively treated by azithromycin single dose (1 g orally) (Martin et al., 1992; Thorpe et al., 1996). The clinical severity of the disease will determine whether hospitalisation of the patient with PID is necessary. Besides the appropriate antibiotic regimen, patient education and treatment of sexual partners are part of the treatment. Several antibiotic regimens have been proven effective, and it is not known whether parental regimens are superior to oral regimens. Treatment of $C$. trachomatis PID should also incorporate treatment to $N$. gonorhoeae and anaerobic microorganisms since co-infection is common. The treatment regimen actually recommended is ofloxacin $2 \times 400 \mathrm{mg}$ and metronidazol $2 \times 500 \mathrm{mg}$ daily for 10-14 days (Sexually transmitted diseases guidelines 2002; Centers for Disease Control and Prevention).

However, as described before, $80 \%$ of C. trachomatis infections remain asymptomatic. These infections remain undiscovered (Thejls et al., 1987). Since the infection is asymptomatic no adequate treatment will be instituted. It has been shown that $C$. trachomatis can persist in the genital tract for a long time (Dean et al., 2000). As described earlier, during this persistent phase long-term sequelae of $\mathrm{C}$. trachomatis infection may occur. The result of this infection only becomes evident if the patient develops long-term sequelae such as tubal subfertility, ectopic pregnancy or chronic pelvic pain syndrome (Paavonen, 1992; Schachter et al., 1997).

Since part of these women will 10-15 years later consult a specialist because of subfertility, asymptomatic $C$. trachomatis infections are a source of an important public health problem. In order to avoid these long-term complications, the possibilities of implementing cost-effective screening programmes are nowadays being investigated (Kretzschmar et al., 2001; Welte et al., 2000). C. trachowatis can be cliagnosed by different tests, such as tissue culture, antibody detection methods, and nucleic acid detection methods such as $L C R$ ) and polymerase chain reaction (PCR) (Black, 1997). Because LCR - and PCR-based tests have a higher sensitivity than the other tests, and can also be applied in urine samples, in screening population groups they are the tests of first choice.

The cost-effectiveness of screening depends strongly on the prevalence of infections in the target population, and a reliable estimate of the prevalence of asymptomatic infection in the general population is still lacking. To improve our knowledge of especially asymptomatic infection, screening studies in non-clinic population groups using vallidated and standardised diagnostic tests have been performed. These studies provide accurate estimates of the prevalence of $C$. trachomatis infection and identify risk factors for infection essential for the planning of screening programmes in selected populations (Simms et al., 1997). Paavonen and coworkers (1998a) demonstrated that screening by DNA amplification tests, 
and subsequent treatment of women with positive test results is cost-effective in populations with a $C$. trachomatis prevalence of $\geq 4 \%$. Health care costs due to short-term and long-term complications resulting from undiagnosed and untreated C. trachonatis infections then will exceed the costs of screening an asymptomatic population.

In the Netherlands the prevalence of asymptomatic C. trachomatis infections has been estimated by screening general populations derived from general practices, of which urine samples were tested by means of LCR. In 5714 asymptomatic women between 15-40 years of age derived from 16 inner city generall practices, van Valkengoed et al. (2000) found an overall prevalence of asymptomatic C. trachomatis infections of $2.8 \%$. The highest infection rates were found in women who were $21-25$ years of age (4.4\%). A prevalence study by van den Hoek et al. (1997) among heterosexually active women attending a general practice with no STD-related complaints, found an overall prevalence of positive tests for women of $4.9 \%$, and an age-related prevalence of $13.4 \%$ (15-19 years), $7.3 \%(20-24$ years), $5.5 \%(25-29$ years $), 2.7 \%(30-34$ years $)$ and $2.3 \%$ (35-39 years). To investigate the effects of various screening programs on the prevalence and incidence of asymptomatic C. trachomatis infections in women, Kretzschmar and coworkers (2001) used a stochastic simulation model for $C$. trachomatis transmission in an age-structured, heterosexual population with a sexually highly active core group. Different screening scenarios were implemented over a time period of 10 years, and prevalence and incidence computed. Through screening of men and women between ages 15 and 24 years, the prevalence of asymptomatic infections in women could be reduced from $4.2 \%$ to $1.4 \%$ in 10 years. Increasing the age range of screening up to ages 29 or 34 years led to prevalences of $0.4 \%$ and $0.06 \%$ respectively, after 10 years. Thus, overall prevalences of asymptomatic cervical $C$. trachonatis infections in the Netherlands between 2.8 and $4.9 \%$ were found. The prevalence seems to be strongly age related with a peak in late adolescence and early adulthood. (15-25 years). Since universal screening may not be approprate in a low prevalence population, selective screening has been suggested. So far however, no suitable selective screening criteria for the general population could be identified (van Valkengoed et al., 2000).

In conclusion, the incidence of $C$. trathomatis female genital tract infections is increasing. They include a spectrum of clinical manifestations, varying from cervicitis to endometritis or salpingitis. Part of the $80 \%$ asymptomatic and untreated cases, cause serious health care problems by the development of late sequelae such as chronic pelvic pain, ectopic pregnancy or tubal factor subfertility. At present screening possibilities to discover asymptomatic C. trachomatis infections are evaluated in order to control health care costs due to the long-term sequelae. 


\section{Diagnostic tests}

For the diagnosis of acute C. trachomatis infection, for years, culture of the organism was the only recommended technique. It has been regarded as the "gold standard" method. This method has the benefit of an excellent specificity, but estimates of sensitivity vary from $50-85 \%$ (Schachter and Stamm, 1995). Recent advances in molecular biology have allowed for the development of more sensitive diagnostic assays based on the detection of specific nucleic acids in clinical specimens. The PCR and LCR have been shown to be effective alternatives to cell culture for screening for C. trachomatis (Schachter et al., 1994; Quinn et al., 1996; Black, 1997; Paavonen, 1998b; Harindra et al., 2003). Both techniques are based on the amplification of plasmid DNA specific for the microorganism, and have a sensitivity of $>90 \%$ (Puollakkainen et al., 1998). Therefore these methods should be considered the tests of choice for diagnosing actual $C$. trachomatis infections. $C$. trachomatis can be detected in endocervical specimens obtained by cervical swabs and in first void urine samples by PCR. This latter non-invasive method of specimen collection is valuable when screening hight-risk adolescents.

Since the majority of Chlamydia infections are asymptomatic in the acute phase, microorganisms will as a rule not be detected at the acute phase of infection. Patients however may present several years later, with symptoms suspicious of a previous infection. Since at that moment Chlamydia particles may not be present endocervically, the diagnosis of such previous infections is not possible by using the above-mentioned methods. Therefore, for detection of previous $C$. trachomatis infections, serologic tests detecting $C$. trachomatis antibodies are used. The most commonly used method for antibody detection is (micro-)immunofluorescence (MIF). The MIF test was developed in Seattle by Wang and coworkers (1970) to be used in sero-epidemiological studies. The method is based on the attachment of antibodies in a serum sample to Chlamydia antigens fixed onto glass slides. The visualisation of the reaction occurs through the use of a second antibody labelled with fluorescein-isothiocyanate-conjugate (FITC). A positive immunoreaction is microscopically visualised as a "starry sky" appearance: fluorescent green spots on a slightly red background. Initially, antigens from EBs of each of C. trachomatis were included in the test, and provided anti-MOMP, serovar-specific antibody testing. The preparation of multiple antigens made the test technically difficult and impractical, and therefore modifications were introduced (Treharne et al., 1977). The number of antigens was reduced by pooling antigens of epidemiologically related serovars (A-C, D-K, L1-L3), or using one broadly reacting serovar (Suchland et al., 1991). Usually serowar $\mathrm{L}_{2}$ is used, since sera from patients with genital infections tend to cross-react with $\mathrm{L}_{2}$. Although the MIF technique is generally considered the standard for serodiagnosis of Chlanydia infections, its use 
has several limitations. When using a broadly reacting antigen in the MIF test, unintended cross-reactions among Chlanydia species (with $C$. premmoniae in particular) and other $C$. irachomatis serovars (not related to genital infections) cannot be excluded. Furthemore, the MIF test is technically demanding, time consuming, and tequires experienced readers for reliable test results. The use of different assay conditions in different laboratories leads to inter-laboratory variability in results (Peeling at a., 1998). In order to decrease the inter-species cross-reactivity in the MIF test, more specific MIF tests have been developed. The Chlamydia species share a major genus-specific LPS, which is a component of the OMP of gram-negative bacteria. In the species-specific MIF test, EBs from $\mathrm{C}$. prewmoniae, $C$ trachomats and $C$. psittaci are used, which are spotted separately on a slide. In onder to diminish cross-reactivity between $C$. trachomatis and $C$. pnewmoniae species, the LPS has been removed in C. pneumoniae and C trachomatis antigets.s. The $C$. psittaci antigen still contains LPS and therefore serves as a control for both LPS and C. psithaci positive sera (Chaim et al., 1989).

In the need for rapid, technically less demanding and reliable tests for detection of Chlanydia antibodies, enzyme-linked immunosorbent assays (ELISA) have been developed. ELISAs, although developed already in the 1980 s, were introduced relatively late in clinical practice, due to problems in preparing genus-specific antigens (Ossewaarde et al, 1994). ELISA utilises the principle of the binding of antibodies, present in a senum sample, to synthetic $C$. trachomatis peptide coated on a plate. The immunoreaction is detected via a second antibody labelled with an enzyme followed by a substrate reaction inducing a colour reaction. The colour intensity is read by a photometer and is directly proportional to the concentration of $C$. trachowatis antibodies in the serum. The antigens are synchetic peptides derived from variable domains of the MOMP of $\mathrm{L}_{2}$ (Närvänen ef al, 1997), or the MOMP of different C trachomatis serovars (Ohana et al, 1996). By using C. trachomaris specific peptides (i.e. without homologous sequences with C. pnewmonine MOMP), the tests are supposed to exclusively detect $C$. trachomatis antibodies (Tuuminen al, 2000). ELISA has many advantages over MIF assays, for example, the objective (observer-independent) reading of the results and the possibility for automation. The newly developed ELISAs have been evaluated and compared by MIF by Clad and coworkers (2000). They used five different serological tests in order to detect seroconversion and persistence of $\mathrm{C}$. trachomatis antibodies, A species-specific MIF according to Wang and Grayston (1974), a C. trachomatis species-specific enzyme immunoassay incorporating LPS-extracted $C$. trachomatis $\mathrm{L}_{2}$ EBs (ImmunoComb Chlamydia bivalent, Orgenics, Israel), two different synthetic peptide based species-specific tests (C trachomatis ELISA, Labsystems, Finland and SeroCT ELISA, Savyon, Israel) and a recombinant LPS genus-specific ELISA test (rELISA, MEDAC, Germany) were performed. All five 
tests were performed on multiple follow-up sera of women with $C$. trachonatis positive cervical swabs with the purpose of verifying the sensitivity of the different tests during C. trachomatis seroconversion, re-infection and long-term follow up. They found $C$. trachomatis ELISA to have the highest sensitivity resulting in earlier seroconversion and higher $\operatorname{IgG}$ prevalence rates in patients with $\mathrm{C}$. trachomatis positive cervical swabs. The increased sensitivity resulted in a higher negative predictive value. The specificity of the test however, still has to be demonstrated.

In order to determine whether ELISAs distinguished patients with tubal factor subfertility or PID from controls, Paukku and coworkers (1998) compared the genus-specific ELISA, based on a recombinant LPS (rELISA, MEDAC, Germany) and the species-specific C. trachomatis ELISA (Labsystems, Finland) with a species-specific MIF (a modified version of Wang and Grayston, 1970). The seroprevalence was measured in patients with known tubal factor subfertility, patients with PID and three control groups. Although neither of the tests was as specific as the MIF, both ELISA tests discriminated well between cases and controls. They found that rELISA was used successfully for the screening for Chlamydia antibodies in general and that C. trachomatis ELISA detected species-specific antibodies. They suggested that performance of a combination of serologic tests with defined antigens (LPS-based and MOMP-based tests) could contribute to the clinical decision making process among patients undergoing subfertility or PID work-up. Assuming a lower half-life of the LPS antibodies detected by rELISA as compared with the longer persisting anti-MOMP antibodies detected by C. trachomatis ELISA, they should be able to discriminate between recent and past infections.

More recently, Morré and coworkers (2002) compared three commercially available peptide-based IgG assays (C. trachomatis ELISA, Labsystems, SeroCT ELISA, Savyon and pELISA, MEDAC) to an in-house MIF assay for detection of C. trachomatis antibodies in patients screened for asymptomatic C. trachomatis infections by PCR. They concluded that the peptide based ELISAs for the serological detection of C. trachomatis antibodies performed as well as the MIF assay, and that since the ELISAs are less time consuming, less expensive and easier to perform than the MIF, they might be preferred in the serodiagnosis of acute $C$. trachomatis infection.

Whether these conclusions are also valid for CAT in screening for tubal factor subfertility remains to be established. 


\section{Serologic sereening for tubal factor subfertility}

Laparoscopy with dye testing of the tubes is the best available diagnostic test for evaluation of tubal patency. As an invasive and expensive procedure, laparoscopy is unsuitable for screening on a large scale. Clinicians have searched for inexpensive and non-invasive screening tests to estimate the risk of tubal factor subfertility in a particular patient, in order to subject a high-risk patient to diagnostic testing (i.e: laparoscopy), and to postpone additional testing in a low-risk patient. Since it was noted that the development of PID and its chronic sequelae is associated with Chlamydia lgG antibody formation, the relation between antibody titres and tubal factor subfertility has been demonstrated in many studies (teviewed by Mol et al., 1997). In a meta-analysis of 23 studies with 2729 patients they assessed the discriminative capacity of CAT in the diagnosis of tubal pathology in subfertile patients. Their results showed that the discriminative capacity depended on the type of assay that was used. ELISA or MIF provided a better discrimination than did immunoperoxidase assays (formerly used technique in screening for Chlamydia and based on peroxidase staining of antigen antibody complexes). They furthermore compared the results of CAT to the results of a former meta-analysis by Swart and coworkers (1995) in which the accuracy of hysterosalpingogram in the diagnosis of tubal pathology was studied. They concluded that accuracy of CAT in diagnosing of tubal pathology (defined as occlusion, hydrosalpinx and peritubal adhesions) is comparable to hysterosalpingography in the diagnosis of tubal occlusion. Based on the initial studies on the association of CAT with tubal factor subfertility, CAT has been introduced as a screening test for tubal factor subfertility, and has been incorporated in fertility work-up on a large scale. The test most widely used for CAT is MIF, which has been considered the gold standard in the serological diagnosis of Chlamydia infection. In the Netherlands, CAT is part of the initial work-up of subfertile couples (NVOG, 2004):

A critical reappraisal of the results reported in literature on screening for tubal factor subfertility by CAT however, reveals heterogenous results and indicates that the predictive value for tubal pathology is limited: sensitivity of CAT varies between 30-88\% and specificity between 33-100\% (Mol et al., 1997). The heterogenous results might be explained by the lack of uniformity in assays and antibodies used, the use of different cut-off levels for titres, and the definitions of tubal pathology applied. A prospective cohort study was performed by Land and coworkers (1998) to evaluate the implications of varying the definitions of tubal pathology and of modifying the cut-off levels on the clinical impact of CAT in predicting tubal factor subfertility. Calculated by statistical means, the optimum cut-off level as the best combination of sensitivity and specificity was 16 . This 


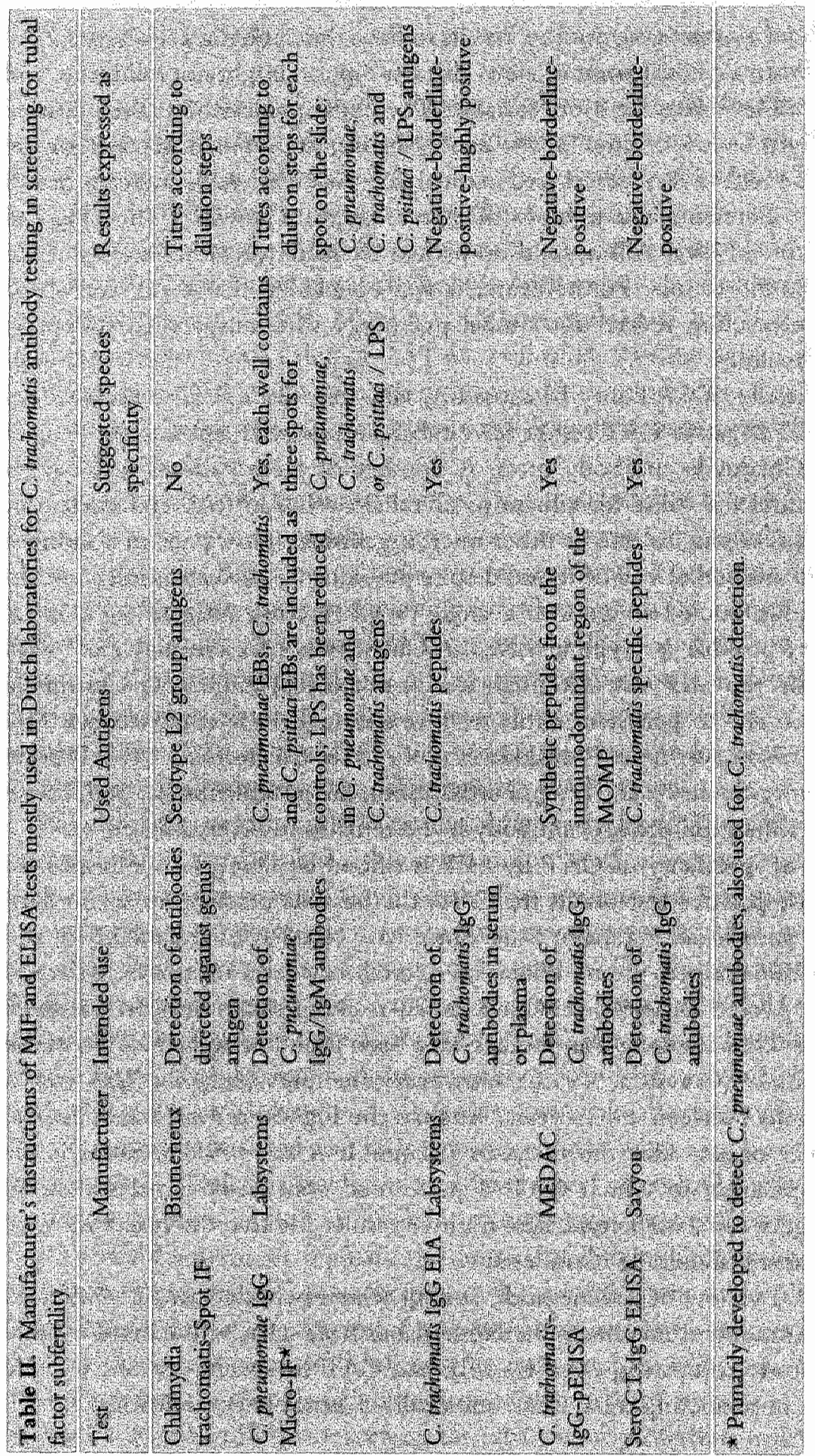


statistical model assumes false positive results to have the same impact as false negative results. From a clinical point of view, this assumption might not hold true, and another cut-off level may be more suitable. The consequences of a false negative test result might be loss of time for the patient by unjustified management, or the institution of ineffective medical treatment. False positive results increase health care costs by increasing the number of laparoscopies. Therefore, choosing the appropriate cut-off level will depend on patient characteristics, facilities available and on economic factors. Furthermore, it was concluded that CAT was more accurate in predicting severe distal tubal pathology than unspecified tuboperitoneal abnormalities.

Low sensitivity of CAT may be caused by false negative CAT results. Patients who have false negative CAT results have tubal pathology at laparoscopy in spite of negative Chlamydia antibody titres. A number of these patients will have a Chlamydia unrelated cause for adhesions or tubal occlusion (e.g. endometriosis, cornual polyps, salpingitis due to other microorganisms). However, in a number of patients no antibodies will be found despite previous $C$. trachomatis infection. In MIF tests, either pooled antigens or a single broad-reacting antigen $\left(\mathrm{L}_{2}\right)$ is used, and not every possible serotype involved in Chlamydia infection may react with the antigens in the MIF test. Although it is assumed that infiltrating Chlamydia infections give rise to persistent antibody formation, there is evidence that $\operatorname{IgG}$ titres may decrease over time (Puolakkinen et al., 1986; Chaim et al., 1992; Piura et al., 1993; Henry-Suchet et al., 1994). Furthermore, the possible impact of effective antibiotic treatment on the $\mathrm{IgG}$ antibody levels remains to be established.

Decrease of specificity of CAT by MIF is caused by false positive results. In discussing false positive test results for CAT, the possible cross-reactivity in MIF tests with C. pnemmoniae is a major issue. Since MIF tests have been modified, and serotype-specific antigens are no longer used, cross-reactivity of other Chlamydia species with pooled antigens or with a broad-reacting single antigen has been demonstrated. Chlamydia IgG antibodies have been found in up to $50-70 \%$ of the adult population (Grayston, 1992). However, the prevalence of $\operatorname{IgG}$ to $C$. trachonatis peaks between 19-29 years, whereas the highest prevalence of IgG to C. pneumoniae occurs after the 60 years (Mannion et al., 1991). Although the subfertile population in which CAT is performed consists of females with an average age between $25-35$ years, false positive results due to cross-reactivity with C. pneminoniae still should be considered.

For CAT, a variety of test methods, among which peptide based ELISA tests, are used. Commonly used tests in the Netherlands have been summarised in table 2. So far, a study comparing CAT by MIF and CAT by species-specific peptide based ELISA in predicting tubal factor subfertility has not been performed. 


\section{Outline of the thesis}

C. trachomatis infections mostly remain asymptomatic. In fertility work-up a patient's history is therefore not helpful to identify patients at high-risk for tubal pathology as a cause for subfertility. CAT has been found useful in screening for tubal factor subfertility. However, screening for tubal factor subfertility due to $C$. trachomatis infection by CAT has limitations. The studies described in the thesis intend to elucidate factors that have been hypothesised to be a cause for the limited predictive value of CAT. Moreover, factors that have been hypothesised to improve the predictive value of CAT are evaluated. Furthermore; a mouse model has been developed to obtain more insight in the development of tubal pathology after silent $C$. trachomatis infections since this may shed more light on other useful screening parameters.

The first aim of the present study is to elucidate the role of $\operatorname{IgG}$ antibody decline over time as a possible cause of false negative CAT results (i.e. negative CAT in patients with tubal pathology at laparoscopy). The course of Chlamydia $\operatorname{IgG}$ antibody levels in asymptomatic subfertility patients in whom no active $C$. trachomatis infection is assumed to be present will be studied and described in chapter 2. The highest prevalence of Chlamydia infections is in young adults, and, if tubal pathology results, it will take several years before subfertility will become evident. Within this period IgG titres may decline, and at the time of subfertility investigation they may result in false negative CAT results.

Besides false negative CAT results, false positive CAT results occur. The second aim was to evaluate the contribution of C. pneumoniae antibodies as a cause of these false positive CAT results (i.e. positive CAT in patients without tubal pathology at laparoscopy), due to cross-reactivity in the MIF test. The results regarding this aim will be presented in chapter 3. For this purpose, an ELISA, considered species-specific for C. trachomatis and C. pneumoniae will be used. Using this technique, the prevalerice of antibodies to $C$. pnetumoniae in subfertile women will be established. Secondly, cross-reactivity in the MIF test with $C$. pneumoniae antibodies will be evaluated as a possible cause of false positive CAT results. Thirdly, as it is postulated that re-infection or reactivation may be responsible for the induction of tubal pathology, the additive effect of both C. pneumoniae and $C$. trachomatis antibodies on the prevalence of tubal pathology will be evaluated.

The third aim is to evaluate the impact of different screening tests on the predictive value of CAT as a screening test for tubal factor subfertility. After the introduction of more species-specific C. trachomatis serology tests, we hypothesised that the predictive value of CAT may be improved by using one of these new tests. Therefore, in chapter 4 the predictive value of CAT by species-specific MIF or peptide based ELISA in screening for tubal factor subfertility will be evaluated 
and dealt with. CAT will be performed by five tests: MIF, a species-specific MIF and three peptide-based species-specific ELISAs. The findings obtained at laparoscopy will be related to the results of the different CAT tests. As described above, CAT by MIF has limited clinical value due to low sensitivity and specificity. It is expected that the use of species-specific tests will decrease inter-species cross-reactivity. Furthermore, the ELISA tests provide automated observer-independent and therefore objective results. The outcomes of the five tests will be conpared to the findings at laparoscopy in order to determine their prognostic value of tubal factor subfertility. Sensitivity, specificity, positive predictive value, negative predictive value, likelihood ratios, odds ratios and $95 \%$ confidence intervals will be calculated: Furthermore the impact of combining two or more tests on the predictive value will be studied. For all five tests the distribution of $C$. pneumoniae antibodies in CAT positive patients will be compared to the distribution in CAT negative patients in order to evaluate the role of $C$. pneumoniae antibodies in false positive CAT results.

Women who undergo uterine instrumentation are considered at risk for pelvic infections by $\mathrm{C}$. trachormatis, which may either derive from ascending endocervical infections or from reactivation of microorganisms persisting in the genital tract from previous Chlamydia infections. Since subfertility patients frequently undergo uterine instrumentation the fourth aim is to determine whether they should either undergo endocervical screening for $C$. trachomatis by PCR, or receive prophylactic antibiotic treatment before the procedure, in order to decrease their risk for reactivation of persistent Chlamydia infections. This will be discussed in chapter 5 .

The fifth aim is to develop a mouse model in which the role of $C$. trachomatis infection on the development of tubal pathology can be studied. Our main interest will be to develop a mouse model that mimics the hypothesised (often asymptomatic) course of Chlanydia infections in women, implying that a primary $C$. trachomatis infection does not result in extensive tubal pathology, and that only subsequent $C$. trachomatis re-infection will induce tuboperitoneal disease. The study in chapter 6 will at first describe a dose finding study in order to find the optimal inoculation dose for inducing infection. IgG antibody formation will be determined. With this optimal dose single inoculation and re-inoculation of $\mathrm{C} 57 \mathrm{BL} / 6 \mathrm{~J}$ mice with human $C$. trachonatis $\mathrm{L}_{2}$ will be performed. At three, nine and eighteen weeks after inoculation genital tracts will be evaluated in situ for gross genital tract pathology after which they will be excised for histologic evaluation. Furthermore, the theory of C. pneumoniae playing a contributory role in the development of $C$. trachomatis induced genital tract pathology will be explored.

Finally, in chapter 7, we will evaluate whether Chlamydia and mouse hsp60 (Chsp60 and Mhsp60) antibodies can be detected in serum following $C$. 
trachomatis or C. pneumoniae infection in a mouse model, to investigate whether auto-immunity, based on cross-reactivity between Mhsp60 and Chsp60 antibodies, could be the underlying mechanism of tubal pathology. 
34 Chapter 1

\section{References}

Amo, JN, Yuan, Y. Cleary, R.E. et. il. (1995) Serologic responses of infertile women to the $60 \mathrm{kD}$ Chlamydial heat shock protein (hsp). Feriil Steril. 64, 730-735.

Ault, K.A., Statland, B.D., King M.M. Dozier, D.L., Joachims, M.L, Gunter, J (1998) Antibodies. to the Chlanydia 160 kilodalton heat shock protein in women with tubal factor infertility. Infect. Dis. Obistet. Gynet. 6, 163-167.

Beaty, W.L., Byme, G.1, Morrison, R.P.(1993) Morphologic and antigenic characterization of interferon-y-mediated persistent C. radhomatis infection in vitro. Proc. Natl. Acad. Sa. USA, 90, $3998-4002$.

Beatry, W.L., Morrison, R.P., Byrne, G.I. (1994a) Persistent Chlamydiae: from cell culture to a paradigm for Chamydial pathogenesis: Microbiol. Rew. 58,686-699.

Beatty, W.L., Byme, G.I., Morrison, R.P. (1994b) Repeated and persistent infection with Chlamydia and the development of chronic inflammation and disease. Trends Micobiol., 2, $94-98$.

Beatty, W. Morrison, R., Byrne, G.I. (1995) Reactivation of persistent C. trachomatis infection in cell culture. Infert. Immwn., 63, 199-205.

Black C.M. (1997) Current methods of laboratory diagnosis of Chlamydia trachomatis infections. Cilim. Microbiol. Rev, 10, 160-184.

Brade, L., Holst, O., Kosma, P., Zhang, Y, Paulsen, H., Krausse, R, Brade, I-I. (1990) Characterization of Murine, Rabbit and human polyclonal antibodies against Chlamydial lipopolysaccharide. Infect. Iwnum, $58,205-213$.

Brumbam, R.C., Kno, C.C., Chen, W.J. (1985) Systemic C. trachonatis infection in mice: a comparison of lymfograntloma venereum and trachoma biovars. Infect. Immun., 48, 78-82.

Brunham, R.C., Maclean, I.W., Binns, B., Peeling, R.W. (1985) C. trachomatis: its role in tubal infertility. If Infer. Dis. $152,1275-1282$.

Campbell, L.A., Kuo, C-C., Grayston, J.T. (1998) Chlamydia pueumoniae and cardiovascular disease. Energ. Infeat Dis., 4, 571-579.

Cates, W.Jr., Wasserbeit J.N. (1991) Genital Chlanydial infections: Epidemiology and reproductive sequelae. Am. J. Obstet. Gymerol., 164, 1771-1781.

Chain, W. Sarov B., Sarov I., Piura, B., Cohen, A., Insler, V. (1989) Serum IgG and IgA antibodies to Chlamydia in ectopic pregnancies. Contraception, 40,59-71.

Chain, W. Edelstein, Z., Sarov, B., Sarov, 1. 1992) The long-term follow-up of asymptomatic women with C. tradhomatis. Arch. Gynecol. Obste, 251, 159-164.

Clad, A. Freidank, H.M., Kunze, M., Schnoekel, U., Hofmeier, S., Flecken, U,m Petersen, E.E (2000) Detection of seroconyersion and persistence of Chawydia trachonatis antibodies in five different serological tests. Eur. J. Clin. Mionobial Infed. Dis., 19,932-937.

Colarizi, P., Chiesa, C., Pacifico, L., Adorisio, E., Rossi, N., Ranucci, A Sebastiani Annicchiarico, L. Panero, A. (1996) Chantydia trachomatis-associated respiratory disease in the very early neonatal period. Acra Padiatr, 85, $991-994$.

Coles, A.M., Pearce, J.H. (1987) Regulation of Chlarnydia psiftad (strain guinea pig inclusion conjunctivits) growth in McCoy cells by amino acid antagonism. J. Gen. Micwobiol, 133, 701708.

Coles, A.M., Reynolds, DJ., Harper, A., Devitt, A., Pearce, J.H. (1993) Low-nutrient induction of abmonmal Chlamydial development- a novel component of Chlamydial pathogenesis. FEMS Miorobiol: Let, $106,193-200$. 
Cotter, T.W.; Meng, Q, Shen, ZL., Zhang, YX, Su, H, Caldwell, H.D. (1995) Protective efficacy of major outer membrane protein-specific inmunoglobulin A (IgA) and IgG monoclonal antibodies in a murine model of Chlawy dia trachomatis gental tract infection. Infect. Immun, $63,4704-4714$.

Daniell, M.D. and Taylor, H.R. (1997) Aspect of trachona: Dew. Ophthalmol, 28, 11-23,

Darville, 'T., Andrews, C.W., Lafoon, K.K., Shymasani, W., Kishen, L.R., Rank, R. G. (1997) Mouse strain-dependent variation on the course and outcome of Chlanydial genital tact infection is associated with differences in host response. lnfettion and lownuty; 65, 3065-3073.

Dean, D., Suchland, R., Stamm, W. (2000) Evidence for long-term cervical persistence of $C$. trachomatis by omp 1 genotyping. J. Wyfect. Dis., 182, 909-916:

Dean, D. and Powers, V.C. (2001) Persistent Chlamydia trathomatis infections resist apoptotic stimuli. Infect. Immum., 69, 2442-2447.

Deschenes, J., Seamone, C., Baines, M. (1990) The ocular manifestations of sexually transmitted dieases. Can. J. Ophthalmol, 4, 177-1.85.

Di Bartolomeo, S., Mirta, D.H., Janer, M., Rodriguez Fermepin, M.R., Sauka, D. (2001) Incidence of Chlamydia trachonatis and other potential pathogens in neonatal conjunctivitis. Int. J. Infect. Dis., 3, $139-143$.

Dieterle, S., Rummel ${ }_{2}$ C., Bader, L.W., Petersen, H., Fenner ${ }^{\text {T T. }}$ (1998) Presence of the major outer membrane protein of $C$. trachomatis in patients with chronic salpingitis istllanica nodosa with tubal occlusion. Fertil. Steril., 70, 774-776.

Dreses Werringloer, U., Padubrin, I., Jurgens Saathoft, B., Hudson, A.P., Zeidler, H., Kohler, L. (2000) Persistence of $C$. trachamatis is induced by ciprofloxacin in vitro. Antimicrob. Agents Chemother., 44, 3288-3297.

Dugan, J.P., Feuge, R.R., Burgess, D.S. (2002) Review of evidence for a connection between Chlamydia pneumoniae and atherosclerotic disease. Clin. Ther, 5, 719-735.

Evans, B.A., Tasker, T., MacRae, K.D. (1993) Risk profiles for genital infection in wonen. Genitourin. Med., 69, 257-261.

Evans B.A., Kell, P.D., Bond, R.A. (1995) Heterosexwal relationships and condom-use in the spread of sexually transmitted diseases to women. Genitourin. Med., 71, 291-294.

Everett, K.D., Bush, R.M., Anderssen, A.A. (1999) Emended description of the order Chlarnydiales, proposal of ParaChlanydiaceae fam. nov., each containing one monotypic genus, revised taxonomy of the family Chamydiaceae, including a new genus and five new spectes, and standards for the identification of the organisms. Int: J: Syst. Bactetiol., 49, 415-440.

Faro, S. Chlamydia trachomatis (2001). In: Infectious diseases in women. Fletcher $J$, ed., W.B. Saunders Company, USA., 451-467.

Findlay, H.E., McClafferty, H., Ashley, R.H. (2005) Surface expression, single-chanmel analysis and membtane topology of recombinant Chlamydia trathonatis major outer membrane protein. BMC Microbiol, $26,5$.

Gaydos, C.A., Howell, M.R., Pare, B., Clark, K.L.; Ellis, D.A., Hendrix, R.M., Gaydos, J.C., McKee, K.T., Quinn, T.C. (1998) Chamydin tradontatis infections in fenale military recruits. N. Eng. J. Med., 339, 739-744.

Gérard, H.C., Branigan, P.J., Balsara, G.R., Heath, C., Minassian, S.S., Hudson, A.P. (1998) Viability of $C$. trachomatis in fallopian tubes of patients with ectopic pregnancy. Fertil. Steril., 70 , 945-948.

Grayston, J.T., Galle, J.L., Yeh, L-J, Yang, C-Y. (1972) Pathogenesis and immunology of traehoma. Tran. Assoc. Alm. Physicians., 85, 203-211.

Grayston, J.T., Wang, S-P, Yeh, L-I, Kuo, C-C (1985) Importance of reinfection in the pathogenesis of trachoma. Rev. Infect. Dis., 7, 717-725. 
Graston, J. T. (1992) Infections caused by Clamydia pnewwoniue strain TWAR. Clin. Inf. Dis., 15. $757-763$

Grayston, J.T. (2000) Background and curtent knowledge of Chlanydia pnemononiae and atherosclerowis. J. Injed. Dis., 181, suppl 3, S402-\$410.

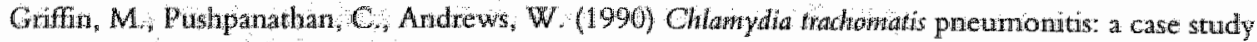
and a literature review. Pediatr. Pathol, $10,843-852$.

Grun, L., Tassano-Sinith, J, Carder, $C$., et al. (1997) Comparison of two methods of screening for gental Chlamydial irfection in wornen attending in general practice: cross sectional survey. B.M.J, 315, 226-230.

Guaschino, S., De Seta, F. (2000) Update on Chinnydia trachonats. Awn. N. Y. Acad. Sa., 900, 293-300.

Hahn, D.L., Azenabor, A.A., Beatty, W.L., Byme, G.I. (2002) Chlamydia pneumoniae as a respiratory pathogen. Frowt Biosci, $7,66-76$.

Hammerschag, M.R. (2000) Chlamydia pneumoniae and the lung. Eur. Respir. J., 5, 1001-1007.

Harindira, V., Underhill; G., Tobin, J.M. (2003) Screening for gental Chlamydia infection: DNA amplification tachniques should be the test of chotce. IM. J. STD AIDS, 14, 723-726.

Henry-Sudhet, J.; Askienazy-Elbhar, M., Thibon, M., Revol, C., Akue, B.A. (1994) The post-therapeutic course of serum antibody titres in women with acute salpingitis and tubal infertility. Fertil Steril., 62, $296-304$.

Hess, D.L. (1993) Chlanydir in the neonate. Neonatal. Netw, 12, 9-12.

Hillis, S.D., Nakashima, A., Marchbanks, P.A., Addiss, D.G., Davis, J.P. (1994) Risk factors for recurrent Chlamydia trachontatis infections in women. Am. J. Obstet. Gyvecol., 170, 801-806.

Hillis, S.D., Owens, L.M. Marchbatnks, P.A., Amsterdam, L.F, Mac Kenzie, W.R. (1997) Recument Chlanydial infections increase the risk of hospitalisation for ectopic pregnancy and pelvic inflammatory disease. Am. J. Obstet. Gyncel, 176, 103-107.

Hoek van den, I A.R., Mulder-Folkerts, D.K.F, Coutinho, R.A., Dukers, N.H.T.M., Buimer;

Holder, D.W., Woods, E.R. (1997) C. trachomatis screening in the adolescent population. Curr. Opin: Pediatr., $9,317-324$.

Holmes, K.K., Sparkling, P.F., Mardh, P.A, et al., eds. (1999) Sexually transmitted diseases, 3rd edition. New York: McGraw Hill Inc. Biology of Chlanydia trachonatis, Schachter, J., 391-405.

Holst, O, Brade, L, Kosma, P. Brade, H. (1991) Structure, serological specificity, and symthesis of antifial glycoconjugates representing the genus-specific lipopolysaccharide epitope of Colatinydia spp. J. Bat., 173, 1862-1866.

Inman, RD. Whithmmudson, JA.; Schumacher, H.R. Hudson, A.P. (2000) Chanydianssociated athritis. Cur Opin Rhewhatol, 12, 254-262.

Islvi, W., Matsuda, M, Okamoto, N., Makaide, M., Shimojima, Y, Ikeda, S. (2005) Ractive arthritis due to asymptomatic infection of Chlanydia trothomatis. Intem. Med., 44, 509-510.

$I_{t o}$, J I., Hamison, H.R., Alexander J.R., Billings, L.J. (1984) Establishment of genital tract infection in the $\mathrm{CF}-1$ mouse by intravaginal inoculation of human oculogenital isolate of Chamyda twrhomatis. I. Liffect Dis., 150,577-582.

Kaushic, C., Murdan, A.D., Underdown, B.J., Wira, C.R. (1998) Chlamydia trachonatis infection in the female reproductive tract of the rat: influence of progesterone on infectivity and immune response. Infed. Imintur, 60, 893-898.

Kaushic, C., Zhou, F., Murdin, A.D., Wra, C.R. (2000) Effects of estradiol and progesterone on susceptibility and early immune responses to Chlomydo whomatis infection in the femalle reproductive tract. Infect. Lawnm, $68,4207-4216$.

Kimnumen, A., Holander, P., Launa, A. et a. (2000) C. trachomatis reactive T lymphocytes from uppeti genital tact issue specimens. Hum Reprod, 15, 1484-1489. 
Kinnumen, A.,Pawonen, J. Surcel, H.M. (2001) Heat shock protein 60 specific T-cell response in Chamydial infections. Scand. J. Inwmol., $54,76-81$.

Kiviat, N.B., Wolner-Hanssen, $\mathrm{P}_{0,}$ Eschenbach, D.A., et al. (1990) Endometrial histopathology in patients with culture-proved upper genital tract infection and laparoscopically diagnosed acute salpingitis. Am. J. Sur g. Pathol, 14, 167-175.

Koehler, L, Nettelnbreker, E., Hudson, A.P., Ott, N., Gerard, H.C., Branigan, P.J., Schumacher, H.R., Drommer, W. Zeidler, H. (1997) Ultrastructural and molecular analyses of the persistence of $C$. trachomatis (serovar $\mathrm{K}$ ) in human monocytes. Mirob. Pathog, 22, 133-142.

Kretzschmar, M., Welte, R., van den Hoek, A., Postma, M. (2001) Comparative model-based analysis of screening programs for $C$. trachomatis infections. Am I. Epidemiol, 153, 90-101.

Kuo CC (1988) Hast response. In: Microbialogy of Chlamydia. A.t. Barron, editor. CRC Press. Boca Ratom, 193-208.

Kuo, C-C., Jackson, L.A., Campbell, L.A., Grayston, J.'T. (1995) Chlamydia pneumonide (TWAR). Clin. Microbiol. Rev, $8,451-461$.

Kuo, C-C. and Campbell, L.A. (2000) Detection of Chlamydia pneumoniae in arterial diseascs. J. Infect. Dis., 181, suppl 3, S432-S436.

Laar, M.W.J. wan de, Ossewaarde, J.M., eds. (1997) Sexually transmited diseases in the Netherlands: update 1996. Bilthoven, RIVM Rapport 441500006 .

Land, J.A., Evers, J.L.H., Goossens, V.J. (1998) How to use Chlanydia antibody testing in subfertility patients: Hum Reprod, 13, 1094-1098.

Lehtinen, M., Rantala, I., Ajne, $\mathbb{R}$. al. (1986) B cell response in C. trachonatis endometritis. Eur.J. Clin. Microbiol. Mufect. Dis., 5, 596-598.

Lehtinen, M. and Paavonen, J. (1994) Heat shock proteins in the immunopathogenesis of Chlamydial pelvic inflammatory disease. In: Chlamydial infections, Orfila, J. Ed. Societa Editrice Esculapio, Bologna, 599-610.

Leinonen, M. and Saikku, P. (2002) Evidence for infectious agents in cardiovascular disease and atherosclerosis. Lancet Infect. Dis., 1, 11-17.

Livengood, C.H., Hill, G.B., Addison, W.A. (1992) Pelvic inflammatory disease: findings during inpatient treatment of clinically severe, laparoscopy-documented disease. Am. J. Obstet. Gynecol., $166,519-524$.

Lopez-Zeno, J.A., Keith, L.G., Berger, G.S. (1985) The Fitz-Hugh-Curtis syndrome revisited: changing perspectives after half a century. J. Reprod. Med., 30, 567-582

Low, N. and Cowan, F. (2002) Genital Chlmydial infection. Clit. Evid, 7, 1409-1415.

Mabey, D. and Fraser-Hurt, N. (2001) Trachona: B.M.J., 7306, 218-221.

Mannion, P.T., Mallinson, H. Treharne, J.D. (1991) Serological diagnosis with the Chlamydia Spot-IF test. J Med. Microbiol., 35, 244--248.

Marra, C.A., Patrick, D.A., Reynolds, R., Marra, F. (1998) Chlamydiat trachowatis in adolescents and adults. Clinical and economic implications. Phamacoeconomics, 13, 191-222.

Martin, D.H., Mroczkowski, T.F., Dalu, Z.A. et al. (1992) A controlled trial of a single dose of azithromycin for the treatment of Clyamydial urethritis and eervicitis. N. Eng. J. Med., 327, 921-925.

Matondo, P., Wall, R., Morgan, K., et al. (1996) Epidemiology of gonococcal and Chlamydial infections in Harrow and Brent. Gevitowrin. Med., 72, 345-357.

De la Maza, L.M., Pal., S., Khamesipour, A., Peterson, E.M. (1994) Intravaginal inoculation of nice

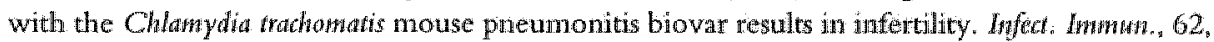
2094-2097.

Mol, B.W.J., Dijkman, B., Wertheim, P., Lijmer, J. van der Veen, F., Bossuyt, P.M.M. (1997) The accuracy of serum Chamydial antibodies in the diagnosis of tubal pathology: a mata-analysis. Fertil. Steril, 67, 1031-1037. 
Monnickendam, M.A., Darougar, S., Trehame, J.D, Thbury, A.M. (1980) Dewelopment of chronic conjunctivitis with scarring and parnus, revembling trachoma, in guinea-pigs. Br. J. Ophthalmol, $64,2884-290$.

Monno, R, De Vito, D., Losito, G. Sibilio, G., Costi, A, Fumarola, L., DAprile, A., Marcuccio, P. (2002) Chlamydia pheumontae in community-acquired pneumomas seven years of experience.J. Hyfot, $45,135-138$.

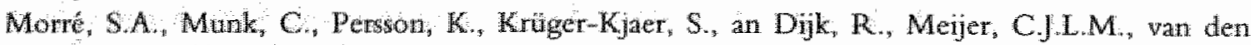
Brule, Af.C (2002) Companson of three commercially avallable peptide-based immunoglobulin $\mathrm{G}(\mathrm{IgC})$ and $\operatorname{Ig} A$ assays to nicrommunofuorescence assay for detection of Chlawydia trathonatis antibodies. J. Clin Microbiol, $40,584-587$.

Morrison, R.P, Belland, R.P., Lyng, K. et al. (1989) Chamydial disease pathogenesis. The 57-kD Chlamydial hypersensitivity is a stress response protein. J. Exp. Med., 169, 663-675.

Moulder, J.W. (1991) Jneraction of Chlamydia and host cells in vitro. Microbiol. Rev, 55, 143-190.

Närwănen, A., Puolakkinen, N., Hao, W., Kino, K. Suni, J. (1997) Detection of antibodies to C. trachomatis witl peptide-based species-specific enzyme immunoassay. Inf. Dis. Obstet. Gynenol, $5,349-354$

Ngeh, J., Anand, V., Gupta, S. (2002) Chlanydia pnewmoniae and atherosclerosis- what we know and what we don't. Clin. Microbsol. Infect, $1,2-13$.

NVOG Richtlin Orienterend Fertilteits-Onderzoek (Ol:O), 2004, Utrecht.

Oakeshot, P., Kerry, S., Hay, S., et al. (1998) Opportunistic screening for Chlamydial infection at time of cervical smear testing in general practice: prevalent study. B.M. J 316, 351-352.

Ohana, B., Pancratova, V., Groln, A., Straube, E., Brand, R., Balicher, A. et al. (1996) SeroCT-a new peptide-based ELISA test for specific detection of C. trachomatis antibodies. Inf. Dis. Obstet. Gynecol. 4, 192 .

Ossewarde, J.M., de Vries, A., van den Hoek, J.A.R., van Loon, A.M. (1994) Enzyne immuno assay with enhanced specificity for detection of antibodies to Chlanydia trachomatis. I. Clin. Microbiol., 32, 1419-1426.

Pavonen, J., Aine, R., Teisala, K. et al (1985) Chlamydial endometritis. J. Clin. Pathol., 38 , $726-732$.

Paavonen, J. and Wolner-Hanssen, P. (1989) C. trachonatist a major threat to reproduction. Hum. Reprod, 4, 111-124.

Paavonen, J. (1992) Genital C. trichownt infections in the female. J. Myfent., 25 (Suppl 1), 39-45.

Paavonen, J., Lehtinen, $M$. (1994) Immunopathogenesis of Chlamydial pelvic inflammatory diseasewhe role of heat-shock proteins. Infer. Dis. Obstet. Gywecol, $2,105-110$.

Pavonkn, J., Puolakkainen, M., Paukku, M., Sintonen, H. (1998a) Screening for $C$. frachomatis would be cost-effective, exen in low-prevalence situations. Obstet. Gynecal., 92, 292-298.

Pavonen, J. (1998b) Comparison of perfomances of two commercially available tests, a PCR assay and a ligase chain reaction test, in detection of urogenital Champdia trachomatis infection. $J$. Clin. Miorobiol. 36, 1489-1493.

Panonen, J. and Eggent-Kruse, W. (1999) Chlanydiat trahomatis: impact on human reproduction. Hum. Reprod. Update, $5,433-447$.

Pal, S., Hui, W., Peterson, E.M., de la Maza, L.M. (1998) Factors influencing the induction of infertility in a mouse model of Chlamydia tradomatis ascending genital tract infection. $J$. Mod. Micobiol, 47, 599-605.

Pal, S., Peterson, E.M., Maza de la, L.M. (2001) Susceptibility of mice to vaginal infection with C. writhowatis mouse pneumonitis is dependent on the age of the animal. Infect. Immun. 69 , 5203-5206.

Patton, DL., Kuo, C-C. (1989) Histopathology of C. trathomatis salpingitis after primary and repeited reinfections in the monkey subcutaneous pocket model. $J$. Reprod. Fertil., 85, 647-656. 
Patton, D L, Wolner-Hanssen, P. Cosgrove, S.J., Holmes, K.K. (1990) The effects of Chlanytha trachomatis on the female reproductive tract of the Macaca nemestrina after single tubal challenge following repeated cervical inoculations obshet Gyncol, $76,643-650$.

Patton, D.L. Askienazy-Elbhar, M., Henry-Suchet, J. et al. (1994) Detection of Chlamydia trathomatis in fallopian tube tissue in women with post-infectious tubal infertility. Am. J. Oustet. Gynecol, 171, 95-101.

Paukku, M., Närłänen, A., Puolakkinen, M., Dreesbach, K, Titinen, A., Hao, W., Anttila, T.I., Paavonen, J. (1998) Detection of Chlamydia trachomatis antibodies by 2 novel tests: rELISA and peptide ELISA. In. J. STD \& AIDS, 9, 604-607.

Pearce, J., Gaston, H, Deane, K., Devitt, A., Harper, A., Jecock, R. (1994) "Persistent' forms and persistence of Chlamydia. Trends Morobiol., 7, 257-259.

Peeling, R.W. and Brunham, R.C. (1996) Chlanydiae as pathogens: new species and new issues. Energ. Lnfect. Dis., 2, 307-319.

Peeling, R.W., Kimani, J., Plummer, F. (1997) Antbody to Chlanydial hsp60 predicts an increased risk for Chlamydial pelvic inflammatory disease. J. Infect. Dis, 175, 1153-1158. Peeling, R.W., Wang, S.P., Grayston, J.T., Blasi, F, Boman, J., Clad, A. et al. (1998) Clananydia serology: inter-laboratory variation in microimmunofluorescence results. In: Stephens, R.S., Byrne, G.I. eds. Chlamydial infections. Proceedings of the $9^{\text {th }}$ International Symposium on Hunan Chlamydial Infections, Napa, 1998, 159-162.

Peeling, R.W., Patton, D.L., Cosgrove Sweeney, Y.T., Cheang, M.S., Lichterwalner, A.B., Brunham, R.C., Stamm, W.E. (1999) Arutbody response to the chlamydial heat-shock protein 60 in an experimental model of chronic pelvic inflammatory disease in monkeys (Macaca nemestrina). J. Infect. Dis., 180,774-779.

Peipert, J.F. (2003) Clinical practice. Genital chlamydial infections. N. Eng. J. Med., 349, 2424-2430.

Persson, K., Osser, S., Birkelund, S., Christiansen, G., Brade, H. (1999) Antibodies to Chlawydia trachowatis heat shock proteins in women with tubal factor infertility are associated with prior infection by C. trachomatis but not by C. pnewmoniae. Hum. Reprod., 14, 1969-1973.

Piura, B., Sarov, B., Sarov, L. (1993) Persistence of antichlamydial antibodies after treatment of acute salpingitis with doxycycline. Eur. J. Obs. G Gyn and Reprod. Biol., 48, 117-121.

Punnonen, $R_{\text {, }}$ Lehtinen, M., Teisala, K. et al. (1989) The relation between serum sex steroid levels and plasma cell infiltrates in endometritis. Awh. Gynecol. Obster, 244, 185-191.

Puolakkainen, M.; Vesterinen, E., Purola, E., Saikku, P., Panonen, J (1986) Persistence of Chlamydial antibodies after pelvic inflammatory disease. J. Clin. Microbiol, 23, 924-928.

Puolakkainen, M., Hilunen-Back, E., Reunala, T., Suhonen, S., Lahteenmäki, P., Lehtinen, M., Pavonen, J. (1998) Comparison of performances of two commercially available tests, a PCR assay and a ligase chain reaction test, in detection of urogenital Chlamydia tradhomatis infection. J. Clin. Microbiol, 36, 1489-1493.

Quinn, T.C., Welsh, L., Lentz, A., Crotchfelt, K., Zenilman, J, Newhill, J, et al. (1996) Diagnosis by amplicor $\mathrm{PCR}$ of $\mathrm{C}$. trachomatis infection in unine saimples from women en men attending sexually transmitted disease clinics. J. Chin. Mirobiol., 34, $1401-1406$.

Ramsey, K.H.., De Wolfe, J.L., Salyer, R.D. (2000) Disease outcome subsequent to primary and secondary urogenital infection with murine or human biowars of Champdiat iradomatis. Infect. Immm ., 68, 7186-7189.

Rank, R.G., Soderberg, L.S., Barron, A.L. (1985) Chronic Chlamydial genital infection in congenitally athymic nude mice. Infect. Imwm., 48, 847-849.

Rank, R.G., Batteiger, B.E., Soderberg, L.S. (1988) Susceptibility to reinfection after a primary chlamydial gental infection. Infect. Immm 
Rark, R.G., Ramsey KH, Pack E.A., Willians D.M. (1992) Effect of ganma interferon on nesolution of mume Chlamydial genital infection. Infect. Inmun., 60,4427-4429.

Rasmussern, S.J., Eckmani, L, Quayle, A.J., Shen, L., Zhang, X.X., Anderson, D.J., Fierer, J., Stephens, R.S., Kagnoff. MF. (1997) Secretion of proinflammatory cytokines by epithelial cells in response to Chlamydia infection suggests a central role for epithelial cells in chlamydial pathogenesis. J. Clin. Furest., 99,77-87.

Saikku, P., Mattila, K., Nieminen, M.S. et al. (1988) Serological evidence of an association of a novel Chlanydia, TWAR, with chronic coronary heart disease and acute myocardial infarction. Lawred, $2,983-986$.

Schachiter, J, Stamm W.E., Quinn, T.C., Andrews, W.W., Burczak, J.D., Lee, H.H. (1994) Ligase chain reaction to detect $C$. trachomatis infection of the cervix. J. Clin. Microbiol, 32, 2540-2543.

Schachter, J and Stamm, W E. (1995) Chlamydia: In: Murray. P.R., Pfaller, M.A., Tenover, F.C., Yolken, R.H eds. Manual of clinical microbiology, $6^{\text {th }}$ edition, American Society of Microbiology, Washingtion; D.C., 669-677.

Schachter, J: MeComack, S., Sweet, R.L. et al., (1997) Control of Chlamydia: a role for every cinician who sees sexually active patients. J. Cin: Out. Mandg., 4, 60-73.

Schachter, J., Stephens, R.S., Timms, P ei al. (2001) Radical changes to Chlamydial taxonomy are not necessary just yet. Int. J. Syst. Evol. Microbiol., 51, 249.

Sciarro, J.J. (1997) Sexually transmitted diseases: global importance. Int. J. Gynecol. Obstet., 58, $107-119$.

Sesculally transmitted dliseases treatment guidelines 2002. Centers for Disease Control and Prevention. MMWR Reromm. Rep., $5 \mathbb{1}(\mathrm{RR}-6), 1-78$.

Sherris, J.C. and Ray, C.G. (1990) An overview of the specific immune response. In: Medical Microbiology; an introduction to infectious diseases, 117-137. J.C. Sherris ed.

Sirimins, 1., Catchpole, M., Brugha, R., et al. (1997) Epidemiology of genital Chlamydia tradtowatis in England and Wales. Genitourin. Med., 73, 122-126.

Starnbach, M.N., Bevan M.J., Lampe, M,F. (1994) Protective cytotoxic T lymphocytes are induced during nurine infection with $C$.trachonatis. J. Inmunol, 153, 5183-5189.

Stephens, $\mathbb{R}$.S., Byrne, G.I. (eds) Chlanydial infections, NAPA, 159-162.

Spandorfer, S.D., Neuer, A., La Verde, D., Byrne, G., Liu, H.C., Rosenwaks, Z. (1999) Previously undetected Chlawy dia trachomatis infection, immunity to heat shock proteins and tubal occlusion in women undergoing in-vitro fertilization. Hwm. Reprod., 14, 60-64.

Swart, P, Mol, B.W., van der Veen, B., wan Beurden, M., Redekop, K., Bossuyt, P.M.M. (1995) The accuracy of hysterosalpingography in the diagnosis of tubal pathology, a metamanalysis. Fevtil. Stertil., 64, 486-491.

Suchland, R.J. and Starmm, W.E. (1991) Simplified microtiter well cell culture method for rapid immunotyping of Chlanydia trochomatis. J. Clit. Miobsiol, 29, 1333-1338.

Sziller, I., Witlkin, S.S., Ziegert, M., Csapo, Z., Ujhazy, A., Papp, Z. (1998) Serological responses of patients with ectopic pregnancy to epitopes of the Chlamydra trachomatis $60 \mathrm{kDa}$ heat shock proteins. Hum. Reprod, 13, 1088-1093.

Tabban, K. . (2001) Trachoma a review J. Chemother, 13, suppl 1, 18-22.

Taylor-Robinson, D., Thomas, B.J. (2000) Chlarnydia pneumoniae in atherosclerotic disease. $J$. Infect. Dis, 181 , suppl 3, S437-S440.

Thej]ls, H., Rahm, V.A., Rosen, G., Gnarpe, H. (1987) Correlation between Chlamydia infection and clinical evaluation, vaginal wet smear and cervical swab test in female adolescents. $A m . J$. Obstat. Gynewl., 157, 974-976.

Thorpe, E.M. Jr, Stamm, W.E., Hook, E.W. $3^{\text {rd }}$, Gall, S.A., Jones, R.B., Henry, K., Withworth, G. Johnson, R.B. (1996) Chamydial cervicitis and urethritis: single dose treatment compared with doxycycline for seven days in community based practises. Genitotrif. Med., 72, 93-97. 
Toye, B., Lafenière, C., Claman, P.et al. (1993) Association between the Chamydual heat sliock protein and tubal infertility. J. Infect. Dis., 168, 1236-1240.

Traharne, J.D., Darougar, S., Jones, B.R. (1977) Modifications of the microimmunofluorescence test to provide a routine serodiagnostic test for Chlamydial infection. $\int$. Clin. Pathol, 55 . 304-310.

Tuffey, M., Taylor-Robinson, D. (1981) Progesterone as a key factor in the development of at mouse model for genital tract infection with Chamydia tadhomatis. FEMS Miorobiol. Leth, 12, $111-115$.

Tuffrey, M., Falder, P., Gale, J., Taylor-Robinson, D. (1986a) Salpingitis in mice induced by human strains of Chlamydia trachomatis. Br. J. Exp. Paihol , 67,605-616.

Tuffrey, M., Falder, P., Gale, J., Quim, R., Taylor-Robinson, D. (1986b) Infertility in mice infected genitally with a human strain of Chlamydia trathowatis. J. Reprod. Fertil, 78, 251-260.

Tuffrey, M., Alexander, F., Innan, C., Ward, M.E. (1990) Correlation of infertility with altered tubal morphology and function in mice with salpingitis induced by a human genital-tract isolate of Chlamydia trachowatis. J. Reprod. Fertil, $88,295-305$.

Tuuminen, T., Palomäki, P., Paavonen, J. (2000) The use of serologic tests for the diagnosis of Chlamydial infections. J. Mic. Meth., 42, 265-279.

Valkengoed, I. G. M. van, Morré, S.A., Brule, A.J.C. van den, Meijer. C. J.L.M., Devillé, W., Bouter, L.M., Boeke, A. I. P. (2000) Low diagnostic accuracy of selective screening criteria for asymptomatic Chlamydia trachomatis infections in the general population. Sex. Transm. Inf., 76, 375-380.

Villareal, C., Whittum-Hudson, J.A., Hudson, A.P. (2002) Persistent Chlamydia and chronic arthritis. Arthritis Res., 1, 5-9.

Voorhis van, W.C., Barrett, L.K., Cosgrove Sweeney, Y.T., Kuo, C.C., Patton, D.L. (1996) Analysis of lymphocyte phenotype and cytokine activity in the inflammatory infiltrates of the upper genital tract of female macaques infected with C. trachomatis. J. Infect. Dis, 174, 647-650.

Voorhins van, W.C., Barrett, L.K., Sweeney, Y.T., Kuo, C.C., Patton, D.L. (1997) Repeated Chlanydia trachomatis infection of Macaca nemestrina fallopian tubes produces a Thl-like response associated with fibrosis and scarring. Infect. Immun, 65, 2175-1282.

Wager, E.A., Schlachter J., Bavoil, P., Stephens, R.S. (1990) Differential human serologic response to two 60.000 molecular weight $C$. tradhontatis antigens. J. Infect. Dis, 162, 922-927.

Ward, M.E. (1995) The inmunobiology and immunopathology of Chlanydial infections. APMS, 103, 769-796.

Wang, S.P., Grayston, J.T. (1970) Immunologic relationship between genital TRIC, lymphogranuloma venereum, and related organisms in a new microutitè indirect immunotuorescence test. Am. J. Ophwalmol., 70, 367-374.

Wang, S.P., Grayston, J.T. (1974) Human serology in Chlawydia trachomatis infection with microimmunofluorescence. J. Infect. Dis., 130, 388-397.

Welte, R., Kretzschmar, M., Postma, M.J. et al. (2000) Cost-effectiveness of screening programs for C. trachomatis: a population based dynamic approach. Sex. Transm. Dis., 27, 518-530.

Weström, L. (1980) Incidence, prewalence and trends of acute pelvic inflammatory disease and its consequences in industrial countries. Am. J. Obstet. Gymetol., 138, 880-892.

Weström, L., Bengtsson, L.P., Mărdh, P.A. (1981) lncidence, trends and risks of ectopic pregnancy in a population of women. B.M. $, 282,15-18$.

Weström, L., Mărdh, P.A. Salpingitis (1984) In: Sexually transmitted diseases. Holmes, K.K., Mărdh, P.A., Sperkling, P.F, et al., eds. New York: McGraw-Hill, 615-632.

Weström, L. (1994) Sexually transmitted diseases and infertility. Sex. Transm. Dis., 21, S32-S37.

Whittum-Hudson, J.A., O'Brien, T.P., Prendergast, R.A. (1987) Murine model of ocular infection by a human biovar of C. trachonatis. Intest. Ophthalmol. Visual. Soi., 36, 1976-1987. 
Witkin, S.S., Jerenias, J., Toth, M, et al.(1993) Cell mediated mumue response to the recombinant $57 \mathrm{kD}$ a heat shock proten of $\mathrm{C}$. Irachowats in women with salpingitis. $J$. Infert. Dis., 167 . $1379-1383$.

Wolner-Hanssen, P. Westrom, L, Mârdh, P.A. (1980) Perihepatitis and Chlamydial salpingitis. Lswivet, 1, $901-903$.

Wholner-Hanssen, P. Svensson, L., Mardh, P.A. (1982) Isolation of Chlanydia trathomatis from the liver capsole of a patient with Fiz-Hugh-Curtis syndrome. N. Eng. J. Med., 306, 113 .

Yuan, Y., Zhang; Y.X., Watkins, N.G., Caldwell, H.D. (1989) Nucleotide and deduced anino acid sequences for the four variable domains of the major outer membrame proteins of the $15 \mathrm{C}$.

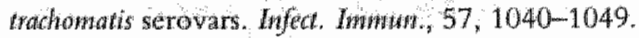

Yong, E. Ch, EY, Chen, W.J, Kuo, C.C. (1986) Degradation of C. trachomatis in humar polymorphonthlear letkocytes; an ultrastructural study of peroxidase-positive phagolysosomes. Infect. Imw

Zeitz, M, Schieferdecker, H.L., James, S.P., et al (1990) Special function features of T-lymphocyte subpopulations in the effector comparment of the intestinal mucosa and their relation to mucosal transformation. Digestion, $46,280-289$. 


\title{
Chlamydia antibody testing in screening
} for tubal factor subfertility: The significance of IgG antibody decline over time

\author{
A. P. Gijsen 1,3 J. A. Land ${ }^{1}$, V. J. Goossens ${ }^{2}$, M.E.P. Slobbe', C.A. Bruggeman ${ }^{2}$ \\ Research Institute Growth and Development (GROW), Department of \\ Obstetrics and Gynaecology ${ }^{1}$ and Cardiovascular Research Institute Maastricht \\ (CARIM), Department of Medical Microbiology 2, Academisch Ziekenlinis \\ Maastricht, Maastricht, the Netherlands
}




\section{Abstract}

Background Chamydia (C.) trachomatis antibody testing in screening for tubal factor subfertility is limited by false negative results, i.e. negative Chlamydia antibody tests in patients with tubal pathology at laparoscopy. The present study was performed to determine whether decline in C. trachomatis $1 \mathrm{gG}$ antibodies over time is responsible for those false negative results.

Methods 39 Women with an initial titre of $\geq 64$ were serologically restudied after 4-7 years. A new serum sample was collected from each patient. The initial and the second serum sample were tested for $C$. trachonatis $\lg G$ antibodies using a micro-immunofluorescence assay (MIF). A species-specific ELISA was used to validate the MIF test results. All patients filled out a questionnaire to determine risk factors for renewed C. trachomatis infection between the initial and second serum sample.

Results Seven of the 39 patients (18.0\%) showed a significant decline in IgG antibodies by MIF over a period of 4-7 years, but IgG antibodies never became undetectable. In the " $7 / 39$ patients who showed a decline by MIF, signal/cut-off values by ELISA did not decrease.

Conclusion $\mathrm{A}$ dedine in $\operatorname{IgG}$ antibody titre is not a significant cause of false negative Chlamydia antibody test results. 


\section{Introduction}

In women, up to $80 \%$ of Chlamydia infections reman asymptomatic (Qumn et al. 1996). These untreated women are at risk of developing chronic sequelae such as periadnexal adhesions and tubal occlusion, and of presenting at fertility clinics about $10-15$ years after the primary infection.

Chlamydia immunoglobulin (Ig) $G$ antibodies are thought to persist for years and have therefore been used as markers of a previous $C$.rachomatis infection (Ngeow et al. 1996). Chlamydia antibody testing (CAT) has been incomporated in fertility work-up on a large scale, and has been shown to be a non-invasive and cost-effective screening method for tubal factor subfertility (Mol ef al., 1997).

The clinical significance of CAT however has its limitations, due to false positive and false negative test results (Land et al, 1998). Patients with false negative CAT results (i.e. negative Chlamydia antibody tests in patients with tubal pathology at laparoscopy) may have non-Chlamydia related causes of adhesions or tubal occlusion, or no antibodies may be found despite previous $C$. trachomatis infection. As a cause of false negative CAT, it has been postulated that $\operatorname{Cg} \mathrm{G}$ antibodies may decline over time after $C$. trachomatis infection, in view of the time span between primary infection in adolescence and fertility work-up in adulthood.

So far, little is known about the course of Chlamydia $\operatorname{IgG}$ antibodies over time. Four studies have been published on this subject. "The post-therapentic course of serum Chlamydia IgG antibody titres has been studied in 47 women with acute salpingitis (Henry-Suchet et al., 1994), who had positive $\operatorname{IgG}$ antibody titres and were treated with doxycycline. Twelve months after treatment, the $\lg \mathrm{G}$ titre had. decreased in 15 of the $47(31.9 \%)$ women. However, only two of the 47 women (4.3\%) reverted from IgG sero-positive to sero-negative in the one-year interval studied. Another report on the effect of treatment with doxycycline on sertim Chlamydia $\lg G$ antibodies is a study performed in 33 women, who had had an episode of acute salpingtis associated with high $\operatorname{IgG}$ titres (> 64) (Piura of al., 1993). Mean follow-up time was 34.2 months (range $24-49$ months). No significant change in $\operatorname{IgG}$ titres was demonstrated in 21 women $(63.6 \%)$, a significant increase in titre (four-fold or more) was found in eight women $(24.2 \%$ ), and a significant decrease in four women (12.1\%). The authors concluded that post-treatment titres remain high in most cases, even when treatment resulted in complete resolution of clinical signs and symptoms of the disease. The third study published deals with the long-term persistence of serum Chlanydia IgG antibodies in patients with high initial $\operatorname{IgG}$ antibody titres $(\geq 1: 128)$ in serum after pelvic inflammatory disease (Puolakkainen et al, 1986). The follow-up time was between 3.1 and 6.3 years. Twenty-six out of 60 patients $(43.3 \%$ ) showed an insignificant change in Chlamydia IgG serum antibody levels, 8 (13.3\%) showed a 
significant increase and $26(47.3 \%)$ showed a significant decrease. The fourth study published on titre course has been performed in asymptomatic patients during a community onented screening program among 860 women of reproductive age (Chain al , 1992). Twenty-one patients (2.4\%) were found to have Chlamydia IgG antibody titres $>64$. These 21 patients were treated with doxycycline, after which $\operatorname{IgG}$ titres were followed in 17 of the cases. Over a five-year interval, $\operatorname{lgG}$ tutres were unchanged in one case $(5.9 \%)$, had increased twofold in one case $(5.9 \%)$, decreased significantly (threefold or more) in 11 cases $(64.7 \%)$ and decreased twofold in four cases $(23,5 \%)$.

In conclusion, the four studies published on the course of Chlamydia IgG antibody titres describe 153 patients, of which $56(36.6 \%)$ had a significant titre decline during the study period. However, all papers concern the post-therapeutic course of $C$ trachomatis levels in patients with active genital infections, immediately after the institution of therapy. The objective of the present study was to investigate the coutse of Chlamydia $\operatorname{IgG}$ antibody levels in asymptomatic subfertility patients, in whom no active $C$. trachomatis infection is assumed to be present. A MIF test was used, as this test is still considered the best available standand, and a species-specific ELISA was used to validate the MIF test results.

\section{Materials and Methods}

In our hospital, CAT has been part of the fertility work-up since 1992. Blood is drawn at the patient's first visit and CAT is performed. Between 1992 and 2000 , from 253 patients spare serum (Sample-1) was stored for research purposes. Of those 253 patients, 67 had an antibody titre of $\geq 64$, which we considered positive (Land ef al., 1998), and had a follow-up period of at least four years. These women were approached for a second blood sample (Sample-2). Forty-five women could be traced, and 39 women agreed to participate in the stidy. After a mean follow-up time of 5 years and 7 months (range 4 years and 0 months to 7 years and 2 months), Sample-2 was obtained from these 39 patients. In all 39 patients Sample-1 was re-determined simultaneously with the determination of Sample-2 by MIF. In 33 patients sufficient Sample-1 and Sample-2 serum was available for additional antibody testing by ELISA.

An indirect MIF antibody technique for C. trachomatis $\lg G$ antibodies was used. In short, $20 \mu$ l of serum was diluted aight times in phosphate buffered saline (PBS) (pH 7.4) and incubated on the $C$. frachomatis-spot immunofluorescence substitute slides (egg grown C. trachomatis biovar $\mathrm{L}_{2}$; Biomerieux, "s Hertogenbosch, the Netherlands) for $30 \mathrm{~min}$ at $37^{\circ} \mathrm{C}$ in a moist chamber. The slides were washed three times for $5 \mathrm{~min}$ in $\mathrm{PBS}$ and incubated with fluorescein-conjugated rabbit 
antihuman IgG (Dako, ITK Diagnostics B.V., Uithoorn, the Netherlands) diluted in PBS for 30 min at $37^{\circ} \mathrm{C}$. After three washings in PBS and one in ultrapure water, processed through a milli-Q purifying system (Millipore, Bedford, MA. USA), slides were embedded in Fluoprep mounting medium (Biomerieux, s Hertogenbosch, the Netherlands) under a cover slip. A positive reaction was characterised by specific fluorescence of the C. tratmonatis elementary bodies. For at quantitative determination of the antibody titre, two-fold serum dilutions in PBS were made. The reciprocal value of the highest dilution giving a positive signal in the MIF was considered as the antibody titre. All slides were evaluated independently by two readers. In case of disagreement, the independent judgement of a third reader was decisive. Differences in titres were expressed in titre steps. A difference of two titre steps or more between Sample-1 and Sample-2 was considered significant.

For validation of the MIF results, a C. rachomatis IgG ELISA (Labsystems, Helsinki, Finland) was performed. Sera were diluted 1:10 with Trisbuffer and tested in microtitre plates coated with synthetic peptides derived from the major outer membrane proteins of $C$. trachomatis $\left(\mathrm{L}_{2}\right)$. The plates were incubated $30 \mathrm{~min}$ at $37 \circ \mathrm{C}$. The strips were washed five times in $300 \mu \mathrm{l}$ washing solution (citrate buffered PBS) and the inverted strips were tapped a few times on a paper towel to remove excess fluid. To each well $200 \mu$ conjugate was added (sheep antihuman $\mathrm{IgG} /$ horseradish peroxidase) and the plate incubated again $30 \mathrm{~min}$ at $37^{\circ} \mathrm{C}$. The washing steps were repeated five times. Citrate-acetate buffered substrate in a volume of $200 \mu$ was pipetted in each well, the plate incubated at room tempera ture in the dark for $15 \mathrm{~min}$. Finally, 50 fll stopreagens $\left(2 \mathrm{M} \mathrm{H}_{2} \mathrm{SO}_{4}\right)$ was added. The absorbance of the plates was measured in a spectrophotometer at $450 \mathrm{~nm}$. Cut-off indexes and signal/cut-off $(\mathrm{S} / \mathrm{C}$ ) values were calculated and the results interpreted according to the manufacturer's instructions. The results were inter preted to be negative (N) when $\mathrm{S} / \mathrm{C}$ was $<1.0$, equivocal (E) when $\mathrm{S} / \mathrm{C}$ was $\geq 1.0$ and $<1.4$, positive (P) when $S / C$ was $\geq 1.4$ and $<2.5$ and highly positive (HP) when $\mathrm{S} / \mathrm{C}$ was $\geq 2.5$. The washing steps are repeated five times. Citrate-acetate buffered substrate in a volume of $200 \mathrm{~mL}$ was pipetted in each well, the plate covered and incubated at room temperature in dark for 15 min. Finally, $50 \mathrm{ml}$ stopreagens ( $2 \mathrm{M} \mathrm{H2SO} 4$ ) was added. The strips are cleaned before reading. The absorbance of the plates is measured in a spectrophotometer at $405 \mathrm{~nm}$. Cut-off indexes are calculated according to the manufacturer's instructions. The cut-off index for a positive test is 1.1. Results were considered different when the $\mathrm{S} / \mathrm{C}$ value of Sample-1 was different from the $5 / \mathrm{C}$ value of Sample-2.

At the time of Sample-2 all patients filled out a questionnaire in order to determine risk factors for a renewed $C$. trachomatis infection after Sample 1. Questions were asked about abdominal complaints compatible with pelvic inflammatory 
disease, fertility treatment in which cervical manpulation is involved, the use of contraceptive methods, and new sexual partners since Sample-1. Furthermore, social habits such as smoking and alcohol use were asked for, since these factors have been associated with the risk of tubal factor subfertility (Bahamondes et al., 1994). For statistical analysis a Fisher's Exact test was used. P-values $<0.05$ were considered significant.

\section{Results}

Initially, in all 39 women CAT was performed as part of their fertility work-up after they had been trying to achieve pregnancy for at least 12 months. At Sample-1, patients had a mean age of 29 years (range 19-38) and at Sample-2 they had a mean age of 36 years (range 26-45). $I g G$ antibody titres by MIF in Sample-1 and Sample-2 are given in table $I$. Also in table $\mathrm{I}, \mathrm{S} / \mathrm{C}$ values of Sample-1 and Sample-2 are shown, to allow comparison of MIF and ELISA results. In $32 / 39$ (82.0\%) patients, no significant change in Chlamydia IgG antibody titre by MIF was demonstrated between Sample-1 and Sample-2. In $7 / 39$ patients (18.0\%) a decline in $\mathrm{IgG}$ antibodies of at least two titre steps was found over a period of $4-7$ years. However, in no patient $\lg \mathrm{G}$ antibodies became undetectable.

The ELISA test showed no significant change in $26 / 33$ patients $(78.8 \%)$, a decline was found in $1 / 33$ patient (3.0\%) and an increase in $6 / 33$ patients (18.2\%). However, in all $7 / 39$ patients in whom a significant decline in $\operatorname{IgG}$ antibody titre was found by MIF, no differences were found by ELISA. In comparing CAT results by MIF and ELISA, a remarkable discrepancy was found: In contrast to MIF, which showed $\operatorname{IgG}$ antibodies in all patients for both Sample-1 and Sample-2, the ELISA showed negative values in $7 / 33(21.2 \%)$ patients in both samples.

For analysis of the questionnaire, patients were divided into two groups, to determine risk factors for renewed $\mathrm{C}$. trachomatis infection after Sample-1. Group $\mathrm{A}$ consists of patients in whom no significant titre decline by MIF was found, and group B of patients with significant tite decline measured by MIF. Groups A and $B$ were compared for the prevalence of risk factors for renewed infection. The results of the questionnaires are shown in table II. The mean time interval between Sample-1 and Sample-2 did not differ for the two groups: 5 years and 8 months in group $A$ and 5 years and 10 months in group B. Comparison of the group of patients without significant titre decline (group A) with those with significant titre decline (group B) revealed no significant differences in prevalences of the factors associated with renewed infection. As many patients in group $A(34.4 \%)$ as in group B (28.6\%) reported an episode of abdominal complaints after Sample-1. In 


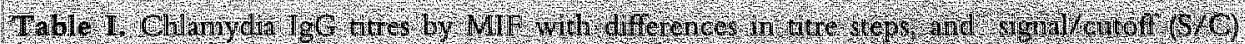

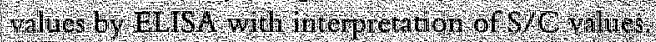

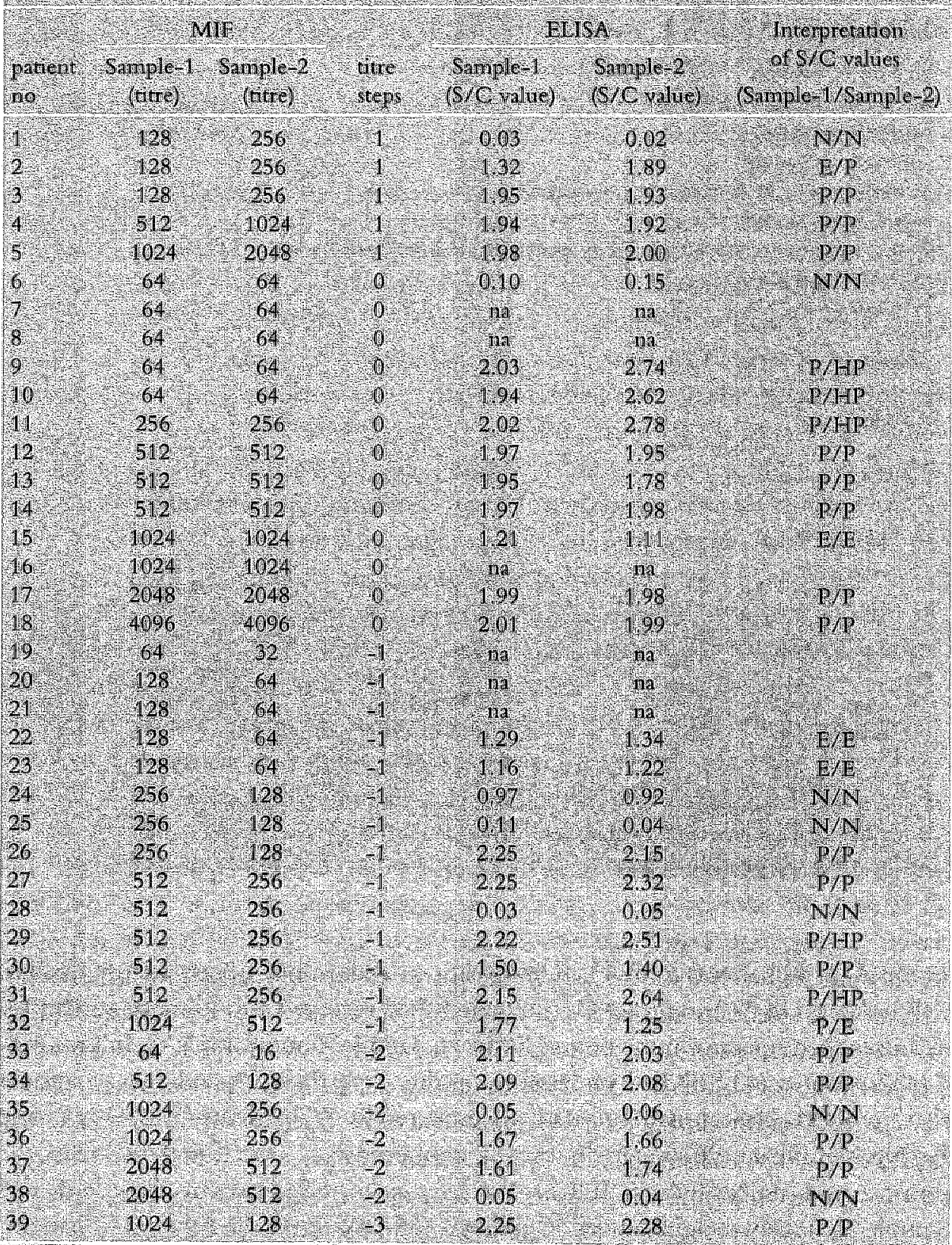

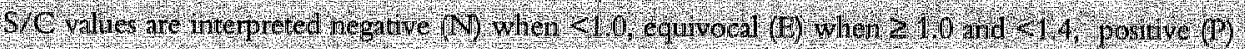

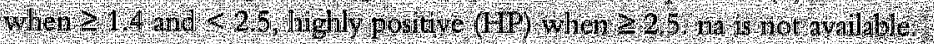




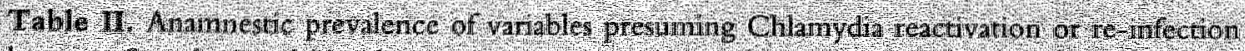
between Sanplet and Simple-2.

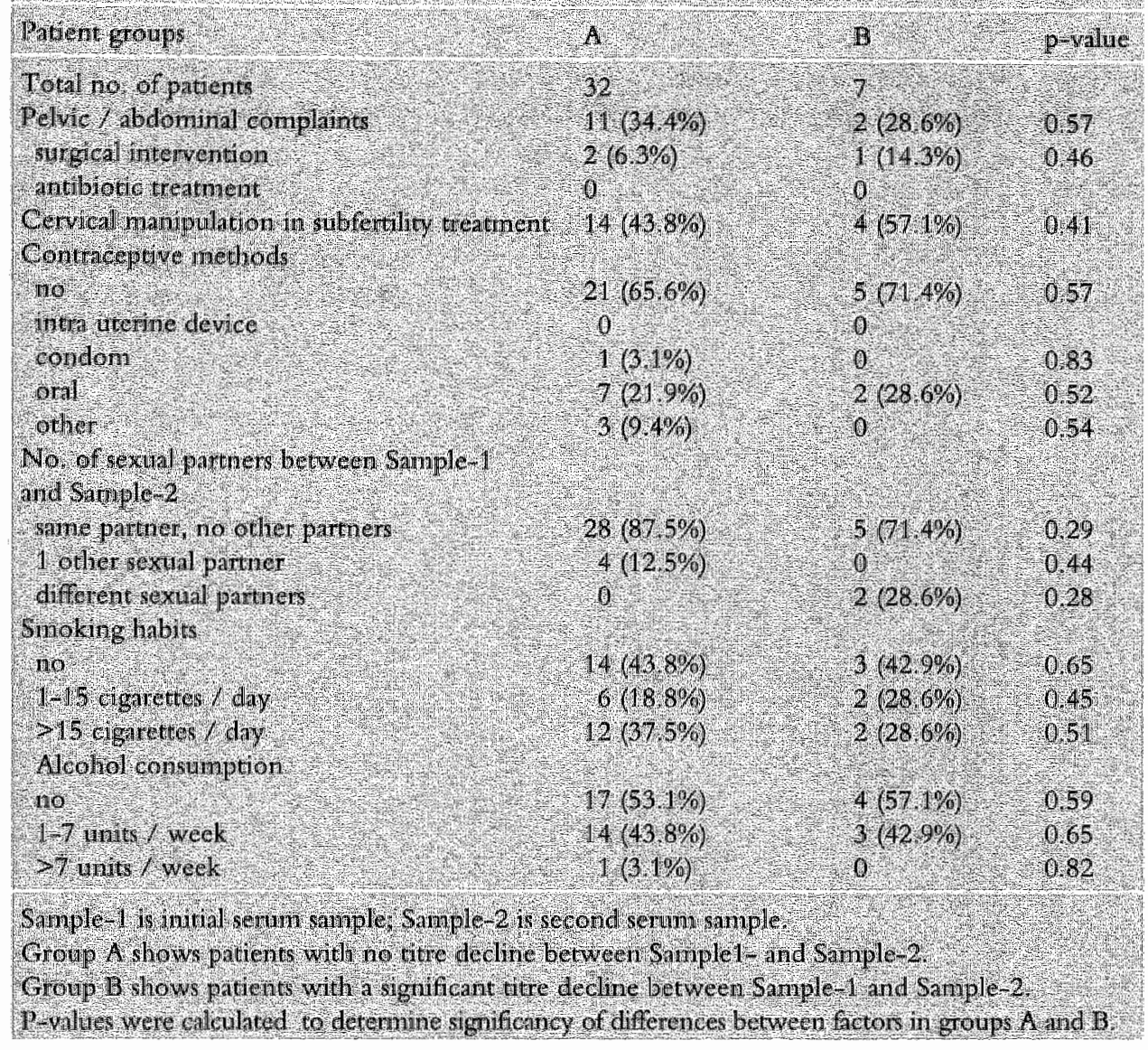

group A, 2/32 patients (6.3\%) had had pelvic or abdominal surgery as compared to $1 / 7$ patients (14.3\%) in group B. No patient had received antibiotic treatment for abdominal complaints in the period between Sample-1 and Sample-2 In group A, $14 / 32$ patients $(43.8 \%)$ had undergone fertility investigations and / or treatment that involved cervical manipulation, as conpared to $4 / 7$ patients $(57.1 \%)$ in group B. No significant difference in use of contraceptives was found between the groups, and especially no IUCD use was reported between Sample-1 and Sample-2. Twenty-eight out of 32 patients ( $87.5 \%$ ) in group A and $5 / 7$ patients (71.4\%) in group B reported to have had the same sexual partner between Sample-1 and Sample-2. Furthermore, 18/32 patients (56.3\%) in group A reported cigarette smoking versus $4 / 7$ patients $(57.1 \%)$ in group B. Alcohol consumption was reported by $15 / 32$ patients (46.9\%) in group $A$ and $3 / 7$ patients 
(42.9\%) in group B. At statistical analysis the above mentioned factors showed no significant differences between groups $\mathrm{A}$ and $\mathrm{B}$.

\section{Discussion}

CAT has been introduced as a simple and inexpensive screening test for tubal factor subfertility. However, little attention has been paid to its limitations: Although it is assumed that Chlamydia infections give rise to persistent $\operatorname{IgG}$ antibody formation, the exact course of titres over time is still poorly understood. The four studies published to date on the course of Chlamydia IgG antibody titres together describe a significant decline of titres of $36.6 \%$ in 153 patients tested, but describe seroconversion from positive to negative as a rare occurrence. However, these studies have all concerned patients recently treated for acute pelvic inflanmatory disease only. To our knowledge, the present study is the first to investigate the course of Chlamydia $\operatorname{IgG}$ antibody levels in asymptomatic subfertility patients.

In our study, by using MIF a decline of $\lg G$ antibody titres of at least two titre steps was found in $7 / 39$ patients $(18.0 \%$ ) over a period of $4-7$ years. However, in no patient IgG antibodies became undetectable. The persistently high Chlamydua IgG antibody titres in $82.0 \%$ of patients might theoretically be explained by re-infections by Chlamydia. Firsty, Chlanydia re-infection might occur by endogenous reactivation of the microorganism that has become latent after a previous infection (Forsey ef al., 1990). Subfertility patients are considered to be at risk for endogenous reactivation by cervical manipulation during fertility investigations (e.g. hysterosalpingography) or treatment (e.g. intra-uterine insemination, IVF). Secondly; exogenous te-infection after a solved prinary infection (Stamm et al., 1986) may occur. A questionnaire was composed to estimate the risks of $C$. trachomats re-infection. We are aware of the fact that a questionnaire is a weak instrument, but there was no better method avallable to determine the risk of re-infection between the two time points studied. The questionnaire showed that there were as many patients who had undergone cervical rmanipulation in the group with titre decline as in the group without titre decline. Furthermore, the prevalence of active cervical $C$. trachomatis infections in subfertility patients has been reported to be $<2 \%$ (Eggert-Kruse et al, 1997; Macmillan et al., 1999). This also suggests the chance for endogenous reactivation in subfertility patients to be small. Our estimation of the risk of exogenous re-infection had to rely on patients" answers in the questionnaire, as patients were not screened for active $C$. molhomatis infections. Questions concerning risk factors associated with infection or re-infection were not answered differently by patients with no titre decline (group A) as compared to patients with titre decline (group B). Nevertheless, although the 
questionnaire indicated exogenous re-infection between the time points studied to be unlikely, re-infection can not be excluded completely. Summarising the results of the questionnare, it can be concluded that in our study $C$. trachomats re-infection by either endogenous reactivation or exogenous re-infection appears to be no major cause of persistence of Chlamydia $\operatorname{lgG}$ antibody titres in the subfertile women studied.

MIF is the most widely used test method for CAT in subfertility patients for screening for tubal pathology due to earlier C. trachomatis infections. CAT by MIF has been shown to have clinical value in predicting tubal pathology (Land et al, 1998). During C. pnewmoniae infection however, antibodies are also formed against the common antigenic epitopes present in all members of the genus Chlamydia. As the MIF test is not species-specific, cross-reaction between $C$. trachomatis and C. pneumoniae might occur (Mannion et al., 1991, Moss et al., 1993, Gijsen al., 2001). Furthermore, interpretation of the MIF results is subjective, and inter-observer differences are inevitable. Recently, ELISAs have become available which are more species-specific, and the results can be objectively analysed by computer. In the present study, an ELISA was used to validate the results on titre decline found by MIF. Overall, in $78.8 \%$ of cases, the ELISA showed no change in the interpretation of $\mathrm{S} / \mathrm{C}$ values between the two samples, and in particular no decline in $\mathrm{S} / \mathrm{C}$ value was found in the $7 / 39$ patients that showed a significant titre decline by MIF. Remarkably however, in $7 / 33$ patients (21.2\%) who had Chlamydia IgG antibodies by MIF, ELISA showed negative S/C values. The discrepancy found between MIF and ELISA results might be due to cross-reaction in the MIF test with other Chlamydia species than C. trachomatis. On the other hand, since in ELISAs synthetic peptides derived from different domains of the major outer membrane are used as antigens, these peptides will affect the specificity of the test. Therefore, patients without antibodies against the particular peptide used in the assay, will have negative ELISA results. Although the ELISA has been shown to be highly sensitive in detecting Chlanydia IgG antibodies in patients with proven acute C. Gachomatis infections (Närvänen et al, 1997), it has not yet been evaluated in screening for tubal factor subfertility in patients with previous subclinical infections.

In conclusion, this is the first paper to report on the course of $C$. trachomatis $\operatorname{IgG}$ antibodies over time in asymptomatic and untreated female subfertility patients. In 39 patients with initial $C$. trachomatis $\lg G$ antibody titres $\geq 64.7$ (18.0\%) showed a decline of at least two titre steps over a 4-7 year interval. However, in spite of this decline, all patients continued to test positive for $\operatorname{Ig} G$ antibodies. Responses to a questionnaire showed that reactivation or re-infection does not seem to be responsible for the persistence of Chlamydia $\operatorname{lgG}$ antibodies, since patients without titre decline did not differ from those with titre decline as regards the risk factors associ- 
ated with renewed $C$. trachowatis infection. We therefore conclude from this study that in subfertility patients, decline in $\operatorname{IgG}$ antibody titres over time is not a signifcant cause of false negative Chlamydia antibody test results (1.e. patients testing negative for Chllamydia antibodies, but with tubal factor subfertility found at laparoscopy). 


\section{References}

Bahamondes, L., Bueno, JG.R., Hardy, E, Vera, S, Pimentel, E., Ramos, M. (1994) Identification of main risk factors for tubal inferility. Fetril. Steril., 61,478-482.

Chaim, W., Edelstein, Z., Sarov, B, Sarov, 1. (1992) The long-term follow-up of asymptomatic wonen with Chamyda trachomatis. Anth. Gymecol. Obster, 251, 159-164.

Eggert-Kruse, W., Rohr, G., Demirakca, T., Rusu, R., Naher, H., Petzoldr, D., Runnebaum, B. (1997) Chlanydial serology in 1303 asymptomatic subfertile couples. Hum. Reprod, 12 , $1464-1475$.

Forsey, J.P. Caul, E.O., Paul, I,O., Hull, M.G. (1990) Chlamydia trachomatis, tubal disease and the incidence of symptomatic infection following hysterosalpingography. Hum. Reprod, $5,444-447$.

Gijen, A.I., Lund, J.A., Goossens, V.J., Leffers, P., Bruggeman, C.A., Evers, J.L.H. (2001) Chlanydia prowwoniat and screening for tubal factor subfertility. Huw Reprod., 16, 487-491.

Hermy-Suchet, J. Askienazy-Elbhar, M., Thibon, M., Revol, C., Akue, B.A. (1994) The post-therapeutic course of serum antibody titres in women with acute salpingiris and tubal infertility. Fentil steril., 62, 296-304.

Land, J.A., Evers, J.L.H., Goossens, V.J. (1998) How to use Chlamydia antibody testing in subfertility patients. Huw. Reprod, 13, 1094-1098.

Macmillan, S., Templeton A. (1999) Screening for Chlawydia trachomatis in subfertile women. Hum. Reprod, 14, 3009-3012.

Mannion, P.T, Mallinson, H., Treharne, J.D. (1991) Serological diagnosis with the Chlanydia spot-1F test. J. Med. Microbiol., 35, 244-248.

Mol, B.W.J, Dijkman, B., Wertheim, P., Lijmer, J, wan der Veen, F., Bossuyt, P.M. (1997) The accuracy of serum Chlamydial antibodies in the diagnosis of tubal pathology: a meta-anallysis. Fextil Steril. 67, 1031-1037.

Moss, T.R., Darougar, S., Woodland, R.M., Nathan, M., Dines, R.J., Cathrine, V. (1993) Antibodies to Chlamydia species in patients attending a genitourinary clinic and the impact of antibodies to $C$. presomomiae and $C$. psittaci on the sensitivity and the specificity of $C$. tradhomatis serology tests. Sex. Transm. Dis, 20,61-65.

Närvänen, A., Puolakkainen, M., Hao, W., Kino, K., Sumi, J. (1997) Detection of antibodies to Chlamydia mathomatis with peptide-based species-specific enzyme immunoassay. Infect. Dis. Obstet. Gypr., $5,349-354$.

Ngeow, Y.E. (1996) Limitations of serodiagnosis in Channdial genial tract infections. Ann. Acad. Med. Simepore, $25,300-304$.

Pura, B., Sarov, B., Sarov, 1. (1993) Persistence of anti-Chlamydial antibodies after treatment of acute salpingitis with doxycycline. Eur. J. Obs. G. Gyn. and Reprod. Biol, 48, 117-121.

Puolakkainen, M., Vesterinen, E., Purola, E., Saikku, P., Pavonen, J. (1986) Persistence of Chlamydial antibodies after pelvic inflammatory disease. J. Clin. Microbial, 23, 924-928.

Quinn, T.C., Gaydos, C., Shepherd, M. (1996) Epidemiologic and microbiologic corralates of Chlanydia tradhomatis infection in sexual partnerships. JAMA, 276, 1737-1742.

Stamm, W.E., Roddy, R.E., Barnes, R.C. (1986) Repeated genital infections with $C$. frachonatis: prevalence and risk factors, p 499-502. Ln: D. Oriel, G. Ridgway, J. Schacher, D. Taylor-Robinson and M. Ward (ed), Chlanydial infections. Cambridge University Press, London. 
Chlamydia pneumoniae and screening for tubal factor subfertility

\author{
A.P. Gijsen', J.A. Land", V.J. Goossens', P. Leffers ${ }^{3}$, C.A. Bruggeman ${ }^{2}$, \\ J.L.H. Evers ${ }^{1}$ \\ Research Institute Growth and Development (GROW), Deparment of \\ Obstetrics and Gynaecologyl, Department of Medical Microbiology ${ }^{2}$, \\ Department of Epidemiology ${ }^{3}$, Maastricht, the Netherlands
}




\begin{abstract}
Chlawpdia (C.) ancibody testing (CAT) by milcroimtnunofluorescence (MIF) tests, has been introduced into the fertility work-up as a sereening test for tubal factor subfertility. In this study the role of $C$. pnewmoniae antibodies, as a cause for false positive CAT resultes due to cross-reactivity with C. trathomatis antibodies in the MIF test, has been evaluated. In 240 subfertile women serologic data were compared to laparoscopy findings.

The prevalence of $C$. phetumoniate antibodies using ELISA was $75 \%$ and did not differ between patients with and without tubal pathology. $C$. pnewmoniae antibodies were found in $87 \%$ of women with a positive MIF test $(\geq 32)$, and in $66 \%$ with a negative MIF test $(p<0.0005)$. Using ELISA instead of MIF for the detection of $C$. trachomatis antibodies, $C$. pnewmonide antibodies were found in $87 \%$ of $C$. trachomatis positive women, and in $69 \%$ of $C$. trachontatis negative women $(p<0.0005)$.

Patients without tubal factor subfertility but a positive MIF rest showed $C$. phewhonwe antibodies more frequently than patients without tubal factor subfertility and a negative MIF test. Therefore it was suggested that $C$. pneunonica antbodies nay be the cause of false positive CAT results. Remarkably, tubal pathology was more common in patients who had antibodies to both $C$. trachertatis and $C$. pherwomiat.
\end{abstract}




\section{Introduction}

Nowadays, C. trachomatis is the most common sexually transmitted disease in industrialised countries. In the majority of female patients Chlamydia infections remain asymptomatic, but they may eventually compromise tubal function and increase the risk of tubal factor subfertility. Clinicians have searched for simple and inexpensive screening tests to estimate the risk for tubal factor subfertility in a particular patient, in order to subject a high-risk patient to diagnostic testing (i.e. laparoscopy), and to postpone additional testing in a low-risk patient. Since it was noted that the development of pelvic inflammatory disease and its chronic sequelae are associated with $C$. trachomatis IgG antibody formation, the relation between antibody titres and tubal factor subfertility has been confirmed in many studies (summarised by Mol et al., 1997).

Chlamydia antibody testing (CAT), e.g. by micro-immunofluorescence (MIF) tests, has been introduced into the fertility work-up as a simple and inexpensive screening test for tubal factor subfertility. The clinical significance of CAT is limited by patients with Chlamydia antibodies but without tubal pathology at laparoscopy (defined as false positive CAT results), and by patients without Chlamydia antibodies but tubal pathology at laparoscopy (defined as false negative CAT results). False negative CAT results may be explained by non-Chlamydia causes of tubal pathology. False positive CAT results increase health care costs by increasing the number of laparoscopies. Therefore, if CAT is applied for selecting patients for laparoscopy, the number of false positive CAT results should be minimised.

In discussing false positive CAT results (i.e. patients with positive antibody titres, without tubal pathology at laparoscopy), the possible cross-reactivity in MIF tests between $C$. trachomatis and C. pnetmonide antibodies is a major issue. Initially, in the MIF test, antigens from elementary bodies of each of the serotypes of $C$. trachomatis were included in the test, and provided serotype-specific antibody testing (Wang et al., 1970). The preparation of multiple immunotype antigens made the test technically difficult to perform and impractical, and therefore modifications were introduced (Trehame et al., 1977). By pooling antigens of epidemiologically related serotypes, or using one broadly reacting serotype (usually $\mathrm{L}_{2}$ ), the number of antigens was reduced. Since MIF tests have been modified, and serotype-specific antigens are no longer used, cross-reactivity with other Chlamydia species (C. pneumoniae in particular) thas been suggested (Mannion ef al., 1991). The aim of this stidy was to evaluate the significance of $C$. pneumoniae antibodies in false positive CAT results in female subfertility patients. Recently, new test methods have been developed, which are considered species-specific for $\mathrm{C}$. trachomatis and $C$. pneumoniae. These tests are commercially 
available enzyme-linked immunosorbent assays (ELISA), which have not yet been evaluated in a clinical setting for CAT in subfertility patients. We used these tests to establish the prevalence of antibodies to $C$. pneumoniae in subfertile women. Secondly, we evaluated cross-reactivity in the MIF test with $C$. pneumoniae antibodies as a possible cause of false positive CAT results.

\section{Materials and Methods}

A prospective cohort study was performed in consecutive patients who sought treatment for subfertility in our clinic. Since 1992, CAT using MIF is a routine procedure in our fertility work-up. In all female patients blood is drawn at their initial visit and an indirect micro-immunofluorescent antibody technique for $C$. trachomatis antibodies is used. All spare serum samples are cryopreserved. Between January 1992 and April 1999, 240 patients underwent laparoscopy and tubal testing with methylene blue dye as part of their fertility work-up and took part in the study. Patients who had undergone previous pelvic surgery (except for an uneventful appendectomy or caesarean section) were excluded. For the sake of the study, tubal pathology at laparoscopy was defined as extensive periadnexal adhesions and/or distal occlusion of one or both tubes (Land et al., 1998). A true positive CAT result was defined as a positive antibody titre using MIF, in a patient with tubal pathology at laparoscopy. A false positive CAT result was defined as a positive antibody titre using MIF, in a patient without tubal pathology at laparoscopy.

After thawing the spare sera of the participating patients, an ELISA for $C$. trachontis antibodies (Labsystems, Helsinki, Finland) and an ELISA for C. pneumoniae antibodies (Bioclone Elegance, Marrickville, Australia) were performed. These ELISAs are considered specific for $C$. trachomatis antibodies (Närvänen et al., 1997) and for C. pnewnoniae antibodies respectively.

\section{Serological wethods}

For the indirect micro-immunofluorescent $\lg G$ antibody test, $20 \mu l$ of the serum is diluted eight times in phosphate buffered saline (PBS) and incubated on the $C$. trachomatis-spot immunofluorescence substitute slides (egg grown C. trachomatis biovar $\mathrm{L}_{2}$; Biomerieux, 's Hertogenbosch, The Netherlands) for $30 \mathrm{~min}$ at $37^{\circ} \mathrm{C}$ in a moist chamber. The slides are washed three times for five min in PBS and incubated with fluorescein-conjugated rabbit antihuman IgG (Dako, ITK Diagnostics BV, Uithoorn, The Netherlands) diluted in PBS for $30 \mathrm{~min}$ at $37^{\circ} \mathrm{C}$. After three washings in PBS and one in ultra-pure water processed through a Milli-Q puri- 
fying system (Millipore, Bedford, MA, USA), slides are embedded in Fluoprep mounting medium (Biomerieux, 's Hertogenbosch, The Netherlands). A positive reaction is characterised by specific fluorescence of the C. trachomatis elementary bodies. For quantitative determination serial dilutions in PBS are performed. All slides are evaluated independently by two readers. In case of disagreement, the judgement of a third reader is decisive. According to receiver operating characteristic curves constructed, an antibody titre of 32 appeared to be the optimum cut-off level in predicting tubal pathology (Land et al., 1998). Therefore, a positive MIF result was defined as a titre $\geq 32$.

For the C. trachomatis IgG ELISA (Labsystems, Helsinki, Finland), sera are diluted 1:10 with Trisbuffer and tested in microtitre plates coated with synthetic peptides derived from the major outer membrane proteins of $C$. trachonatis $\left(\mathrm{L}_{2}\right)$. The plates are incubated $30 \mathrm{~min}$ at $37^{\circ} \mathrm{C}$. The strips are washed five times in $300 \mu \mathrm{l}$ washing solution (citrate buffered PBS) and dried. To each well $200 \mu$ conjugate is added (sheep antihuman IgG/horseradish peroxidase). The plate is incubated again $30 \mathrm{~min}$ at $37^{\circ} \mathrm{C}$. The washing steps are repeated five times. Citrate-acetate buffered substrate in a volume of $200 \mu \mathrm{l}$ was pipetted in each well, the plate incubated at room temperature in dark for $15 \mathrm{~min}$. Finally, $50 \mu \mathrm{l}$ stopreagens $(2 \mathrm{M}$ $\mathrm{H} 2 \mathrm{SO} 4$ ) was added. The absorbance of the plates is measured in a spectrophotometer at $405 \mathrm{~nm}$. Cut-off indexes are calculated according to the manufacturer's instructions. The cut-off index for a positive test is 1.1 . The washing steps are repeated five times. Citrate-acetate buffered substrate in a volume of $200 \mu \mathrm{l}$ was pipetted in each well, the plate covered and incubated at room temperature in dark for $15 \mathrm{~min}$. Finally, $50 \mu \mathrm{l}$ stopreagens ( $2 \mathrm{M} \mathrm{H} 2 \mathrm{SO} 4$ ) was added. The strips are cleaned before reading. The absorbance of the plates is measured in a spectrophotometer at $405 \mathrm{~nm}$. Cut-off indexes are calculated according to the manufacturer's instructions. The cut-off index for a positive test is 1.1.

For the C. pneumoniae $\lg$ G ELISA (Elegance, Marrickville, Australia), human sera are diluted 1:210 with washing solution and tested in strips coated with highly purified C. preumoniae-specific outer membrane complexes. The plate is covered and incubated for $30 \mathrm{~min}$ at $37^{\circ} \mathrm{C}$. The strips are washed three times with $300 \mu \mathrm{l}$ washing solution. To each well, $100 \mu \mathrm{l}$. pneumoniae $\operatorname{lgG}$ antibody reagent (labeled anti-human IgG polyclonal antibodies) is added, the plate is incubated again for $60 \mathrm{~min}$. The plate is washed as described before. To each well $100 \mu \mathrm{l}$ substrate solution (diethanolamine) is pipetted. The plate is incubated at room temperature for $10 \mathrm{~min}$. Finally, $25 \mu \mathrm{l}$ Chlamydia stop solution is added and the thuid on the plate gently mixed. The Optical Density of the plates is measured in a spectrophotometer at $405 \mathrm{~nm}$. The cut-off index for a positive test, as recommended by the manufacturer, is 1.1 . 


\section{Statistical methods}

Data obtained at laparoscopy were correlated to serological test results, using the Chi-square test. P-values $<0.05$ were considered significant. Differences between proportions were calculated by using proportion tests for two independent proportionis. 95\%-Confidence intervals for proportion differences and $\mathrm{p}$-values were calculated. P-values $<0.05$ were considered significant.

\section{Results}

In 240 patients serologic data as well as laparoscopy results were available for analysis. The mean age of the patients was 30.3 years (range 19 to 40 years).

C. pneumoniae antibodies were detected by ELISA in $75 \%$ of patients. In $40 \%$ of patients a positive MIF test for $C$. trachomatis antibodies was found. $C$. pnetumoniae antibodies were found in $83 / 95$ (87\%) of patients who had a positive MIF test for C. trachomatis, and in $96 / 145(66 \%)$ of patients with a negative MIF test $(\mathrm{p}<0.0005)$. C. pnewmoniae antibodies were found in $66 / 76(86 \%)$ of patients who had a positive ELISA for C. trachomatis antibodies, and in 51/164 (69\%) of patients who had a negative ELISA for $C$. trachomatis antibodies $(\mathrm{p}<0.0005)$. Table I summarises positive serologic test results in patients with and without tubal pathology at laparoscopy respectively.

Cross-reactivity in the MIF test between C. pneumoniae and C. trachomatis antibodies is a possible cause for false positive CAT results. In order to study cross-reactivity, C. trachomatis and C. pneumoniae ELISAs were performed. The prevalence of C. pneumoniae antibodies has been studied in two different subgroups of patients in whom no tubal pathology was found at laparoscopy (table II).

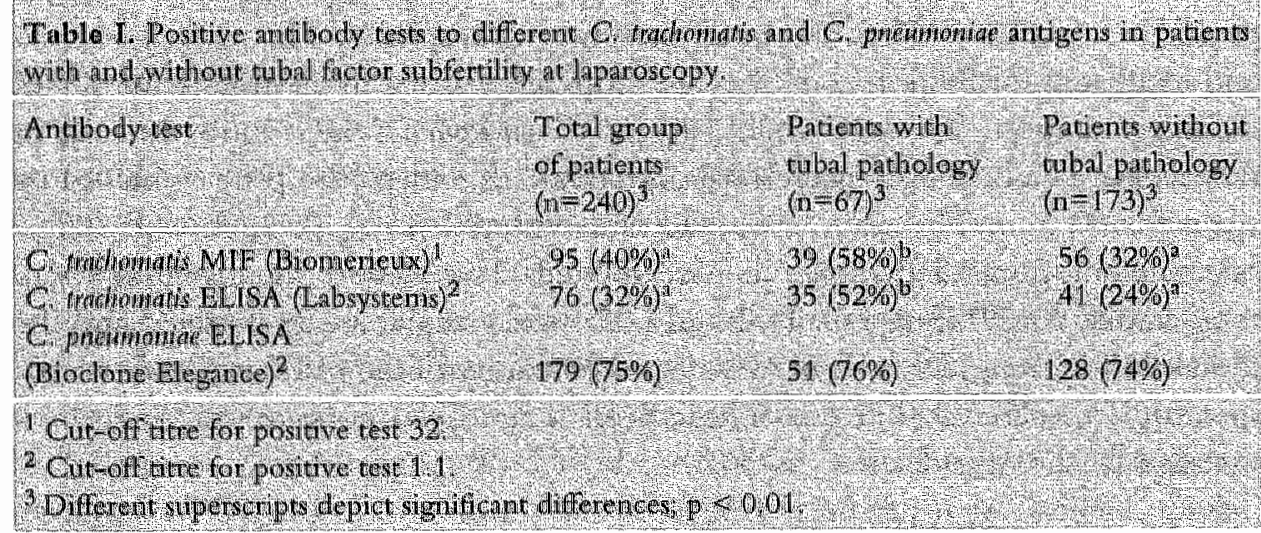




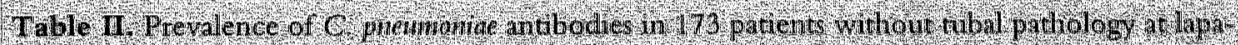

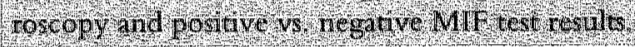

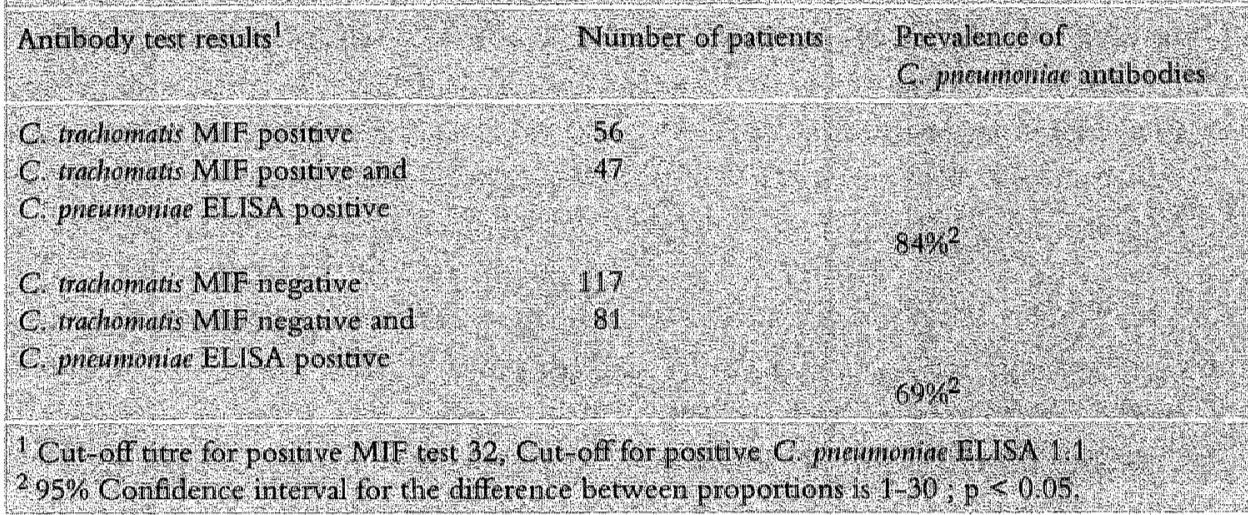

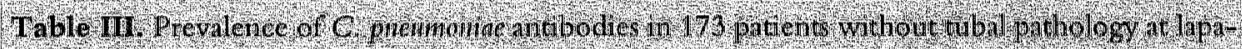

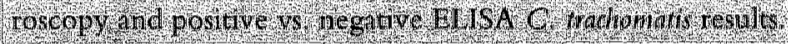

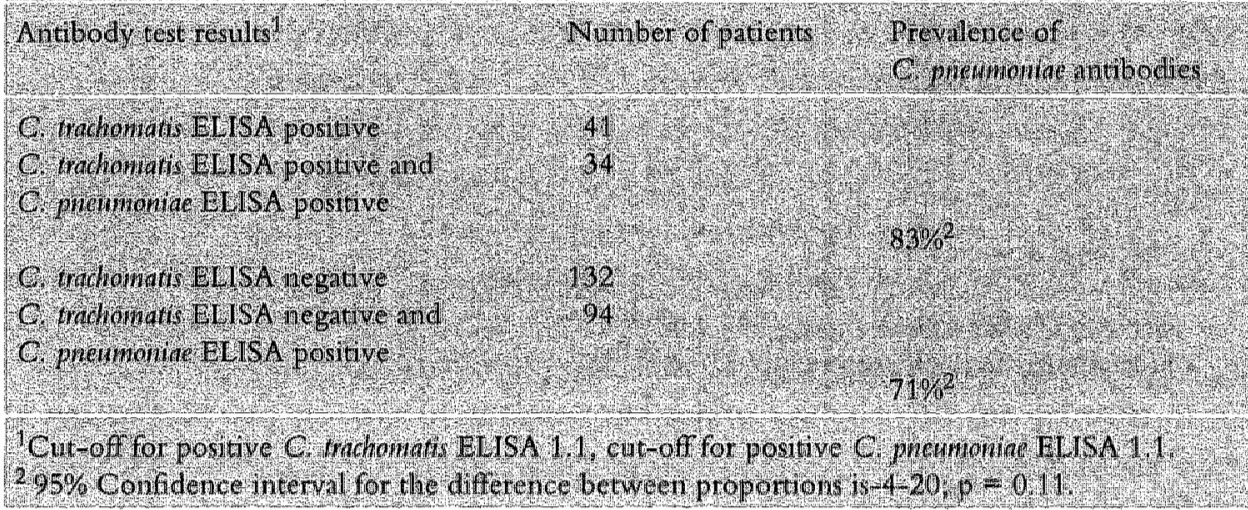

C. pnetmonine antibodies were found in $47 / 56(84 \%)$ of patients who had a positive MIF test and no tubal pathology at laparoscopy (false positive CAT). In a control group of patients who had a negative MIF test and no tubal pathology (true negative CAT), 81/117 (69\%) had C. pneumoniae antibodies $(p<0.05)$. In table III, in the same subgroups, ELISA for C. trachomatis was performed, which confirmed the results found by MIF. C. pnemmoniae antibodies were found in $34 / 41(83 \%)$ of patients who had a positive ELISA for C. trachomatis and no tubal pathology at laparoscopy. In a control group of patients who had a negative ELISA for $C$. trachomatis and no tubal pathology, $94 / 132$ (71\%) had $C$. pneumoniate antibodies $(p=0.11)$. 


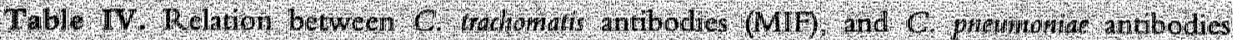

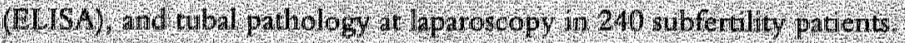

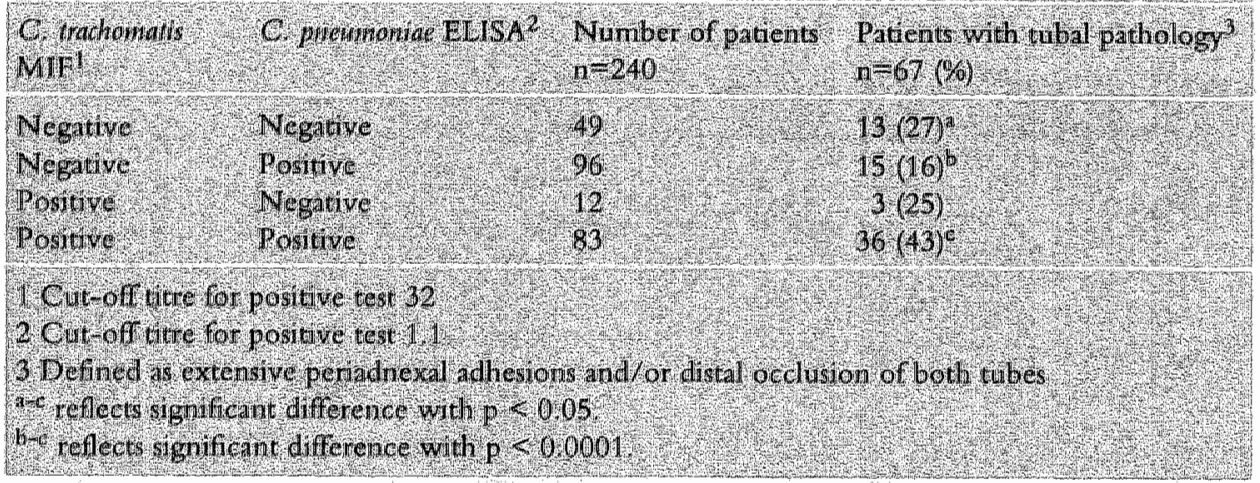

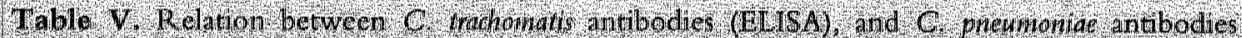
(ELWA) and wbil pathology at laproscopy in 240 subferility patienis.

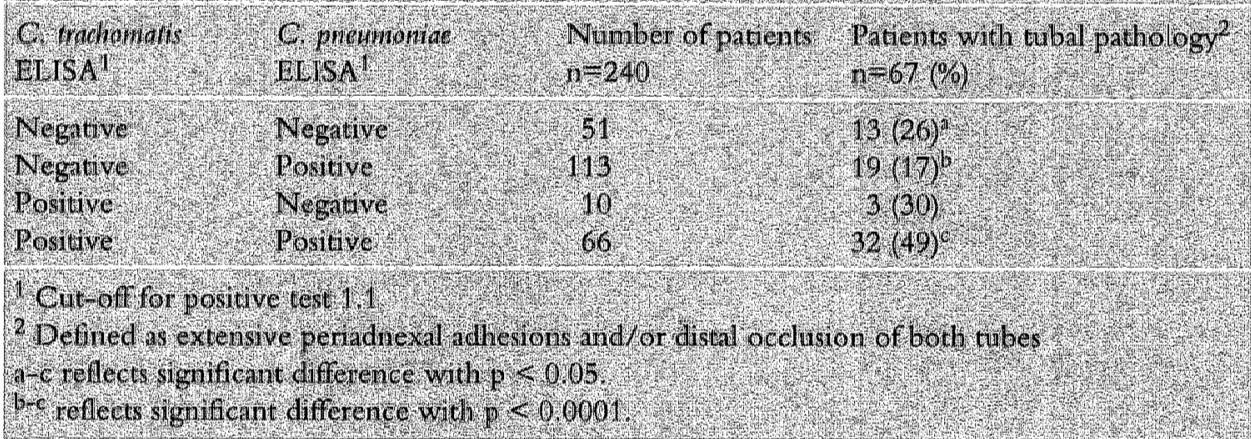

In table IV the correlation between the presence of antibodies to $C$. trachomatis by MIF and/or to C. pneumoniae using ELISA, and tubal pathology found at laparoscopy is given. The presence of both antibodies to $C$. trachomatis and to $C$. pneumoniae was associated with a higher rate of tubal factor subfertility (43\%), as compared to no antibodies $(27 \% ; \mathrm{p}<0.05)$, antibodies to $C$. trachomatis only ( $25 \%$; $\mathrm{p}=0.23)$ or C. pnewwontate only $(16 \% ; \mathrm{p}<0.0001)$.

In table $\mathrm{V}$ the correlation between the presence of antibodies to $C$. trachomatis using ELISA and/or to C. pneumoniae using ELISA, and tubal pathology found at laparoscopy is given. The presence of both antibodies to $C$. trachomatis using ELISA and to $C$. pmeumoniae was associated with a higher rate of tubal factor subfertility $(49 \%)$, as compared to no antibodies $(26 \%$ p $<0.05)$, antibodies to $C$. trachomatis only $(30 \%, \mathrm{p}=0.2)$ or C. preumoniae only $(17 \% ; \mathrm{p}<0.0001)$. 


\section{Discussion}

The aim of performing CAT as a standard procedure in subfertility patients is to identify patients with previous C. trachomatis infections. Using MIF, a positive test result is assumed to be associated with $C$. trachomatis antibodies, and the patient is considered to be at high risk for tubal pathology. However, the results reported in literature on screening for tubal factor subfertility by CAT using MIF are heterogeneous. Correlating CAT results with laparoscopy results, both false positive and false negative results are found. In the present study we evaluated the role of $C$. pneumoniae antibodies, as a cause of false positive CAT results, due to cross-reactivity of $C$. pneumoniae antibodies with $C$. trachomatis antibodies. Furthermore the prevalence of C. pnestmoniae antibodies in subfertile women was calculated.

From table I it can be concluded that the prevalence of $C$. trachomatis antibodies in the group of subfertile women studied here was comparable using MIF and ELISA, $40 \%$ and $32 \%$ respectively. Using ELISA the prevalence of C. pnetmoniae $\operatorname{lgG}$ antibodies was $75 \%$. In patients with tubal pathology at laparoscopy the prevalence was $76 \%$. It was $74 \%$ in women without tubal factor subfertility (table I). Several reports on the prevalence of C. pnetmoniae antibodies in West European countries have been published. In $21 \%$ of over 4500 women attending a genitourinary clinic C. pneumoniae antibodies were found using MIF (Moss et al., 1993). In adolescents the prevalence of C. pneumoniae antibodies using MIF was $69 \%$ in men, and $57 \%$ in women (Freidank and Brauer, 1992). Another study confirmed the prevalence of C. pneumoniae antibodies to be higher in men (72\%) than in women $(56 \%)$, and showed the prevalence to increase with increasing age (Karvonen et al, 1994). In female subfertility patients the prevalence of $C$. pneumoniae antibodies was significantly higher in patients with bilaterally occluded tubes at laparoscopy $(75 \%)$, as compared to patients with normal tubes (56\%) (Freidank et al:, 1995). The prevalence of C. preumoniae antibodies found in our study $(75 \%)$ is comparable with the prevalences reported in literature in asymptomatic women and subfertility patients.

In discussing false positive test results for CAT, cross-reactivity in MIF tests with C. pneumoniae is a major issue. Since MIF tests have been modified and serotype-specific antigens are no longer used, cross-reactivity with Chlamydia species other than C. trachomatis has been demonstrated (Mannion et al., 1991).

Comparison of subfertility patients with positive and negative MIF test results respectively, revealed a significant difference in the prevalence of $C$. pneumoniae antibodies ( $87 \%$ and $66 \%$ respectively). A possible explanation for the difference found is cross-reactivity between C. pneumoniae and C. trachomatis antibodies in the MIF test. To explore the likelihood of cross-reactivity further, the prevalence of $C$. pneumoniae antibodies has been analysed in two subgroups of patients. (tables 
II and III). In patients without tubal factor subfertility but a positive MIF test result (table II), C. pneumoniae antibodies were found more frequently than in patients without tubal factor subfertility and negative MIF test results. These data suggest that $C$. preumoniae antibodies can be a cause of false positive CAT results. Analysis of the same groups using C. tractiomatis ELISA instead of MIF (table III) showed the same.

Reports in the literature are rare and controversial concerming cross-reactivity between $C$. pnewmoniae and $C$. trachomatis antibodies in MIF tests. In female patients with tubal factor subfertility and pregnant controls, the presence of $C$. trachomatis and C. preumoniae antibodies has been studied (Persson et al., 1999). C. trachomatis antibodies were detected more often in patients $(88 \%)$ than in controls $(48 \%)$. In contrast, no difference was found for C. pnetumoniae antibodies between patients $(52 \%)$ and controls $(58 \%)$. The authors concluded that cross-reactivity did not occur, as $C$. trachomatis antibodies were equally common in patients with and without C. pneumoniae antibodies (89\% and $87 \%$ respectively). A study (Moss et al. 1993) in over 4500 serum samples of women attending a genitourinary clinic, using a modified MIF test to detect type-specific antibodies to Chlamydia species, has been performed. The IgG responses to Chlamydia species were detected in three distinct forms: species-specific (where $\operatorname{IgG}$ was directed against one species only), cross-reactive (where the IgG level against one species was twofold or higher than the IgG levels against other species), or group-specific (where IgG levels were similar against all species tested). In $67 \%$ of women Chlamydia IgG antibodies were found. Species-specific or cross-reactive IgG against $C$. trachomatis, C. pneumoniae and C. psittaci was present in $38 \%, 21 \%$ and $0.1 \%$ of the samples respectively. In $8 \%$ of samples, the IgG level was similar against all three species (groutp-specific). The authors conclude that antibodies to C. pneumonine may account for up to half of all Chlamydia positive test results using MIF. From the latter study (Moss $t$ t al., 1993) and our study it can be concluded that, due to cross-reactivity, C. pneumoniae antibodies are probably major contributors to the low specificity of those MIF tests in which pooled antigens are used. Species-specific antibody tests for $C$. trachomatis are prerequisites for improving the predictive value of CAT.

In our study, tubal pathology was more frequent in patients in whom both antibodies to $C$. trachomatis and to C. pneumoniae were found (tables IV and V). The precise mechanism by which Chlanydia causes tissue damage remains to be elucidated, but immune-mediated inflammatory responses seem to be involved in the process (Brunham and Peeling, 1994). It has been suggested that primary Chlamydia infections do not necessarily cause tubal tissue damage, but that tissue damage will develop only after re-infection or after reactivation of a primary infection (Patton and Kuo, 1989). Re-infection or reactivation of primary infections is 
considered to induce a booster immune response and subsequently tubal pathology. It has been liypothesised that this immune response may not be specific for C. trachomatis, and may be induced by $C$. phewmowat antibodies as well (Freidank ef al., 1995). In their study Freidank ef al (1995) found the presence of both antibodies to $C$. trachomatis and $C$. pnewnonia in the MF test to be associated with a significantly higher rate of tubal occlusion. Our findings are in agreement with the findings of Freidank et al. (1995), 1.e. more tubal pathology was found in patients with both $C$. trachomatis and $C$ pmeunowiae antibodies. This supports the contention that $C$. wachomatis infection and (highly prevalent) $C$. pnewmoniae infections might have a synergistic effect on the development of tubal pathology. However, the exact rolle of C. pneumoniae in this process needs further exploration.

In conclusion, in 240 subfertility patients a prevalence of $C$. pnewnoniae antibodies of $75 \%$, using a specific ELISA for $C$. phewnonine was found. Comparison of laparoscopic and serologic data suggests cross-reactivity between antibodies to $C$. trachomatis and antibodies to $C$. pnewmoniae in the MIF test, as a cause for low specificity of CAT. The simultaneous presence of antibodies to $C$. rachomaris and to $C$ pneumoniae was associated with a significanty increased rate of tubal factor subfertility. C. pnetmoniae antibodies, which are widespread, nay be involved in Chlamydia upper genital tract infections and/or subsequent tubal damage. 


\section{References}

Brunham, R.C. Peeling, R W (1994) Chlamydia trahomatis antigens: role in immunity and pathogenesis Infect Agents Dis, 3, 218-233.

Freidank, H.M. Braver, D (1992) Prevalence of antibodies to Chamydia pretunoniae TWAR in a group of Cerman medical students. I. Infet, $27,89-93$.

Fredank, HM, Cla, A, Hert, A S, Wiedmann-Al-Ahmad, M., Jung, B. (1995) Immune response to Chlanydin thomatis heat-shock protein in infertile female patients and the influence of Chlamydia pinewmonine antibodies Eur. J. Clin. Morobiol. Infet, 14, 1063-1069.

Karvonen, M., Tuomilehto, J., Pitkäniem, J., Naukkarinen, A., Saikku, P. (1994) Chlanvydia phewnonac $\operatorname{lgG}$ prevalence in South-Western and Eastern Finland in 1982 and 1987. Int J. Epidem, 23, 1276-184.

Land, J.A., Evers, J.L.H, Goossens, V.J (1998) How to use Chlamydia antibody testing in stubfertility patients. Huw Reprod., 13, 1094-1098.

Mannion, P.T., Mallinson, H., Trehame, J.D. (1991) Serological diagnosis with the Chamydia Spot-if test. J. Med. Mionliol, 35, 244-248.

Mol, B.W., Dijknan, B., Wertheim, P.et al. (1997) The accuracy of serum chlamydial antibodies in the diagnosis of tubal pathology: a meta-analysis. Fertil. Steril, $67,1031-1037$.

Moss, T.R., Darougar, $S$, Woodland, R.M, ef al (1993) Antibodies to Chlamydia species in patients attending to a genitourinary clinic and the impact of antibodies to $C$. pnewnoniae and $C$. psittaci on the sensitivity and the specificity of $C$. wachomatis serology tests. Sex. Transm. Dis., 20, 61-65.

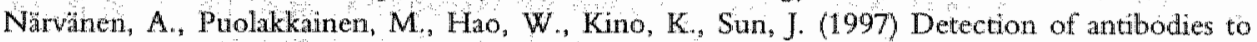
Chlamydia tradomatis with peptide-based species-specific enzyme immunoassay. Inf. Dis. Otstet. G)necol., 5, 349-354:

Patton, D.L., Kuo, C.C. (1989) Histopathology of C. trachomatis salpingitis after primary and repeated reinfections in the monkey subcutaneous pocket model. J. Reprod. Fertil, 85, 746-656.

Persson, K., Osser, S., Birkelund, S., Christiansen, G., Brade, H. (1999) Antibodies to Chlanydid trachomatis heat shock proteins in women with tubal factor subfertility are associated with prior infection by C. trachomatis but not by C. pnemmoniac. Hunn. Reprod., 14, 1969-1973.

Treharne, J.D., Darougar, S., Jones, B.R. (1977) Modification of the microimmunofluorescence test to provide a routize serodiagnostic test for chlamydial infection. J. Clin. Panthol, 30, 510-517.

Wang, S.P. Grayston, I.I. (1970) Immunologic relationship between genital TRIC, lynohograntoma venereum, and related organisms in a new microtitre indirect inmunofliorescence test. Ans. J. Ophrahnol, 70, 367-374t. 


\section{Performance of five serological Chlamydia} antibody tests in subfertile women

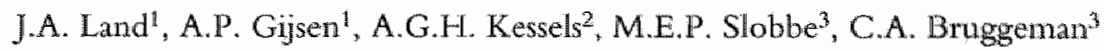

Department of Obstetrics and Gynaecology ${ }^{\ddagger}$, Department of Clinical

Epidemiology and Medical Technology Assessment ${ }^{2}$, Department of Medical

Microbiology", Academisch Ziekenhuis Maastricht, Maastricht, the Netherlands 


\begin{abstract}
Backgrotund Micro-immunofuorescence (MIF) is widely used for Chlanydia antibody testing (CAT). Recently a species-specific MIF and three enzyme-linked inmunosorbent assay (ELISA) tests have been introduced. We compared five commercially available CAT tests, using laparoscopy as a reference, and evaluated whether combinations of tests could improve the predictive walue of CAT.

Methods In a consecutive cohort of 315 subfertile women, results of the five CAT tests were correlated to findings at laparoscopy. Likelihood (LR) and odds ratios (OR) were calculated for single tests and for combinations of tests.

Results Of the tests evaluated, MIF Labsystems had the best diagnostic perfomance (OR 15.7), while pELISA Medac (OR 8.2) was the best of the three ELISA tests. Stepwise logistic regression analysis showed that performance of MIF Labsystems could not be improved by adding a second test. Sigmificant cross-reactivity with $C$. priemonomiae antibodies was found in all tests evaluated, except in pELISA Medac.

Conclusions In sereening for tubal factor subfertility, MIF Labsystems was superior to the ELISA tests evaluated, and combining two CAT tests dild not improve its predictive value. Economic analysis will show whether serial testing by pELISA Medac, and retesting positive samples by MIF Labsystems, is most cost-effective. In CAT, cross-reactivity with $C$. pnewnonide antibodies is still a major concern.
\end{abstract}




\section{Introduction}

Since the association between $Q$. trachomatis antibodies in serm and tubal pathology: was noticed (Punnonen et al. 1979), Chlamydia antibody testing (CAT) has been used in the fertility work-up as a screening test for tubal factor subfertility. A widely used test for CAT is the micro-immunofluorescence test (MIF), which has been considered the gold standard in the serological diagnosis of Chlamydia infection (Dowell et al., 2001). Initially, antigens from elementary bodies of each of the serotypes of $C$. arachomatis were included in the MIF test, which provided serotype-specific antibody testing (Wang and Grayston, 1970). Later, for practical reasons, the number of antigens has been reduced by pooling antigens of epidemiologically related serotypes, or by using one broadly reacting serotype (usually $\mathrm{L}_{2}$ ) (Treharne et al, 1977). However, in modified MIF tests, cross-reactivity between $C$. trachomatis and C. phewnoniae occurs (Mannion et al. 1991; Gijsen et al., 2001). To overcome this, species-specific MlF tests have been developed. In these tests, the cross-reactivity between the different Chlamydia species has been reduced by subtracting lipopolysaccharide (LPS), a common component of the outer membrane of all Chlamydiacene, from $C$ pnemmoniae and C. trachomatis antigens. Other disadvantages of the MIF tests are that they are labour intensive, their reading is observer dependent, and inter-laboratory variation is significant (Peeling et al,; 2000). To overcome these drawbacks, enzyme-linked immunosorbent assay (ELISA) tests with high specificity have been developed, using LPS-stripped elementary bodies as antigens (Ossewaarde et al, 1994). Recently assays have become commercially available in which specific synthetic peptides are used. These peptides are based on the major outer nembrane protein (MOMP) of $\mathrm{C}$. trachomatis, which contains species-specific and serotype-specific epitopes (Närvänen et al, 1997). These ELISA tests are easy to perform and are well standardized (Tuuminen et al, 2000). But the value of CAT using ELISA and species-specific MIF in predicting tubal factor subfertility has not been evaluated yet.

The first aim of this study was to compare five commercially available Chlamydia $\operatorname{lgG}$ antibody tests in their accuracy to predict tubal factor subfertility, using laparoscopy as a reference. The performances of a species-specific MIF test and three ELISA tests were compared with findings obtained with a MIF test that had been used in our hospital for 10 years. Cross-reactivity with $C$. pnewnoniae antibodies was evaluated in the five CAT tests as a possible cause of false positive CAT results. The second aim was to evaluate whether combinations of two tests could improve the predictive value of CAT. 


\section{Materials and methods}

The stady was performed in female patients who sought treatment for subfertility in our clinic, a tertiary care center. Since 1992, CAT using MIF has been a routine procedure in our fertility work-up. In all female patients blood is drawn at their initial visit and a MIF test for C. trachomatis IgG antibodies (Biomerieux, The Netherlands) is performed, and all spare serum samples are cryopreserved at $-20^{\circ} \mathrm{C}$. CAT is used for selecting patients at high risk for tubal factor subfertility. Patients who have antibody titres $<64$ are considered low risk and tubal factor is evaluated initially by hysterosalpingography (HSG). In cases of an abnormal HSG or failure of pregnancy to occur in the 6 months following HSG, the fertility work-up is concluded by laparoscopy and tubal testing with methylene blue dye. In patients who have antibody titres $\geq 64$, no HSG is performed, but tubal factor is evaluated primarily by laparoscopy.

Between June 1992 and September 2001, 315 successive patients underwent laparoscopy as part of their fertility work-up. All took part in this study. Patients who had undergone previous pelvic surgery (except for an uneventful appendectomy or Caesarean section) were excluded.

All laparoscopy reports were scored by two gynaecologists, who were blinded for the CAT results: For the sake of the study, tubal pathollogy at laparoscopy was defined as extensive periadnexal adhesions and/or distal occlusion of both tubes, since this has been shown to reflect Chlamydia associated tubal disease most accurately (Land ef al., 1998).

After thawing the cryopreserved sera of the participating patients, the five different CAT tests were performed. A number of patients had participated in a previous study (Land et al., 1998), but for the present study all serum samples were retested. Finally, data obtained at laparoscopy were correlated to the serological test results.

\section{Serological methods}

All assays and calculations were performed according to the manufacturers' instructions. For each test all sera were tested simultaneously using the same batch of test kits, to avoid inter-test variability.

MIF Bionerietx: Chlamydia trachomatis-spot IF test (Biomerieux). In this indirect fluorescent $\lg G$ antibody test, $C$. trachomatis $\mathrm{L}_{2}$ is used as a group antigen. A positive reaction is characterized by specific fluorescence of the $C$. trachomatis elementary bodies. For quantitative determination seriall dilutions are made. In this study all slides were evaluated independently by two readers. In case of disagree- 
ment, the judgement of a third reader was decisine. In this study a third reader was needed in four cases.

MIF Labsystens: Chlampdia prewmoniae $\operatorname{IgG/IgM}$ micro-IF test (Labsystens, Finland). In this species-specific MIF test $C$. pnewnomiac, $C$, thathomatis and $C$. psitiaci elementary bodies are used as antigens. In order to diminish cross-reactivity the immunological activity of Chlamydia LPS in C. pnemmoniae and C. trachomatis antigens has been reduced. In this study the test was used to detect anti- $C$. trachomatis and anti-C. pnemmoniae $\operatorname{Ig} G$ antibodies. A positive reaction is characterized by specific fluorescence of the respective elementary bodies. For quantitative determination serial dilutions are made. In this study all slides were evaluated independently by two readers. In case of disagreement, the judgement of a third reader was decisive. In this study a third reader was needed in three cases.

ELISA Labsystens: Chlamydia trachomatis JgG EIA (Labsystems, Finland). In this indirect enzyme immunoassay synthetic peptides are used, which are derived from MOMP of C. trachomatis (Narvänen el al., 1997). The optical density of the test plates is read in a spectrophotometer, and the signal to cut-off indices (SCI) are categorized as negative, equivocal, positive or highly positive.

pELISA Medac: Chlawydia trachowatis-IgG-pELISA (Medac, Germany). Medac has a LPS based, genus-specific test (rELISA) and a species-specific ELISA ( $p E L I S A$ ) on the market. The pELISA has been used in this study, and, according to the manufacturers information it is based on "a synthetic peptide" from MOMP of $C$. trachomatis. The optical density of the test plates is read in a spectrophotometer, and the SCI are categorized as negative, equivocal, or positive.

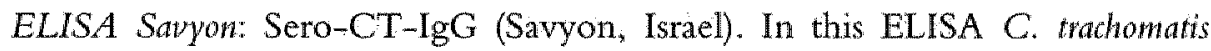
species-specific peptides, derived from "different serotypes" are used. "The optical density of the test plates is read in a spectrophotometer, and the SCl are categow rized as negative, equivocal, or positive.

\section{Statistical methods}

The outcomes of the five tests were compared to the findings at laparoscopy in order to determine their prognostic value of tubal factor subfertility. Sensitivity, specificity, positive predictive value (PPV), negative predictive value (NPV), likelihood ratio (LR), odds ratio (OR) and $95 \%$ confidence interval (CI) were calculated.

For comparison of LR of the results of the CAT tests, the Chi-square test was used. To test the difference between OR of the different tests, the bootstrap technique was used (Efron and Tibshiram, 1993). Two sided $\mathrm{P}<0.05$ were considered significant. A stepwise logistic regression analysis was used to select the best combination of tests. For evaluation of agreement between tests, $K$ was calculated, 
and $\mathrm{k}>0.7$ were considered to indicate good agreement. For comparison of the distributions of $C$. pnewmoniae titres in patients with a positive and negative Chlamydia antibody test respectively, the Mamn-Whitney $U$ test was used. $\mathrm{P}<0.05$ were considered significant.

\section{Results}

In 315 subfertile women, results of five different CAT tests and laparoscopy were available for analysis. In 51 patients $(16 \%)$ tubal pathology was found at laparoscopy. In table I results are given for each test, reflecting its accuracy in predicting tubal factor subfertility. The effect of using different cut-off levels for a positive test is shown. Within each test, increase of the cut-off titre or SCI increased specificity and PPV at the expense of sensitivity. When using 32 or 64 as the cat-off level for a positive test, the OR of MIF Labsystems differed significantly from all OR of the other four CAT tests. For funther analyses not all different cut-off levels and SCI were used. MIF Biomerieux and MIF Labsystems were considered positive if the lgG titre was 232 , ELISA Labsystens was considered positive if SCI was positive or highly positive, and pELISA Medac and ELISA Savyon if SCI was positive.

When MIF Biomerieux was used 132 women had a positive CAT/test, 52 women had a positive test by MIF Labsystems, 53 by ELISA Labsystems, 62 by pELISA Medac and 87 women had a positive test when ELISA Savyon was used (table 1). The OR of MIF Labsystems (15.7) was significantly better than the OR of all other tests evaluated. pELISA Medac had the highest OR (8.2) of the three ELISA tests.

In 158 patients all five CAT tests were negative, 67 patients had one positive test, 25 had two positive tests, 18 had three positive tests, 20 had four positive tests and in 27 patients all five tests were positive. Table II gives the number of positive CAT tests in 315 patients. The LR of tubal factor subfertility was correlated to the number of positive tests. A statistically significant difference was found between the LR of three, fout and five simultaneously posicive tests as compared with the $\mathrm{LR}$ of one positive test only.

The impact of combining two different tests on the predictive value for tubal factor" subfertility was studied. Three different strategies were evaluated. First, a stepwise logistic regression analysis was performed to investigate whether combinations of tests would perform better than the best single CAT test (1e. MIF Labsystems). From the logistic regression analysis it could be concluded that the dagnostic performance of MIF Labsystems could not be improved significantly by adding another CAT test. 


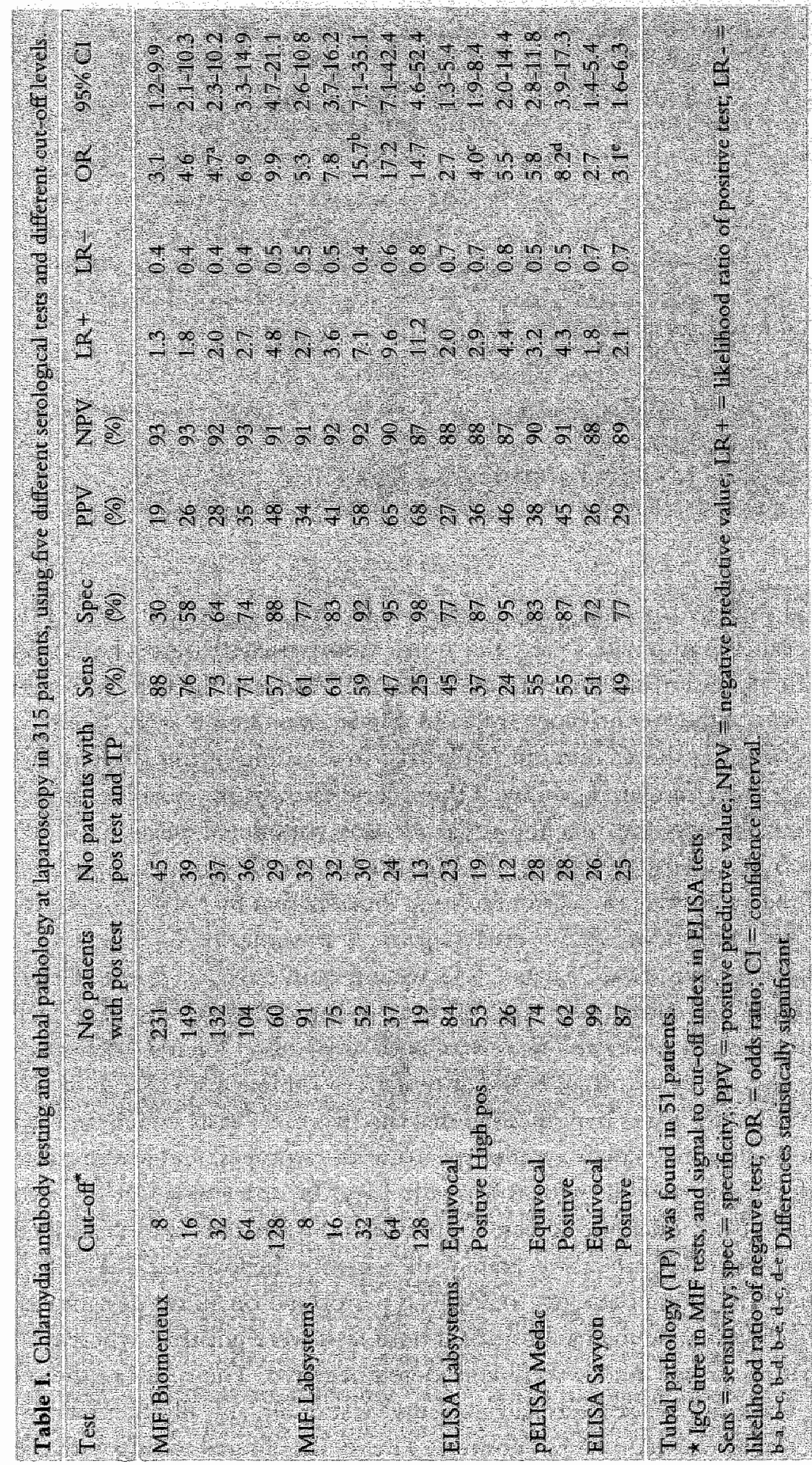




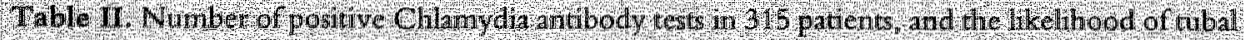
pathology at h paraseopy

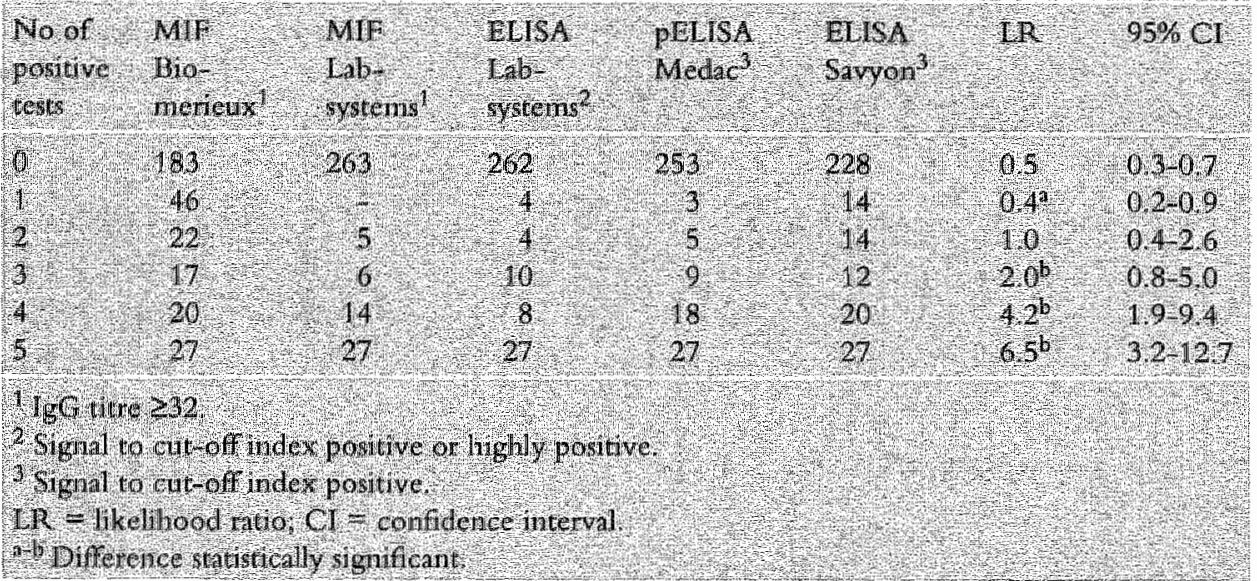

As a second strategy the CAT tests were divided into two groups: the ELISA tests, as they can be automated, and the more laborious MIF tests. Based on stepwise logistic regression analysis with the three ELISA tests in the first block and the two MIF tests in the second block, pELISA Medac was chosen as the first test, and MIF Labsystems as the second test (table III). In retesting of initially positive sera the serial set was considered positive if the second test was allso positive, and in retesting of initially negative sera the serial set was considered negative if the second test was also negative. Using pELISA Medac on all serum samples, 62 patients (20\%) had a positive test. After retesting these 62 sera by MIF Labsystems, 44 sera (14\%) remained positive. An initial negative test was found in 253 patients $(80 \%)$, and after retesting these $253 \mathrm{sera}, 245$ were negative $(78 \%)$. The results of serial testing with the chosen set of CAT tests (i.e. pELISA Medac and MIF Labsystems) are given in table III. The OR of both serial sets (14.2 and 9.2 respectively) were lower than the OR of MIF Labsystems as a single test (15.7; table I).

In the third strategy it was hypothesised that the two CAT tests which differed most from each other may cover a wider spectrum of serotypes, and act complementary in identifying women with tubal pathology. In order to select the two tests to be used in the model, the agreement between the five tests was established (table IV). For evaluation of the third strategy the set with the lowest $\kappa$, i.e. ELISA Labsystems and MIF Biomerieux ( $K=0.35)$, was performed on all serum samples. The result of the set was defined as positive if both tests were positive, whereas all other combinations of test results were considered negative. The result of the set was considered negative if both tests had a negative test result, and all other combinations of test results were considered positive. The results of serial testing with the 


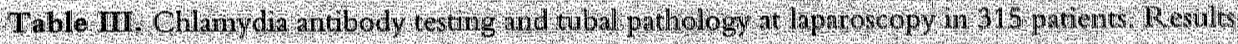
for serial testing with two different ets of cest:

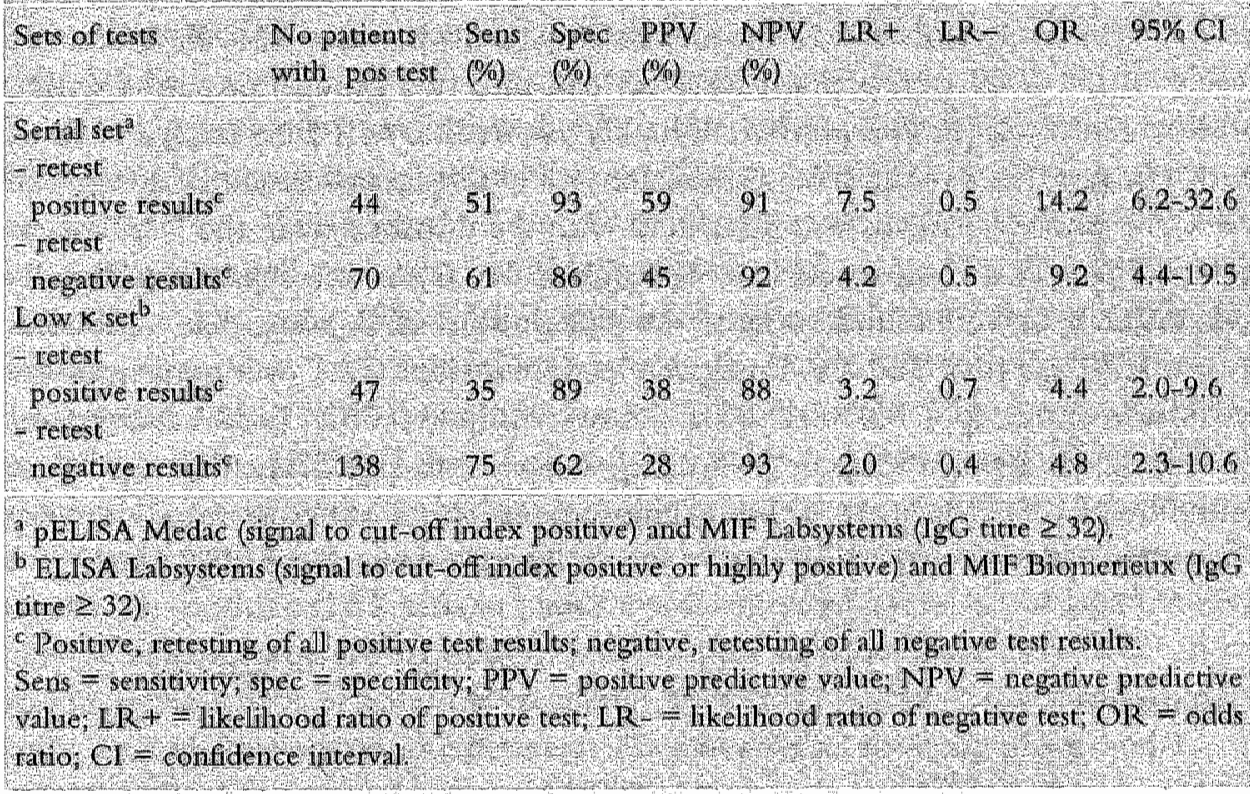

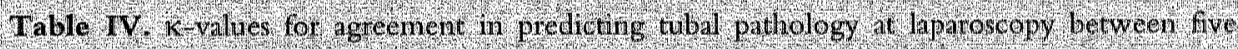
Chlinydiz antilbody tests:

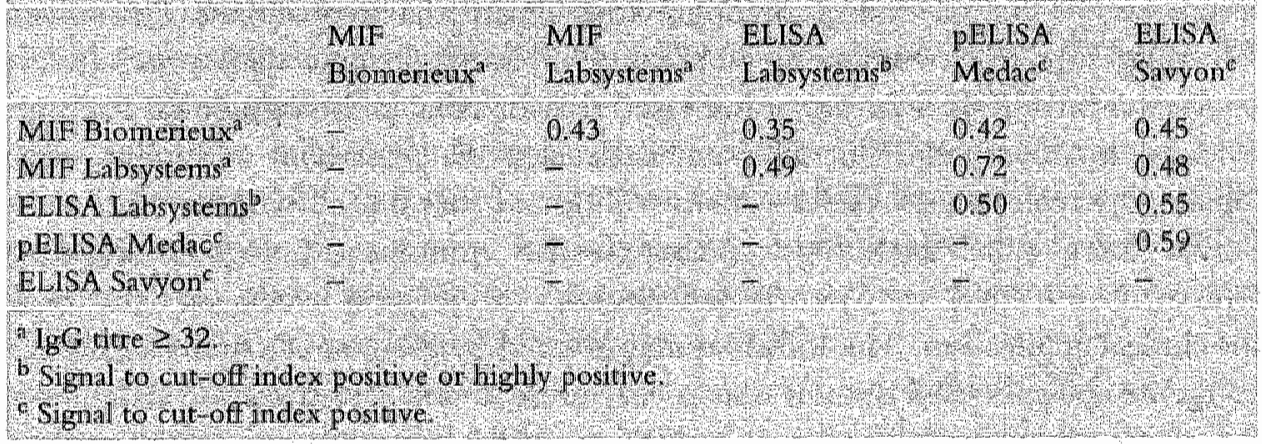

low $K$ set are given in table III. The OR of the low $\kappa$ set ( 4.4 and 4.8 respectively) did not differ significantly from the OR of the single tests of which the sets were composed (4.0 for ELISA Labsystems and 4.7 for MIF Biomerieux respectively; table I). This indicates that serial testing with the two CAT tests which differed most from each other could not improve the predictive value of CAT.

In order to study cross-reactivity with $\mathrm{C}$. pneumoniae antibodies in the five CAT tests, in all 315 patients $C$. pneumoniae IgG antibody titres were determined by 
MIF Labsystems. In 41 patients the IgG titre was $<8$, in five patients it was 8 , in 33 patients it was 16 , in 61 patients it was 32 , in 83 patients it was 64 , in 56 patients it was 128 , in 20 patients it was 256 and in 16 patients it was $>256$. Based on the results of the CAT test, patients were divided into two groups, i.e. those with a positive test result (ELISA positive or highly positive, or MIF titre $\geq 32$ ) and those with a negative test result. The distribution of the $C$ pnewnonue antibody titres in the CAT positive patients was compared with the distribution in the CAT negative patients. This comparison was made for all five CAT tests separately. Significant differences were found between the distributions of $C$. pnemmoniae antibodies in the CAT positive and CAT negative patients when CAT was performed by MIF Biomerieux ( $p<0.00001)$, MIF Labsystems $(\mathrm{p}=0.001)$, ELISA Labsystems $(p=0.02)$ or ELISA Savyon $(p=0.02)$, whereas no significant difference was found by pELISA Medac ( $p=0.06$ ). This suggests significant cross-reactivity with C. pneumoniae antibodies in all CAT tests evaluated, except in PELISA Medac.

\section{Discussion}

Active genital tract infections with $C$. trachomatis can be diagnosed by direct detection of the microorganism from the infected site. After the acute episode however, the microorganism may not be detectable any longer, and Chlamydia antibodies in serum may be the only indication of previous Chlamydia involvement. The aim of screening subfertile women by CAT is to identify patients with previous $C$. trachomatis infections, who are at increased risk for tubal pathology. It has become evident, however, that not all women develop $C$. trachomatis antibodies after Chlamydia infection (Schachter ef al., 1979), and that not all women with antibodies have tubal pathology. Although the immunopathology underlying Chlanydia infection is still poorly understood, antibody tests have been developed for clinical application. The information provided by the manufacturers about the antigenic epitopes used in their tests is very limited, and is restricted to statements that the test contains "a" or "some" specific peptides. Furthermore, manufacturers modify the epitopes used in their tests, which may remain unnoticed by the customers who therefore cannot anticipate changes in test perfornance. The present study is a clinical comparison of five commercially available Chlamydia antibody tests in their ability to predict tubal pathology in subfertile women. Four of these tests had not been evaluated as screening tests for tubal factor subfertility before. We are aware that the results of the study show the diagnostic performances of the tests at a given moment in time only.

In the present study CAT results were compared to the findings at laparoscopy, and therefore only women who had undergone a laparoscopy were included. 
Patients with low Chlamydia antibody titres are less likely to have tubal pathology and were less likely to be included in the study, since many will have conceived before laparoscopy can be done. This verification bias (Mol et al., 1999) will influence predictive values of CAT, which are dependent on the prevalence of disease. Verification and selection bias is hard to prevent in clinical studies, bowever, unless one is prepared to perform the complete fertility investigation of a patient on a single day. Although the bias will result in overestimation of the LR, the overestimation will be similar for all tests investigated.

In comparing the five CAT tests considerable variation was found in the number of patients with a positive test (table I). An lgG titre $\geq 32$ was found in 132 women using MIF Biomerieux and in 52 using MIF Labsystemis, 53 had a positive test by ELISA Labsystems, 62 by pELISA Medac and 87 by ELISA Savyon. The tests with the highest number of positive test results had the lowest PPV, indicating the highest rates of false positive test results. False positive CAT results (i.e. positive CAT tests in patients without tubal pathology at laparoscopy) may be explained by cross-reactivity with $C$. pneumoniae antibodies, which can be found in about $70 \%$ of subfertile women (Gijsen et al., 2001). In this study a significant correlation was found between $C$. pneumoniae antibody titres and $\mathrm{CAT}^{\mathrm{T}}$ results in four tests, in particular in MIF Biomerieux ( $\mathrm{p}<0.00001)$. This confirms the findings of our previous study using a $C$. pnetumoniae IgG ELISA, in which we found cross-reactivity to occur between $C$. pneumoniae and $C$. trachomatis antibodies in MIF Biomerieux. Since the only CAT test (pELISA Medac) in which no significant correlation with the distribution of $C$. pnemmoniae titres was found did not have the highest PPV, cross-reactivity with C. pneumoniae antibodies does not seem to be the only explanation for the high rates of false positive test results obtained in the CAT tests. Since not all women with Chlamydua antibodies have tubal pathology at laparoscopy, it has been suggested that genetic factors in the host may also play a role, by modulating immune defense mechanisms and the development of late sequelae (Kinnunen et al., 2002).

Comparing MIF and ELISA, the results (table I) suggest that ELISA tests tend to have lower sensitivity and NPV, i.e. more false negative test results: In ELISA tests chosen for this study, specific synthetic peptides are used which are considered analogous to the serotype-specific antigenic determinants of MOMP of $C$. trachomatis (Närvänen et al., 1997). These serotype-specific determinants differ between tests, and may explain the differences found in test performances between ELISA tests of different manufacturers. Furthermore, tests based on highly specific peptides may be so specific that they are not able to detect all relevant antigens (Bas et $\left.a l_{.}, 2001\right)$. Variants of serotypes have been identified in urogenitall isolates (Morré et al., 1998) and mutations have been shown to occur in positions within MOMP (Dean et al., 2000). Consequently, highly specific tests may not be able to 
identify all serotypes involved in Chlamydia infection, and cause false negative CAT results (i.e. negative CAT tests in patients with tubal pathology at laparoscopy).

There are a few reports in the literature on the diagnostic accuracies of different antibody tests for $C$. trachowatis, in which the tests evaluated in our study have been included. In these studies either tubal pathology; or the direct demonstration of the microorganism in the genital tract; have been used as reference standards for the serologic tests. Each reference standard has its limitations, however. Since tubal pathology can be caused by other microorganisms in addition to $C$. trachomatis, it is obvious that tests based on Chlamydia antibodies will be imperfect in predicting all tubal pathology. Studies in which the direct detection of the microorganism is used as a reference have limited diagnostic accuracy as well (Chernesky et al., 1998; Bas et al, 2001), since superficial infections may provide a poor stimulus for antibody formation. Paukku et al. (1998) did not find a significant difference between the presence of IgG antibodies in 78 patients with tubal factor subfertility, using a modified MIF test and ELISA Labsystems. In a serological follow-up study of 16 women with C. trachomatis positive cervical swabs, ELISA Labsystems, ELISA Savyon and a MIF test have been used (Clad et al., 2000). ELISA Labsystems was found to be the most sensitive test, and it was concluded that ELISA Savyon did not cover all Chlamydia serotypes. Morré et al. 2002 studied the IgG prevalences in 43 women with $\mathrm{PCR}$ positive cervical swabs and $106 \mathrm{PCR}$ negative women. Results obtained by two in-house MIF tests were compared to results by ELISA Labsystems, pELISA Medac and ELISA Savyon. The authors concluded that the ELISA tests performed equally well as the MIF tests used.

In the present study the likelihood of tubal factor subfertility improved as the number of positive CAT tests in a patient increased (table II). Compared with one positive CAT test; the LR improved significantly in patients in whom three, four or five positive tests were found. But from a clinical point of view, performing more than two CAT tests in patients is impractical and expensive. Therefore, we evaluated whether two serially performed tests could be of any benefit in predicting tubal factor subfertility. Firstly, from a stepwise logistic regression analysis it was concluded that the diagnostic performance of the best single CAT test (i.e. MIF Labsystems) could not be improved by adding a second CAI test. Secondly, we evaluated the performance of a serial set of tests from a laboratory perspective, by constructing a model in which pELISA Medac was performed as the first test and MIF Labsystens as the second test. Although pELISA Medac was found to have a significantly lower OR (8.2) as compared with MIF Labsystems (15.7), ELISA tests have the advantage over MIF tests of being less laborious. From our results it can be concluded that if pELISA Medac is performed as the first test on all samples, and all samples with positive test results (i.e. $20 \%$ of all samples) are 
retested with MIF Labsystems, the predictive value of the set (OR 14.2) is comparable to the predictive value of MIF Labsystems as a single test (OR 15.7 ). Cost-effectiveness analysis has to demonstrate which strategy is to be preferred: MIF Labsystems as a single test on 11 samples, or pELISA Medac on all samples and retesting of the positive ones with MIF Labsystems. Thirdly, we hypothesised that two tests with poor agreement (low $\kappa$ ) might have different antigenic properties, and might react with a greater number of serotypes and therefore complement each other. From the results presented in table III it can be concluded that the low $\kappa$ set of tests (ELISA Labsystems and MIF Biomerieux) did not improve the predictive value of CAT significantly, compared with the predictive values of the single tests of which the set was composed. Therefore the hypothesis of complementary testing with the set of tests with low $\mathrm{K}$ had to be rejected.

The results of the present study show that there still is no excellent screening test for tubal pathology in subfertile women. In order to develop more accurate tests for the prediction of Chlamydia-associated tubal pathology, future research should focus on the immunopathology of Chlamydia infections. Evidence exists that patients with chronic, persisting Chlamydia infections are particularly at risk for developing late sequelae. Although $\operatorname{IgG}$ antibodies are markers of a previous infection, they do not reflect an ongoing chronic inflammation properly. Candidates to be introduced into screening for tubal factor subfertility, in addition to specific C. trachomatis IgG antibodies, are anti-HSP60 and anti-LPS antibodies. HSP60 has been shown to play a prominent role in chronic inflammation and scarring (Claman et al, 1997), and anti-LPS antibodies might be indicators of ongoing Chllamydia infection (Tuuminen et al., 2000).

In conclusion, although ELISA tests have been claimed to be highly sensitive and specific, in the present study they were not superior in predicting tubal factor subfertility. Of the five CAT tests evaluated, MIF Labsystems had the best diag nostic performance, and among the three ELISA tests, pELISA Medac performed best. MIF Bionerienx had the largest number of false positive test results, probably due to cross-reactivity with $C$. pnewmoniae antibodies. Combining two different CAT tests did not improve the predictive value for tubal factor subfertility. Health care evaluation from an economic perspective has to prove whether serial testing with the automated pELISA Medac as a first test, and retesting of all positive serum. samples with the more laborious MIF Labsystems, is to be preferted to testing of all samples with MIF Labsystems only. 


\section{References}

Bass, S., Muzzin, P., Ninet, E. Bornant, J.E, Scieux, C. and Vischer, T.L. (2001) Chlamydia serology : comparative diagnostic value of immunoblotting microimmunofluorescence test, immunoassays using different recombinant proteins as antigens. J. Chin. Microbiol, 39, $1368-1377$.

Chernesky, M, Luinstera, K., Sellors, J, Schachter, J, Moncada, J, Caul, C., Paul, L, Mikaelian, L., Toye, B, Pawonen, J and Mahony, J. (1998) Can serology diagnose wpper genital tract Chamydia trachomatis infections? Studies on wonen with pelvic pain, with or without Chlanydial plasmid DNA in endometrial biopsy tissue. Sex. Transm. Dis, 25, 14-19.

Clad, A., Freidank, H.M., Kunze, M., Schnoedkel, U., Hofneier, S, Flecken, U. and Petersen E.E. (2000) Detection of seroconversion and persistence of Chlamydia trachomatis antibodies in five different serological tests. Eur. J: Clin Mi Mobial. Infect. Dis., 19, 932-937.

Claman, P., Honey, L., Peeling, R.W., Jessamine, P. and Toye, B. (1997) The presence of serum antibody to the Chlamydial heat shock protein (CHSP60) as a diagnostic test for tubal factor infertility. Fertil. Steril., 67, 501-504.

Dean, D., Suchland, R.J. and Stamm, W.E. (2000) Evidence of long-term cervical persistence of Chlanydia trachomaits by ompl genotyping I. Infect. Dis., 182, 909-916.

Dowell, SF, Peeling, R.W., Boman, J., Carlone, G.M, Fields, B.S., Guaner, I., Hammerschlag, M.R., Jackson, L.A., Kuo, C.C., Maass, M. et al (2001) Standardizing Chlamydia pneumoniae assays; recommendations from the Centers for Disease Control and Prevention (USA) and the Laboratory Centre for Disease Control (Canada), Chin. Liffet. Dis, 33, 492-503.

Efron, B. and Tibshiram, R.J (1993) An introduction to the bootstrap. Chapman and Halk, New York, USA.

Gijsen, A.P., Land, J.A., Goossens, VJ., Leffers, P., Bruggeman, C.A. and Evers J.L.H. (2001) Chlanydia pnemoniae and screening for tubal factor subfertility. Huw. Reprod., 16, 487-491.

Kinmunen, A.H., Surcel, H.M., Lelhtinen, M., Karhukarpi, J., Tiitinen, A., Halttumen, M., Bloigu, A., Morisson, R.P., Kartunen, R. and Paawonen, J. (2002) HLA DQ alleles and interlenkin-10 polymorphism associated with Chlawydia trachomatis-related tubal factor infertility: a case-control study. Hum. Reprod., 17, 2073-2078.

Fiandi, I H A subfertility patents. Hwm. Reprod.,13,1094-1098.

Mannion, P.T., Mallnson, H. and Treharne, J.D. (1991) Serological diagnosis with the Chlanydia spot-IF test. J. Med. Miowbiol, 35, 244-248.

Mol, B.W.J., van der Veen, F, and Bosschtiyt, P.M.M: (1999) Chamydia antibody titres. Hum. Reprod, 14, 268-270.

Morrë, S.A., Ossewarde, J.M., Lan, J., Man Doomum, G.J.J., Walbooners, JM.M., MacLaren, D.M., Meijer, C.J.M. and wan den Brule, A.J.C. (1998) Serotyping and genotyping of genital Chlamydia trathonatis isolates reveal wariants of serovar $\mathrm{Ba}, \mathrm{G}$ and J as confirmed by ompt nucleotide sequence andysis. J. Chin. Miorobiol, 36, 345-351.

Morré, S.A., Munk, C., Persson, K., Krüger-Kjaet, S., van Dijk, R, Mejer, C.J.L.M. and van den Brule, A.J.G. (2002) Comparison of three commercially available peptide-based immunoglobulin $\mathrm{G}$ ( $\mathrm{IgC}$ ) and $\operatorname{IgA}$ assays to microimmunofluorescence assay for detection of Chlamydia tradronatis antibodies. J. Clin. Micobiol., 40, 584-587.

Nairwinen, A., Puolakkainen, M., Hao, W., Kino, K, and Suni J. (1997) Detection of antibodies to Chlamydia rachomatis with peptide-based species-specific enzyme immunoassay. Infect. Dis. Obitet. Gynewh, 5, 349-354. 
Ossewarde, J.M. de Vries, A., van den Hoek, J.A.R. and van Loon, A.M. (1994) Entene immunoassay with enhanced specificity for detecrion of antibodies to Chlamydia tradhomatis $I$. Clin, Micolviol, $32,1419-1426$.

Paukku, M., Närvänen, A., Puolakkainen, M., Dreesbah, K., Titunen, A., Hao, W., Anttila, T.I. and Paavonen, J. (1998) Detection of Chlanydar trachomatis antibodies in 2 novel tests: rELISA and peptide EIA. Int. J. STD E AIDS, 9, 604-607.

Peeling, R.W., Wang, S.P., Grayston, J.T., Blasi, F., Boman, J., Clad, A., Freidank, H., Gaydos, C.A., Gnarpe, J., Hagiwara, T. ef al. (2000) Chomydia pnethnowial serology: interlaboratory variation in microimmunofluorescence assay results. J. Infect. Dis, 181 (suppl 3 ), $\$ 426429$.

Punnonen, R., Terho, P., Nikkanen, V. and Meumnan, O. (1979), Chlamydial serology in infertile women by immunofluorescence. Fertit. Steril, 31, 656-659.

Schachrer, J., Cles, L., Ray, $\mathbb{R}$. and Hines P.A. (1979). Failure of serology in diagnosing Chlamydial infections of the female genital tract. J. Clin. Microbiol, 10,647-649.

Trehame, J.D., Darougar, S. and Jones, B.R. (1977) Madification of the microinmunofluorescence test to provide a routine serodiagnostic test for Chlannydial infection. J. Clim. Pathol., 30, $510-517$.

Tuuminen, T., Palomaki, P. and Pavonen, J. (2000) The use of serologic tests for the diagnosis of Chlamydial infections. J. Microbiol. Methods, 42, 265-279.

Wang, S.P. and Grayston, J.T. (1970) Immunologic relationship between genital TRIC, lymphogranuloma venereum, and related organisms in a new microtiter indirect immunofuorescence test. Am. J. Ophialmol, 70, 367-374. 


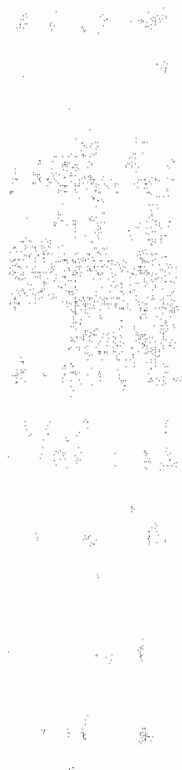




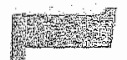 \\ 1.7. \\ Chlamydia trachomatis in subfertile women andergoing uterine instrumentation: screen or treat?
}

\author{
J.A. Land ${ }^{1}$, A.P. Gijsen ${ }^{1}$, J.L.H. Evers ${ }^{1}$, C.A. Bruggeman ${ }^{2}$ \\ Research Institute Growth and Development (GROW), Department of \\ Obstetrics and Gynaecology ${ }^{1}$ and Department of Medical Microbiology ${ }^{2}$, \\ Maastricht, the Netherlands
}




\begin{abstract}
Women who undergo uterime instrumentation are considered at risk for pelvic infections by Chlamydia (C) indhomatis, which may derive either from ascending endocervical infections or from reactivation of microorganisms persisting in the genital tract after previous Chlamydia infections. Women presenting at fertility clinici frequently undergo uterine instrumentation (e.g. hysterosalpingography and laparoscopy with hydrotubation).

Studies in subfertile women using DNA amplification techniques have shown that the prevalence of endocervical Chlamydia infections is low $(1.8 \%)$. In contrast, in $30-60 \%$ of subfertile women Chlamydia IgG antibodies can be found in serum, indicating previous Chlamydia infections. It has been demonstrated that, several years after Chlamydia infections, viable microorganisms may still be present in the upper genital tract. Therefore, subfertile women with Chlarnydia antibodies should be considered at risk for reactivation of persistent Chlamydia infections after uterine instrumentation, even after exclusion of endocervical Chlamydia infections. Moreover, in subfertile women without Chlamydia antibodies, the presence of vable microorganisms in the genital tract cannot be excluded. As a conseguence, prophylactic antibiotic before uterine instrumentation should be considered in all subfertile women, instead of endocervical screening for $C$. trachomatis and treatment of positive cases only.
\end{abstract}




\section{Introduction}

C. trachomatis is the most common sexually transmitted disease in industrialised countries. Chlanydia infections remain often undiagnosed, as they are asymptomatic in the majority of patients. Undiagnosed and untreated Chlanydia infections, however, may have considerable consequences in women, by increasing the risk for pelvic inflammatory disease, tubal factor subfertility and ectopic pregnancy. In women with asymptomatic endocervical Chlamydia infections, ascending spread of microorganisms from the cervix can cause upper genital tract infections. Women with endocervical Chlamydia infections are considered particularly at risk for ascending infections during uterine instrumentation.

Hysterosalpingography (HSG) and laparoscopy with hydrotubation are common procedures of uterine instrumentation in subfertile women. Clinical pelvic infection following HSG has been reported in up to $4 \%$ of cases, and in $10 \%$ of patients with tubal disease (Forsey et al., 1990). In a number of patients with post-HSG infections due to $C$ : trachomatis, the microorganism could be isolated from the cervix prior to HSG, indicating spread of the microorganism from the cervix into the upper genital tract. However, in some patients with post-HSG infections due to C. trachomatis, the microorganism could not be recovered from the cervix prior to HSG, suggesting post-HSG infection to be caused by reactivation of viable microorganisns which had persisted in the genital tract (Forsey et al, 1990).

Although pelvic Chlamydia infections may derive from ascending endocervical infections as well as from reactivation of microorganisms persisting in the upper genital tract, different intervention strategies have been proposed for the prevention of ascending infections only. In 1996, the Royal College of Obstetricians and Gynaecologists recommended that all women undergoing uterine instrumeratation should be screened for Chlamydia, or should receive prophylactic antibiotics (Royal College of Obstetricians and Gynaecologists, 1996). In 2000, in its more recent guidelines, the Royal College is ambiguous in its recommendations: screening for Chlamydia prior to uterine instrumentation should be considered only in patients at risk, i.e. women $<25$ years, but protection against upper genital tract infections should be considered in all women presenting for subfertility investigation (Royal College of Obstetricians and Gynaecologists, 2000). Therefore, the controversy between the administration of prophylactic antibiotics and a screen-and-treat policy remains still unresolved. 


\section{Endocervical Chlamydia infections in subfertile women}

Sudies published on endocervical Chlamydia colonization in subfertility patients have reported the prevalence to range from $0-10.4 \%$ (Macmillan and Templeton, 1999; for summary). Most studies used cell culture, which has a serisitivity of $<70 \%$. In DNA amplification tests, polymerase chain reaction (PCR) and ligase chain reaction (LCR), sensitivity is $>90 \%$ (Puolakkainen et al., 1998) and therefore these must be considered the tests of choice for diagnosing $C$. trachomatis infections. Studies in subfertility patients using $\mathbb{L C R}$ on endocervical specimens have reported prevalences of $1.3 \%$ (95\% Cl 0.2-4.7\%) (Eggert-Kruse et al., 1997) and $1.9 \%$ (95\% CI 0.5-4.8\%) (Macmillan and Templeton, 1999). We performed a study in 255 femalle subfertility patients by PCR, and found endocervical Chlamydia infections in $2.0 \%$ (95\% CI $0.6-4.5 \%$ ) (unpublished data). From the combined data of the three studies using DNA amplification tests, it can be concluded that endocervical Chlamydia infections are infrequent in subfertility patients (prevalence $1.8 \%, 95 \% \mathrm{CI} 0.9-3.2 \%$ ). Screening women for asyrmptomatic endocervical Chlamydia infections, in order to reduce the rate of pelvic inflammatory disease, has been debated. It has been demonstrated that screening by DNA amplification tests, and subsequent treatment of women with positive test results, is only cost-effective in populations with a prevalence of $C$. trachomatis of $\geq 4 \%$ (Paavonen et al., 1998).

In order to identify high prevalence populations for Chlamydia infections, criteria have been developed for high-risk patients. Age $<25$ years, two or more sexual partners in the past year, and single status have independently been associated with an increased risk for endocervical Chlamydia infection (Stergachis $e t$ al, 1993). The majority of fenale subfertility patients are $>25$ years of age (in our study $4.0 \%$ of women were $<25$ years old $)$, and couples attending fertility clinics usually have had monogamous relationships for several years. Therefore, factors identifying high-risk patients for Chlamydia infections in a general population are not applicable in subfertility patients:

Chlanydia IgG antibodies have been found in 30-60\% of subfertile women (Mol et al., 1997; for review), and are considered markers for past pelvic infections. Cervical infection causes only rarely a rise in Chlamydia antibody titre (Tayler-Robinson, 1997). Therefore, Chlamydia IgG antibody testing is not helpful in identifying patients with active endocervical infections. This is in agreement with findings by others (Eggert-Kruse et al., 1997), who found no relation between LCR results and Chlamydia IgG antibody titres in 150 patients, of whom two were LCR positive. In fact, more data on LCR / PCR positive subfertile women are needed to confirm these findings, but the low prevalence of endo- 
cervical infections in subfertility patients makes studies with adequate numbers difficult to perform.

\section{Persisting Chlamydia microorganisms in the upper genital tract: the role of screning}

PCR testing of endocervical swabs is based on DNA amplification of Chlamydia antigen obtained from the lower genital tract. Exidence exists however that $C$. trachomatis may persist in the upper genital tract despite negative PCR test results from the cervix. In patients with bilateral tubal occlusion due to Chlamydia infection, tubal biopsies have been evaluated by a fluorescent antibody test for the presence of the major outer membrane protein (MOMP) of C. trachomatis (Dieterle et al. 1998). MOMP was found in tubal specimens from 11/56 women, in whose endocervical specimens the presence of $C$. trachomatis could not be demonstrated. PCR testing of Fallopian tube tissue from 10 women with ectopic pregnancies (Gérard et al, 1998) showed that 7/10 tubes were positive for Chlamydia DNA. In each PCR-positive sample, transcripts from Chlamydia genes were present, indicating that the Chlanydia cells identified were viable and metabolically active at the time of biopsy. Evaluation by in-situ hybridisation or immunoperoxidase staining technique of tubal specimens of patients with tubal pathology showed DNA or antigens in $19 / 24$ women (Patton et al, 1994). There was no difference in detection rate of $C$. trachomatis between patients who had been treated by antibiotics (tetracycline, ofloxacin or roxythromycin) and untreated patients. These studies indicate that $C$. trachomatis may persist in a viable state in Fallopian tubes for a long period, even after antibiotic treatment. Reactivation of Chlamydia infection may occur, but it is still speculative which stimuli may induce reactivation of upper genital ract infection. Uterine instrumentation might be such a stimulus. Therefore, reactivation of Chlamydia upper genital infections may occur in subfertility patients with Chlanydia antibodies (indicating a previous infection), despite the fact that no Chlamydia DNA can be detected in the cervix. This questions screening by cervical swabs in subfertile women before uterine instrumentation, and also raises questions considering PCR-negative patients not at risk for subsequent upper genital tract Chlamydia infections.

\section{Prophylactic antibiotics}

Since the presence of viable Chlamydia microorganisms in the upper genital tract can be excluded by invasive methods only, there is no feasible screening method available in daily practice. Therefore, prophylactic antibiotics may be considered in subfertility patients before uterine instrumentation. Guidelines for the treatment of patients with genital Chlanydia infections (Centers for Disease Control and 
Prevention, 1998) have recommenided azithromycin as a single oral $1 \mathrm{~g}$ dose as equivalent to the 7 day regimen of doxycycline (100 $\mathrm{mg}$ twice daily) for treating uncomplicated genital Chlamydia infections. Pharmacokinetic studies in man have shown the time to adequate tissure concentrations after a single oral dose to be $12-14 \mathrm{~h}$, tissue concentrations being 10-100 times higher than in serum and to remain high for several days (Foulds et al, 1990). These pharmacokinetic characteristics of azithromycin encourage its use as prophylaxis in subfertility patients before procedures which might reactivate Chlanydia infections.

\section{Conclusions}

Upper genital tract Chlanydia infections may derive from ascending endocervical infections, but reactivation of domant microorganisms in the upper genital tract is another possibility. Endocervical infections can be excluded by LCR or PCR, but the prevalence of active endocervical Chlamydia infections in subfertile women is low $(1.8 \%)$. Concerning reactivation, it has been shown that several years after Chlamydia infections viable $C$. trachomatis microorganisms may still be present in the upper genital tract: Therefore, subfertile women with Chlamydia antibodies (indicating a previous Chlamydia infection) should be considered at risk for reactivation of persistent Chlamydia microorganisms after uterine instrumentation, even after exclusion of Chlamydia in the cervix. From this point of view, prophylactic antibiotics should be considered in subfertile women who have Chlanydia antibodies in serum and have to undergo uterine instrumentation, as opposed to endocervical screening for $C$. trachomatis and treatment of positive patients only. In subfertile women who have no Clamydia antibodies in serum, the presence of Chlamydia in the genital tract cannot be excluded however. Since iatrogenic spread of Chlamydia in subfertile women has severe consequences for the preservation of fertility, prophylactic antibiotics before uterine instrumentation should also be considered in subfertile women without Chlamydia antibodies. Clinical studies which allow the assessment of the effectiveness of antibiotic therapy in preventing pelvic infections after uterine instrumentation are impracticable, since the majority of Chlamydia infections will remain subclinical and therefore will go undiagnosed. Thus, clinical guidelines concerning precautions in subfertile women undergoing uterine instrumentation can be based on theoretical arguments only. Prophylactic antibiotics (e.g. azithromycin in a single oral $1 \mathrm{~g}$ dose, 12 h before the planned procedure) should replace endocervical screening for $C$ : trachomatis and treatment of positive cases only. 


\section{References}

Centers for Disease Control and Prevention (1998) 1998 guidelines for treatment of sexually transmitted diseases. $M M W R, 47, \mathrm{R}$ - 1 .

Dieterle, S., Rummel, C., Bader, L.W., Petersen, H. and Fenner, T. (1998) Presence of the major outer membrane protein of Chlamyda trachomatis in patients with chronic salpiugitis and salpingitis isthmica nodosa with tubal ocdusion. Fertil. Steril., 70, 774-776.

Eggert-Kruse, W., Rohr, G., Demirakca, T., Rusu, R., Naher, H., Petzoldt, D and Rumebaum, B. (1997) Chlamydial serology in 1303 asymptomatic subfertile couples. How Reprod, 12, $1464-1475$.

Forsey, J.P., Caul, E.O., Paul, I.D. and Hull, M.G.R. (1990) Chantyda trahomatis, tubal disease and the incidence of symptomatic and asymptomatic infection following hysterosalpingography. Hum. Reprod, 5, 444-447.

Foulds, G., Shepard, R.M. and Johnson, R.B. (1990) The pharmacokinetics of azithromycin in human serum and tissues. J. Antimicrob. Chenother, 25, (suppl.A), 73-82.

Gérard, H.C., Branigan, P.J., Balsara, G.R., Heath, C., Minassian, S.S. and Hudson, A.P. (1998) Viability of Chanydia trachomatis in fallopian tubes of patients with ectopic pregnancy. Fentil. Steril., 70, 945-948.

Macmillan, S. and Templeton, A. (1999) Screening for Chamydia tradhonatis in subfertile women. Hum. Reeprod., 14, 3009-3012.

Mol, B.W.J., Dijkman, B., Wertheim, P., Lijmer, J., van der Veen, F. and Bossuyt, P.M.M.

(1997) The accuracy of serum Chlamydial, antibodies in the diagnosis of tubal pathology: a meta analysis. Fertil. Steril., 67, 1031-1037.

Paavonen, J., Puolakkainen, M., Paukku, M. and Sintonen, H. (1998) Screening for Chlawnda trathonatis would be cost-effective, even in low-prevalence situations. Otstet. Gywecol., 92, 292-298.

Patton, D.L., Askienazy-Elbhar, M., Henry-Suchet, J., Campbell, L.A., Cappuccio, A.,

Tannous, W., Wang, S. and Kuo, C. (1994) Detection of Chlawydia trachowatis in fallopian tube tissue in women with postinfectious infertility. Am. J. Obstet. Gynecol, 171, 95-101.

Puolakkainen, M., Hiltunen-Back, E., Reunala, T., Suhonen, S., Lähteenmäki, P., Lehtinen, M. and Pavonen, J. (1998) Comparison of performances of two commercially avalable tests, a PCR assay and a ligase chain reaction test, in detection of urogenital Chlawydid trachonatis infection. J. Clin. Microbiol, 36, 1489-1493.

Royal College of Obstetricians and Gyraecologists (1996) The initial investigation and management of the infertile couple. RCOG Press, London, UK, p. 12.

Royal College of Obstetricians and Gynaecologists (2000) The management of infertility in tertiary care. www rcog.org.uk/guidelines/tertiarycare.hmi.

Stergachis, A., Scholes, D., Heidrich, F.E., Sherer, D.M. Holmes, K.K. and Stamm, W.E. (1993) Selective screening for Chlanydia trachostatis infection in a primary care population of wonen. Am. J. Epidemiol., 138, 143-153.

Tayler-Robinson D. (1997) Evaluation and comparison of tests to diagnose Chatatida frachowatis genital infections. Hwm. Reprod, 12 (Suppl. 2), 113 120. 
A mouse model for genital tract pathology by Chlamydia trachomatis

\author{
A.P. Gijsen 1,3, J.A. Land ${ }^{1,3}$, FR.M. Stassen ${ }^{2,4}$, M.J J. Gijbels ${ }^{4,5}$, \\ G.E.L.M. Grauls ${ }^{2} 4$, J.L.H. Evers ${ }^{1,3}$, C.A. Bruggeman ${ }^{2, *}$. \\ Departments of Obstetrics and Gynaecology ${ }^{1}$, Medical Microbiology ${ }^{2}$ and \\ Pathology ${ }^{5}$, Research Institute Growth and Development (GROW) \\ Cardiovascular Research Institute Maastricht (CARIM) , Maastricht, \\ the Netherlands
}


$92 \mid$ Chapten 6

\section{Introduction}

C. trachomatis is the most common sexually transmitted disease in industrialised countries. In the majority of female patients, Chlamydia infections remain asymptomatic (silent infections) (Thejls et al, 1987). In a number of these asymptomatic patients involvement of the upper genital tract occurs, leading to pelvic inflammatory disease (PID) and finally resulting in tubal factor subfertility or ectopic pregnancy (Paavonen and Wolner-Hanssen, 1989). The largely unknown pathogenesis of tubal factor subfertility after silent $C$. trachomatis infections, and the unknown role of immunologic or genetic factors in this process hinder the search for a clinically significant screening test for tubal factor subfertility.

Animal studies have been performed in order to shed more light on the pathogenesis of $C$. trachomatis genital tract infections and re-infections. These papers report on acute ascending $C$. trachomatis genital infections and subsequent infertility, using macaques (Patton et al., 1987, 1989, 1990), guinea pigs (White et al., 1979) and mice. In mice most experiments have been done using the $C$. trachomatis mouse pneumonitis (MoPn) strain (Barron et al., 1981; Tuffrey et al., 1981, 1986a, 1986b, 1990; Swenson et al., 1983 and 1984; de la Maza et al., 1994; Perry et al., 1999; Pal et al., 1998; Ramsey et al., 2000). However, this MoPn strain is much more virulent than human serovars and causes infections throughout the genital tract in mice (Williams et al., 1981). Furthermore, since genome analysis has shown that human isolates are genetically clearly different from the MoPn strain, MoPn has recently been reclassified as a new species within the genus Chlamydia and is now named C. mutidarum (Everett et al., 1999; Read et al., 2000). Because of the genomic differences between $C$. muridarum and human strains, use of $C$. muridarum as a model for human pathology has become a matter of debate (Morré et al., 2000; Morrison et al., 2000).

Knowledge about the pathogenesis of long-term sequellae of human $C$. trachomatis serovars in mice is rather limited. Human biovars have been demonstrated to cause post-infectious sequelae only if high doses were inoculated directly into the uterine horns of mice pre-treated with progesterone. A reason for the effect of progesterone pre-treatment could be a local action of progesterone in the genital tract, e.g. by increasing the susceptibility of the epithelium to an infection with $C$. trachomatis, or by a generalized immunosuppressive effect of this hormone (Tuffrey at al., 1981, 1986a, 1986b, 1990).

Re-infection has been studied in macaques and in mice. In macaques cervicall priming with $C$. trachomatis prior to tubal inoculation increased the extent of tubal pathology (Patton al., 1990). In mice, re-inoculation with the same serovar induced pronounced tubal pathology whereas mice re-inoculated with different serovars remained fertile (Ransey et al., 2000). 
Tubal pathology due to $C$. trathonatis infection is assumed to be immunopathologically mediated (Morris et al., 1985; Brunham and Peeling, 1994). Although early studies on tubal pathology did not concentrate on $C$. frachomatis specifically, in patients with acute PID it was shown that the infertility rates after one, two and three episodes of symptomatic PID were $13 \%, 20 \%$ and $75 \%$ respectively (Weström and Mårdh, 1975). Similarities exist between the $C$. trachomatis induced immune response occurring in trachoma, i.e. keratoconjunctivitis due to $C$. trachomatis, and the response in genital tract infection (Brunham et al, 1985). Animal studies on the pathogenesis of trachoma have shown that primary Chlamydia infection does not lead to permanent tissue damage, but that re-infection induces an inflammatory reaction that may ultimately culminate in fibrosis and scarring and lead to ocular damage (Grayston et al., 1972, 1985). The specific immunologic pathways that underlie this tissue damaging response to infection and re-infection are unknown (Patton and Kuo, 1989; Monnickendam et al, 1980).

Moreover, in assuming that the immune response not only consists of a species-specific response, but also contains genus-specific features, the development of tubal pathology might not only be induced by $C$. trachomatis infection alone, but 'antigenic related' other Chlamydia infections might also play a role. Chlanydia species which, besides $C$. trachomatis, can cause infections in humans are C. pneumoniae and C. psittaci. The presence of $C$. psittaci in the general population is, with a prevalence of $0.1 \%$ C. psittaci antibodies, very low (Moss et at., 1993; Wong et al., 1999). C. pneumonide however is a widespread pathogen in humans and (re-)infections commonly occur (Thom et al., 1991). A prevalence of C. pneumoniae antibodies of $63-74 \%$ in healthy males and females has been found (Karvonen et al., 1994; Wong et al., 1999). The microorganism causes acute respiratory infections (Kalayoglu et al, 1998; Monno ef al, 2002), but has also been associated with several chronic diseases, like asthma, reactive arthritis and atherosclerosis (Campbell et al,, 1998; Grayston, 2000).

As expected, the prevalence of $C$. presmoniae $\lg G$ antibodies in subfertile women was comparable to the prevalence in healthy males and females, ranging from 56 to $76 \%$, regardless of the cause of subfertility (Freidank et al., 1995; Gijsen et al., 2001). Because of the high antibody prevalence in subfertile women, we postulated C. pneumoniae to be a possible contributor to the development of $C$. trachowatis induced tubal pathology. Previous data in our laboratory are in agreement with this hypothesis by suggesting a correlation between the presence of both antibodies to $C$. trachonatis and $C$. preumoniae, and tubal pathology at laparoscopy. The presence of both antibodies to $C$. trachowatis and to $C$. pnewmoniae was associated with a higher rate of tubal factor subfertility (49\%), as compared to 
no antibodies $(26 \%, \mathrm{p}<0.05)$, antibodies to $\mathrm{C}$.radhomats only $(30 \%, \mathrm{p}>0.05)$ or C. pnenwoniae only (17\%,p<0.0001) (Gijsen et al, 2001).

Animal studies on $C$. wachomatis thus far have focussed on the development of acute PID and not on slent infections and their chronic sequelae. We bypothessed that in silent infections a primary $C$. trachomatis infection does not result in extensive genital tract pathology, and that only subsequent $C$. trochomatis re-infection induces tubal disease. Our main goal was to develop a small-animal model that mimics this hypothesised course of Chlamydia infections in women. The main part of the current study evaluates infection of a low susceptible mouse strain, i.e. C57BL/6] mice (De la Maza et al., 1994), using a human C. trachomatis serovar (experimental design A). For this purpose mice were inoculated intravaginally and the development of histopathologic changes and tissue damage in the genital tract at different time points after infection were studied. Of these mice, one group was submitted to re-infection while the others werc not re-infected. Furthermore, to explore whether other Chlamydia species, i.e. C pnemmoniae, contribute to the development of C. trachomatis induced tubal pathology, a small pilot study with $C$. puetumoniae inoculation was performed (experimental design B). The results of experimental design $\mathrm{B}$ are, due to technical problems, incomplete, and therefore only shortly described. For this reason, the discussion and conclusions of the present chapter deal with experimental design $\mathbf{A}$ only.

\section{Materials and methods}

\section{Microorganisms}

C. modhomatis (human serovar $L_{2}$ ) and $C$. pnemmoniae (TWAR2043) were inoculated in flask ( $75 \mathrm{~cm}^{2}$ ) containing $\mathrm{Hep}-2 \mathrm{C}$ (ATCC CCL-23) monolayers. The Glasks were centrifuged for 1 hour at $3000 \mathrm{~g}$. Chlamydia growth medium was added, containing Eagles minimal essential medium (Bio Whittaker, Verviers, Belgium) ( $\mathrm{pH} 7.5), 0.15 \% \mathrm{NaHCO}, 10 \%$ fetal calf serum, $1 \%$ non essential amino acids, $1 \%$ glutamine, gentamilin $(25 \mu \mathrm{g} / \mathrm{ml})$ and cycloheximide $(1 \mu \mathrm{g} / \mathrm{ml})$. After 72 hours the monolayer was harvested by scraping the cells, and sonicated twice for 15 sec using a Branson sonifier 250 (Brouwer Scientific BV, Soest, The Netherlands). Cell debris was pelleted by centrifugation for $10 \mathrm{~min}$ at $100 \mathrm{~g}$, after which the supernatant was used for pelleting the Chlamydia elementary bodies at $30.000 \mathrm{~g}$ for 45 minutes at $4^{\circ} \mathrm{C}$. The pellet was resuspended in Sucrose Phosphate Glutamate medium (SPG) and stored at $-80^{\circ} \mathrm{C}$. The concentration of inclusion forming units (IFU) was determined by culturing a serial tenfold dillution range of the isolated Chlamydia in a 96-well culture dish containing Hep-2C monolayers. 
After fixation of the cell monolayer, the concentration of $C$. frachomatis IFU was determined by immunofluorescence staining with monoclonal antibodies CF2 (Washington Research Foundation, Seattle, Washington, USA) and FITC-labeled rabbit anti-mouse conjugate (DAKO F313, Glostrup, Denmark). The concentration of $\mathrm{C}$. pneumoniae IFU was determined by immunofluorescence staining with monoclonal antibodies RR402 (DAKO 6600, Glostrup, Denmark) and FITC-labeled rabbit anti-mouse conjugate (DAKO F313, Glostrup, Denmark).

\section{Animals}

Specific-pathogen-free eight week old female C57BL/6J mice were obtained from Charles River Laboratories (Someren, The Netherlands). They were kept in an isolator-type cage under standard environmental conditions. Mice were given subcutaneous injections containing $2.5 \mathrm{mg}$ of medroxyprogesteronacetate (Anovulin $($, Produlab Pharma, Raamsdonkveer, The Netherlands) in $100 \mu$ li of phosphate buffered saline (PBS) ten and three days prior to inoculation with $C$. trachomatis, C. pneumoniae or PBS (control group); to synchronise oestrus ('Tuffrey and Taylor-Robinson, 1981). For vaginal inoculation the mice were manually fixated and the urine bladder emptied by light rubbing of the abdomen. This was performed to prevent the mice from expelling the inoculum by urinating immediately in response to the inoculation. For $C$. preumoniae inoculation the mice were fixated manually, and C. pneumoniae was injected intraperitoneally, as described by Ezzahiri and coworkers (2002 and 2003).

\section{Experimental design $A$ : C. trachomatis infection experiments}

A dose finding study was performed to establish the optimal dose for infection. In this study three groups of twelve mice were inoculated intravaginally with $10^{3}, 10^{5}$ and $10^{7}$ IFU $C$. trachomatis $\mathrm{L}_{2}$ respectively in $10 \mu \mathrm{PBS}$ medium, and control mice were given $10 \mu \mathrm{l}$ PBS only. Infection was assessed by determining $C$. trachomatis $\operatorname{IgG}$ antibodies in serum three and nine weeks after inoculation using the micro-immunofluorescence (MIF) assay, as described below.

Five groups of mice were entered in the C. trachomatis pathogenesis study. Three groups of six mice each were inoculated once with $10^{7} \mathrm{IFU}$, the dose of $C$. trachomatis selected from the dose finding study. Mice were sacrificed at regular intervals, three weeks (single-3), nine weeks (single-9) and eighteen weeks after inoculation (single-18). Six mice were inoculated with $10^{7}$ IFU $C$. trachomatis and re-inoculated after nine weeks and sacrificed eighteen weeks after the primary inoculation (re-inoc group). The control group was sacrificed nine weeks after inoculation (PBS-control group). 
Before sacrifice, mice were anaesthetised with a weight-adjusted dose of pentobarbital (Nembutal, Sanof Sante BV, Maassiuis, the Netherlands) and sacrificed by perfoming a heart puncture. Gross genital tract pathology was examined and scored in vivo, and genital tracts were excised for histologic evaluation.

\section{Experimental design $B . C$. pneumoniae infection experiments}

A dose funding study was performed to study whether $C$. pnemmoniae is able to induce pathologic changes in the genital tract without the interference of $C$. trachomatis. To establish the optimal dose for infection, three groups of six mice were inoculated with $10^{3}, 10^{5}$ and $10^{7} \mathbb{I F U} \mathrm{C}$. pnewmonite TWAR respectively in $200 \mu \mathrm{PBS}$ medium according to a standardised procedure as described by Ezzahiri et al. (2002 and 2003). Infection was assessed by determining $C$. pneumoniae $\operatorname{IgG}$ antibodies in serum three weeks after inoculation using MIF. Gross genital tract pathology was examined and scored in vivo, and genital tracts were excised for histologic evaluation.

Subsequently, experiments using successive inoculations with $C$. pnewmoniae and $C$. thachomatis were done. Three groups of six mice were inoculated with $10^{7}$ IFU $C$. pnewmoniae per mouse and / or $10^{7}$ IFU $C$. trachomatis as described before. One group was inoculated with C. pmenmoniae and re-inoculated with PBS (single-Cp group). A second group was inoculated primarily with $C$. pnewmoniae and re-inoculated with $C$. machomatis (Cp-Ct group): The third group was inoculated primarily with $\mathrm{C}$. trachomatis and re-inoculated with $\mathrm{C}$. pnewwowiae $(\mathrm{Ct}-\mathrm{Cp}$ group).

For all three groups re-inoculation was planned at nine weeks, and sacrifice at 18 weeks aftet primary inoculation. However, due to miscalculation $\mathrm{Cp}$-Ct mice were re-inoculated affer 18 weeks and subseguently sacrificed after 27 weeks.

\section{Antibody detection}

Mice were tested for the presence of $C$. trachomatis IgG antibodies using a commercially available indirect micro-mmunofuorescent (MHF) antibody technique (C. pnemoniae IgG Micro-IF, Labsystems, Helsinki, Finland). This test was originally developed to detect $C$. pnetmoniae antibodies, but each well also contains a spot appropriate for $C$. trachomatis detection. Moreover, in screening for human nubal factor subfertility, this test was superior to four other Chlamydia antibody tests evaluated (Land et al, 2003). In short, 10 fl serum was diluted 10 times in PBS ( $\mathrm{pH} 7.4$ ) and incubated on the spots containing Chlamydia antigens, for 30 min at $37^{\circ} \mathrm{C}$ in a moist chamber. The slides were washed two times for five min in PBS and once in ultrapure water, processed through a Milli-Q purifying system 
(Millipore, Bedford, MA, USA) and placed into $37^{\circ} \mathrm{C}$ until dry: The spots were incubated with $10 \mu \mathrm{l}$ rabbit anti-mouse IgG-FITC-labeled conjugate (DAKO F313, Glostrup, Denmark) and placed in a moist chamber for $30 \mathrm{~min}$ at $37^{\circ} \mathrm{C}$. The slides were washed after serum incubation, and placed into $37^{\circ} \mathrm{C}$ until dry. Slides were embedded in mounting fluid under a cover slip. A positive reaction was characterised by specific fluorescence of the respective elementary bodies. All slides were evaluated independently by two readers. In the case of disagreement, the judgement of a third reader was decisive. A positive MIF result was defined as a titre $\geq 10$.

\section{Gross genital tract pathology}

After sacrifice of the mice, the genital tracts were exposed by an abdominal midline incision and examined for gross pathology in situ, using a light-microscope. In the present study, colour changes of the uterine horns and tubes were scored (as normal, red or pale) as parameters of intlammation. Since genital tract infections in mice can cause fluid retention and enlargement of the uterine horns and tubes (hydrosalpinx), dilatation of the uterine horns and tubes was scored (as absent or present) (Cotter et al, 1997). Thereafter, the genital tracts were excised completely for histologic examination.

\section{Histology}

Paraffin embedded genital tracts were sectioned in $4 \mu \mathrm{m}$ slides and evaluated after hematoxylin and eosin staining. Blinded sections were scored by an experimental pathologist (M. Gijbels), and histopathologic evaluation of the genital tracts focussed on several infection parameters. In stroma, values were assigned to the amount of plasma cells, lymphocytes and neutrophylic granulocytes. The endometrium was scored for atypia, presence of mitosis, apoptosis and T cells, and the endometrial crypts for presence of mitosis and apoptosis. The severity of the inflammatory response, as indicated by the infiltration of different inflammatory cells; mitosis and apoptosis, was scored as absent (0), very mild (1), mild (2), moderate (3) or severe (4). Atypia of the endometrium was scored as absent (0), focal (1), multifocal (2) or extensive (3). The sum of the values per parameter was calculated and the average \pm standard error of mean (SEM) was given for each group of mice. For statistical analysis a Mann-Whitney test was used. P-values of $<$ 0.05 were considered to reflect statistical significance. 


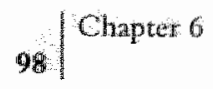

\section{Results of experimental series A}

Determination of optimal dose for C. trachomatis intravaginal infection.

Since it is known that different mouse strains show different susceptibilities to infection with $C$. trachomatis, a dose finding study with $C$. trachomatis $\mathrm{L}_{2}$ was performed in order to deternine the optimal inoculation dose to induce infection in C57BL/6J mice. Two mice died during the experiments: one mouse inoculated with $10^{3}$ IFU died due to dental problems and one scheduled for inoculation with $10^{7}$ IFU died between progesterone pre-treatment and inoculation.

In order to confirm whether the animals were infected with C. trachomatis, IgG antibody detection was performed. Table I summarises the results of the $C$. trachomatis antibody detection at three and nine weeks after inoculation. Mice inoculated with the lowest dose $\left(10^{3} \mathrm{IFU}\right)$ did not develop $\mathrm{IgG}$ antibodies three weeks after inoculation, and only 1 out of 6 mice showed anti-C. trachomatis antibodies nine weeks after inoculation. The number of sero-positive animals increased with higher doses of C. trachomatis, resulting in $100 \%$ sero-positivity in mice nine weeks after inoculation with $10^{7}$ IFU. Based on these data, it was decided to use $10^{7}$ IFU C. trachomatis as inoculation dose for further experiments.

\section{C. trachomatis pathogenesis study}

Mice were sacrificed at several time points after inoculation in order to evaluate the development of gross (Table II) and microscopic morphological changes (Table III) of the genital tracts.

One mouse from the single-9 group died before inoculation due to an unknown cause. In the PBS-control group no gross abnormalities were noticed. As shown in table $\mathbb{I}$, in the $C$. trachomatis inoculated animals, in 3 mice redness was observed in the single- 3 group. The single- 3 group showed no other abnormalities, while the single-9 group showed paleness, dilatation of uterine horns and tubes in about one third of the animals. These aspects had disappeared nine weeks later, i.e. the single-18 group showed redness in 3 mice and dilatation of uterine horns in only one. However, $4 / 6$ mice from the re-inoc group, did show dilatation of uterine horns and tubes. In this re-inoc group dilatation was demonstrated more often than in the single-18 group. In summary, these results show that in a number of mice gross genital tract pathology developed in nine weeks after $C$. wachomatis inoculation. The effects had a mild and temporary character; since eighteen weeks after inoculation gross genital tract pathology had resolved. After re-inoculation gross genital tract pathology was noted again. Since the end-point of the study was nine weeks after re-inoculation, we could not evaluate whether the effects seen after re-inoculation were permanent. 


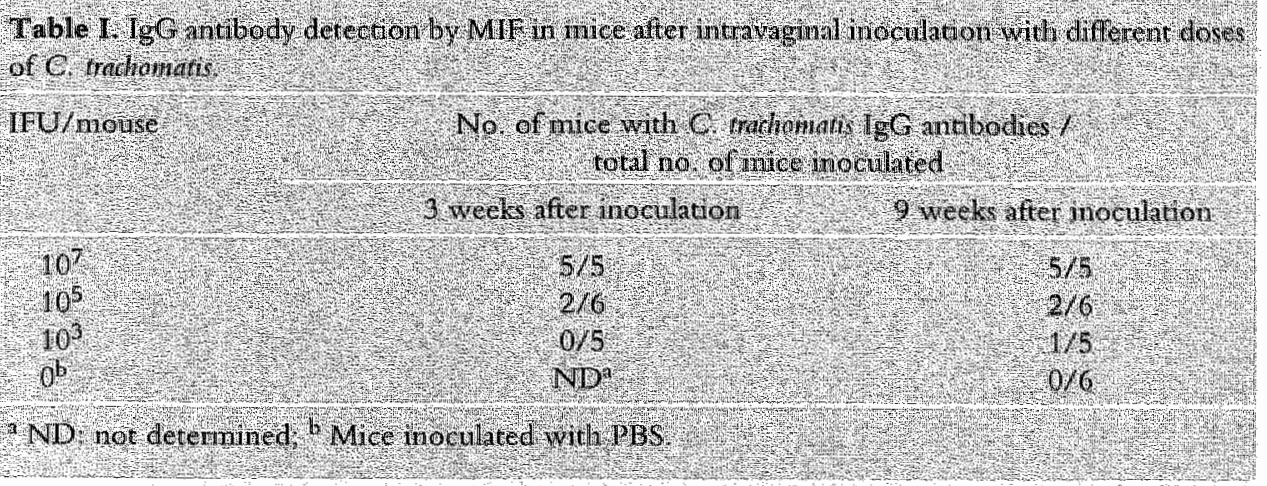

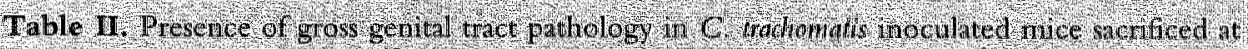
different lime goints after nowiltion.

Gross genutal hact patliclogy. Ineculation gioups

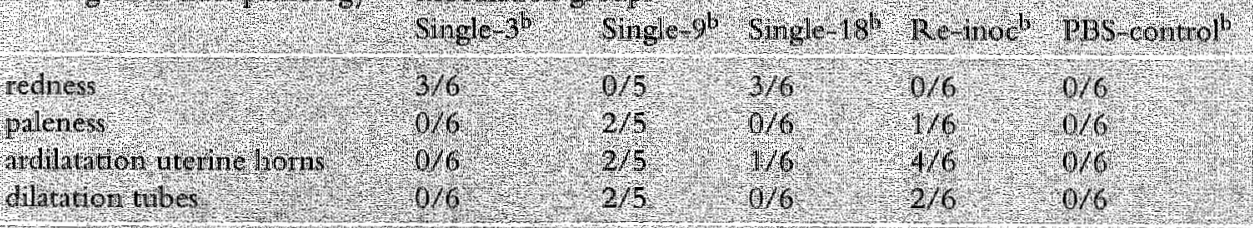

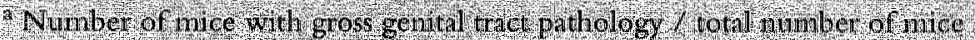

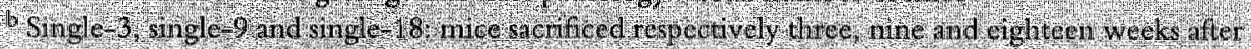

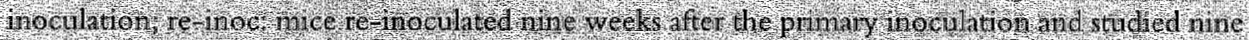

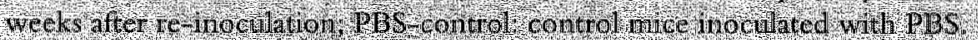

Table III summanises histologic parameters for the different inoculation groups. In the stroma of the PBS-control group very mild infiltration of inflammatory cells was observed and the endometrium of two out of six animals showed focal atypia. After single inoculation with $C$. trachomatis the infiltration of inflammatory cells (lymphocytes, macrophages and granulocytes) increased with time $(p<0.05$ in the single- 18 group as compared to the single-3 group), while in the endometrium of these animals no abnormalities were observed in comparison to the PBS-control group. Mitosis and apoptosis in the endometrium and crypts were present more often in the single-9 and PBS-groups compared to the other inoculation groups. Atypia of the endometrium was found more often (multifocally) in the re-inoc group as compared to the single inoculation groups in which atypia was scored as focal. In the re-inoc group infiltration of inflammatory cells was significantly increased as compared to the PBS-control group. Figure I shows hematoxylin and eosin stained sections of uterine horns from mice of the PBS-control group and the re-inoc group. 


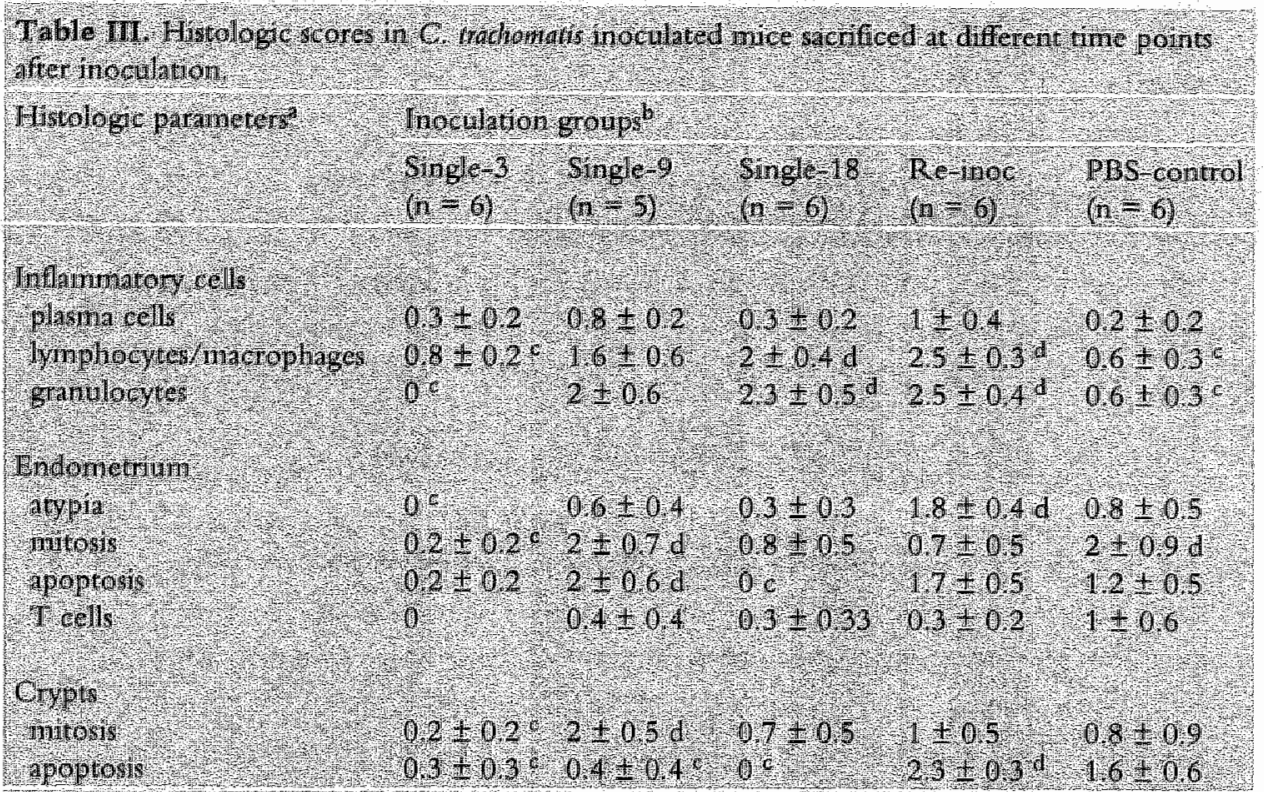

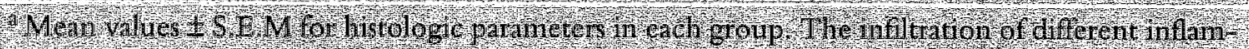

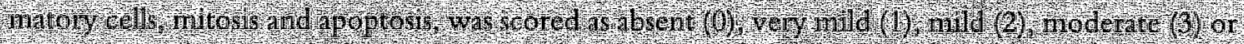

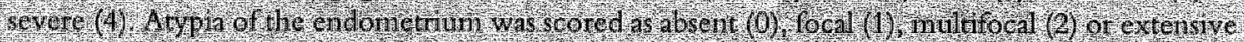
(3)

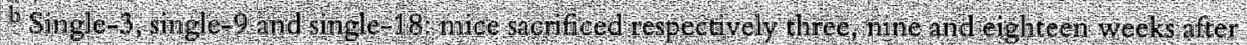

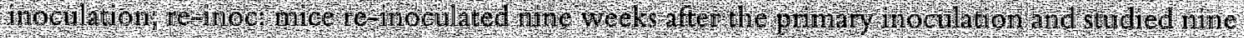

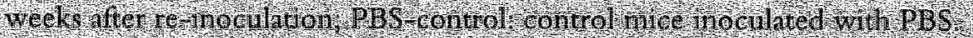

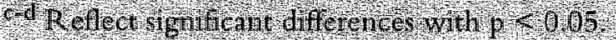
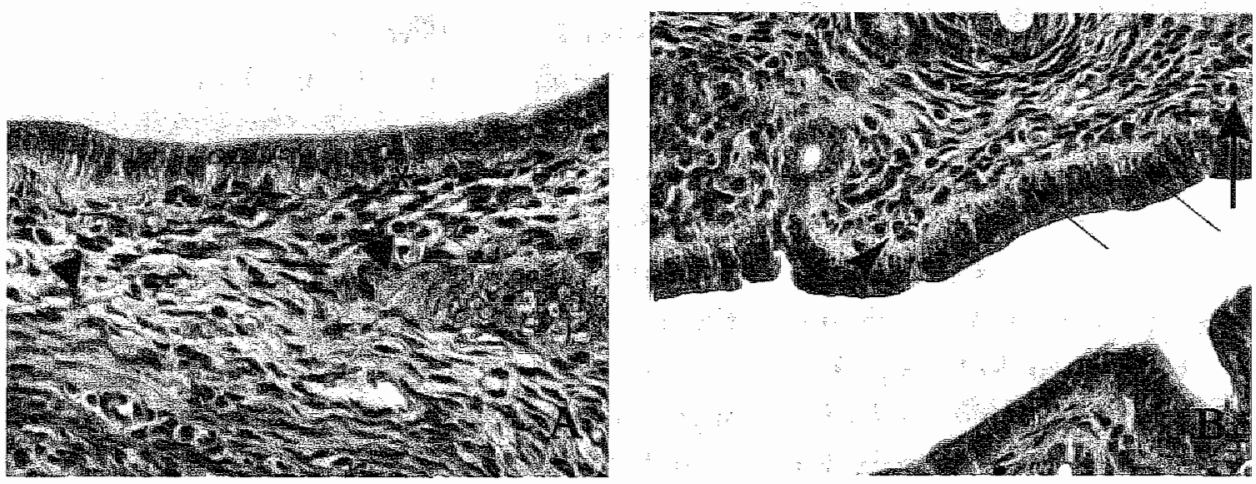

Figure 1. Henatoxylin and cosin stained sections; $100 \mathrm{X}$.

A: Uterus of PBS-control group mitosis is observed (asterisk) and some inflammatory cells (arrow head). B: Utertus of re-inoculation group: many apoptotic cells in the glandular epithelium (small arrow) and in the stroma nacrophages (thick arrow) and netrophylic granulocytes (amow head). 


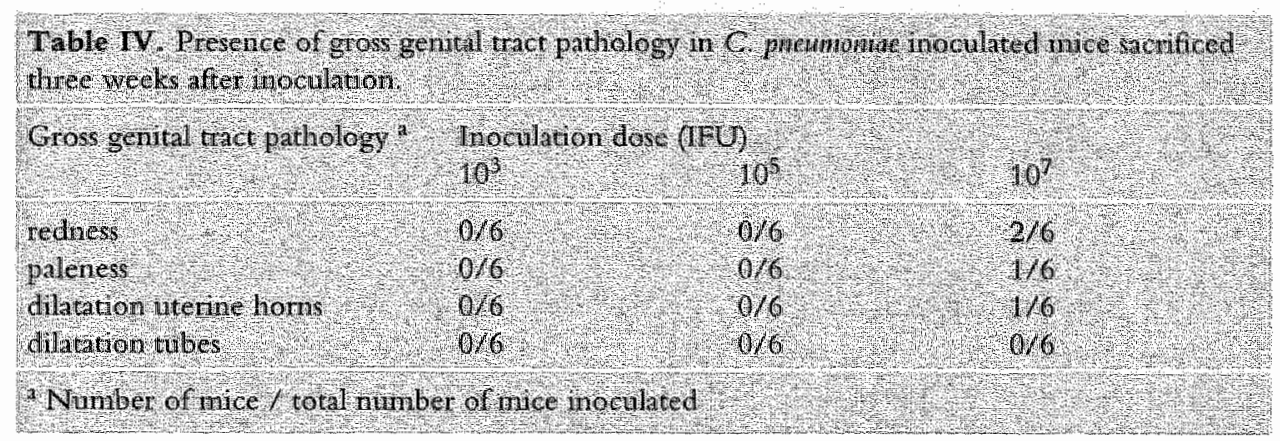

\section{Results of experimental series B}

\section{C. pneumoniae dose finding experiment}

Since the susceptibility of mice genitall tracts to $C$. pnewmoniae has not been described before, a dose finding study with C. pneumoniae was performed. Serologic response, gross and microscopic genital tract pathology were studied three weeks after inoculation.

In the group of mice inoculated with the lowest dose $\left(10^{3}\right.$ IFU) no $C$. pneumoniae $\operatorname{IgG}$ antibodies were detected. The number of sero-positive animals increased with higher doses of $C$. pnesumoniae. In the group of mice inoculated with $10^{5}$ IFU $C$. pneumoniae, three out of six mice sero-converted while in six mice inoculated with $10^{7}$ IFU C. pnetumoniae $100 \%$ sero-positivity was found, indicating that inoculation with high doses of $C$. pneumoniae $\left(10^{7} \mathrm{IFU}\right)$ leads to infection of all mice.

As shown in table IV, no gross abnormalities were observed in both lower doses $\left(10^{3}\right.$ and $\left.10^{5} \mathrm{IFU}\right)$, while inoculation with $10^{7}$ IFU C. pneunoniac resulted in genital tract redness in two out of six mice, with dilatation of uterine horns in one of these and paleness in one other mouse. After C. pnetwoniae inoculation the infilltration of inflammatory cells increased with higher doses, but in the endometrium of these animals no abnormalities were observed (table V). Based on these data, it was decided to use $10^{7}$ IFU $C$. pnewmoniae as inoculation dose for the C. pnemwoniae study.

\section{C. pneumoniae pathogenesis study}

In order to study the role of $C$. pneumoniae as a contributor to the development of C. trachomatis induced tubal pathology, mice were successively inoculated with $C$. pneumoniae and $C$. tradhomatis or vice versa. As described earlier, miscalculation of 


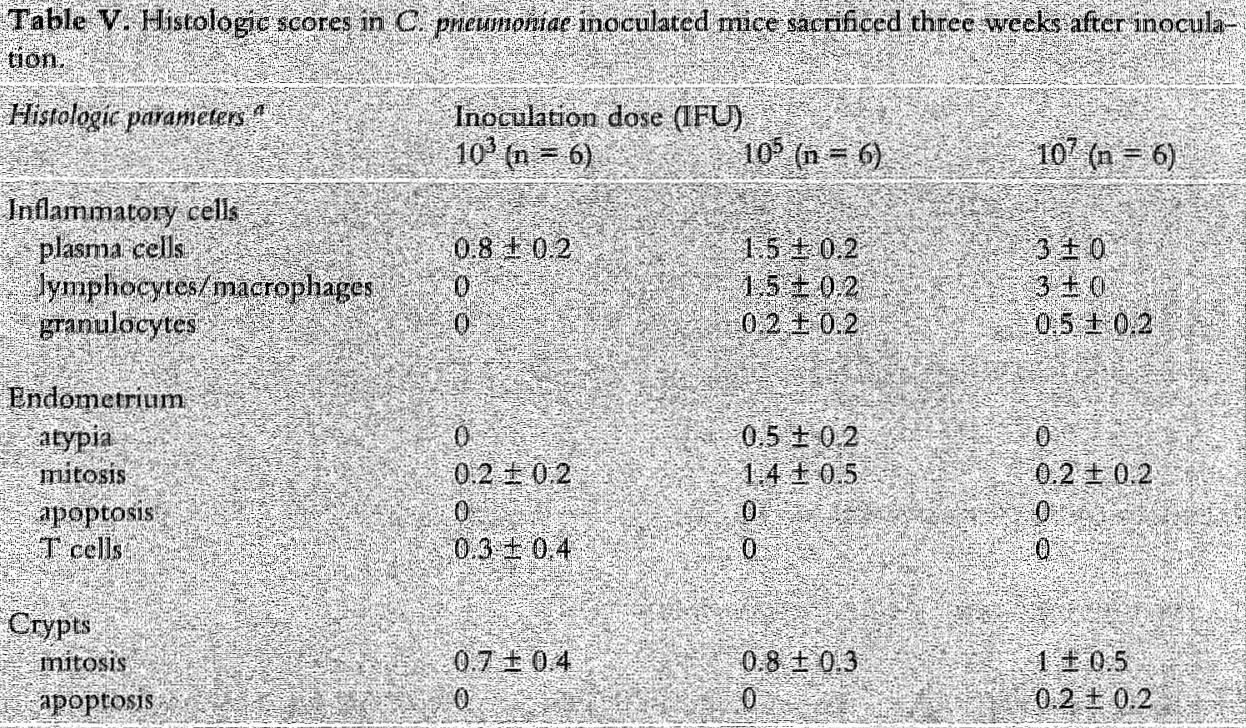

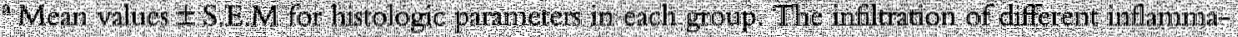

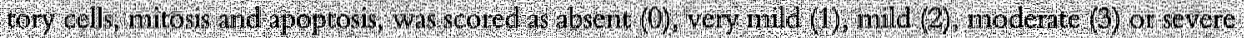

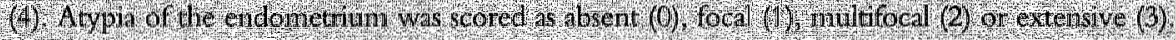

the time of re-inoculating of the $\mathrm{Cp}-\mathrm{Ct}$ mice has precluded from comparing them with single- $\mathrm{Cp}$ or $\mathrm{Ct}-\mathrm{Cp}$ inoculated mice. For the sake of completeness the results of the $\mathrm{Cp}-\mathrm{Ct}$ group are presented in the tables separately.

As shown in table VI, the presence of redness and paleness as parameters for gross genital tract parameters was not different between the single-Cp and $\mathrm{Ct}-\mathrm{Cp}$ groups. The single $-\mathrm{Cp}$ group showed no other abnormalities, while dilatation of uterine horns and tubes was observed in the $\mathrm{Ct}-\mathrm{Cp}$ group in 3 mice.

Due to technical problems in the preservation process, histologic material of all six mice in the $\mathrm{Ct}$-Cp group became unusable After single inoculation with $C$. pneumoniae mild to moderate infiltration of inflammatory cells in the stroma was observed, and the endometrium showed multifocal atypia. These results indicate that inoculation with $C$ pneumonice may induce genital tract inflammatory processes without the interference of $C$. trachomatis. Tables VI and VII summarise macroscopic and microscopic changes of the genital tract for the different study groups. 


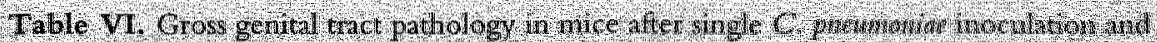

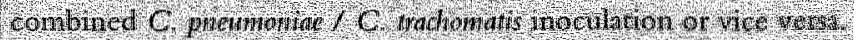

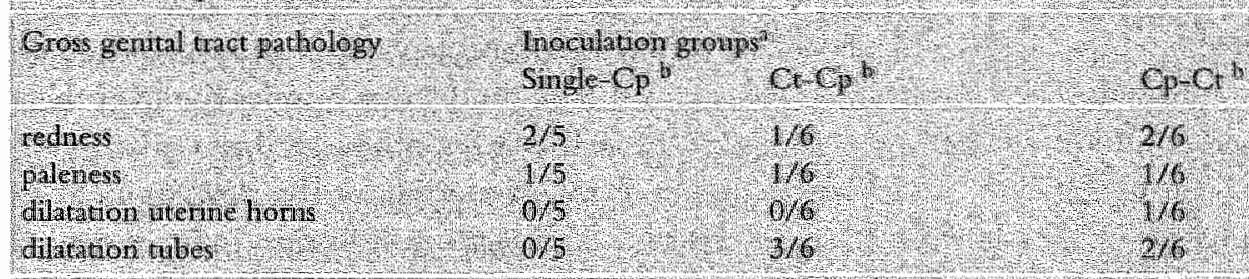

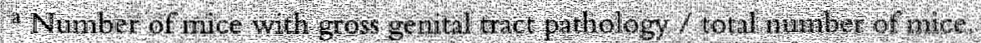

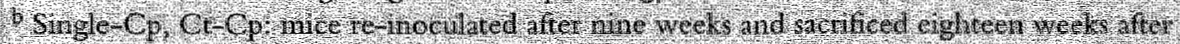

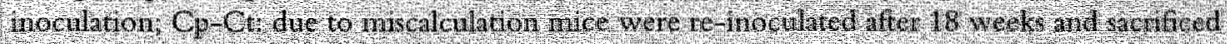
27 we ks after inoctiluion.

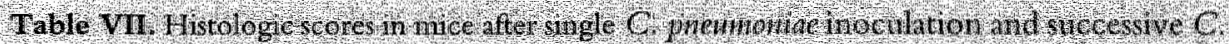
phennonice $/$, Mollondits moculation or vice versa

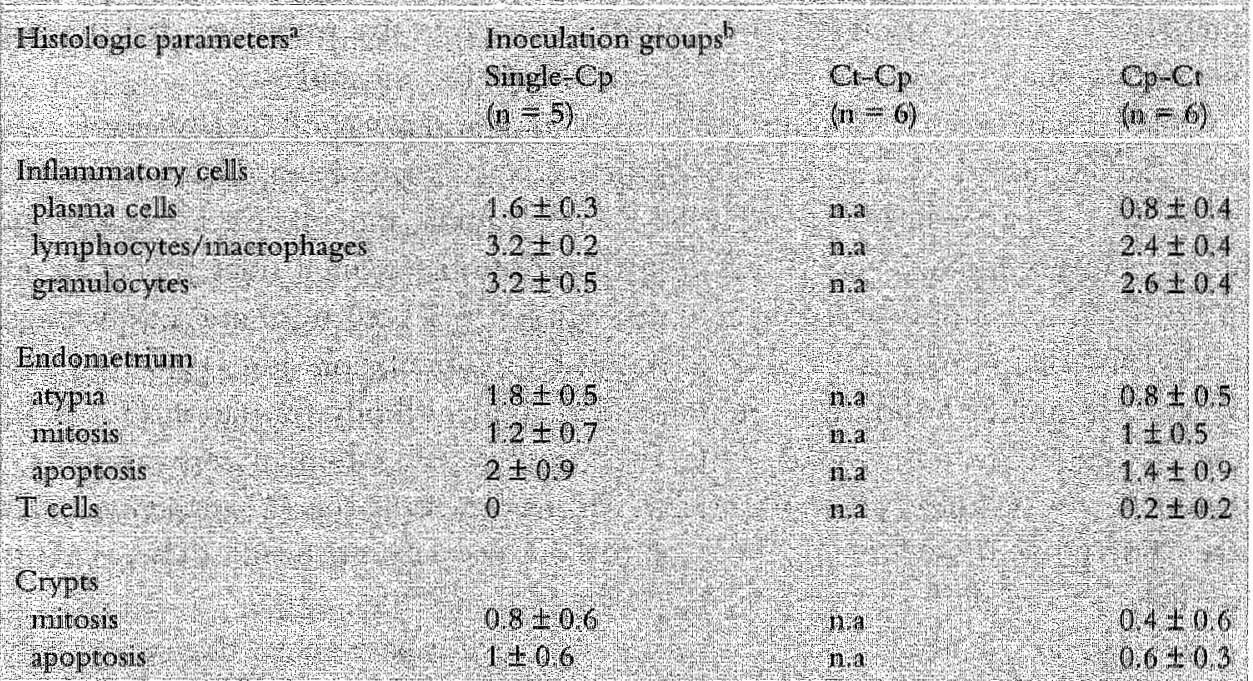

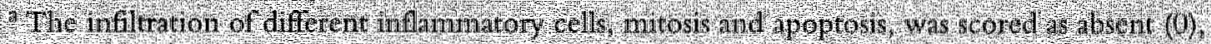

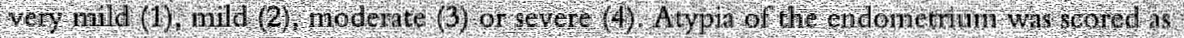

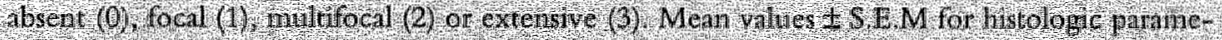
ters in each group.

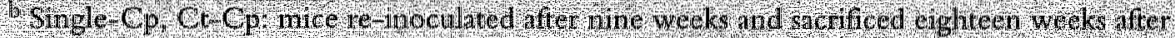

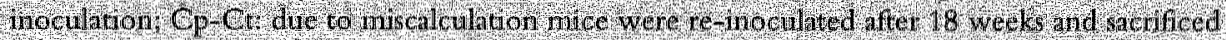
27 weeks afer inocilation.

n.a. not vallable? 


\section{Discussion}

In contrast to earlier animal studies which addressed acute PID and the induction of infertility, the current study presents a mouse model that mimics the hypothesised course of silent $C$. trachomatis infection. It was hypothesised that a primary $C$. trachomatis infection results in an immune response without the development of tubal pathology, and that a subsequent $C$. trachomatis re-infection induces genital tract pathology. In developing the model, knowledge was derived from earlier animal studies for $C$. trachomatis infections, in which acute PID with short-term infertility had been studied.

For our study, the choice for the C57BL/6J mouse was based on the study by De la Maza et al. (1994), who compared $\mathrm{C} 3 \mathrm{H}, \mathrm{Balb} / \mathrm{C}$ and $\mathrm{C} 57 \mathrm{BL} / 6 \mathrm{~J}$ mice in their ability to develop salpingitis and tubal pathology after intravaginal inoculation with $C$. muridarum, and found $\mathrm{C} 57 \mathrm{BL} / 6 \mathrm{~J}$ mice to develop the mildest disease. Since our main interest was to induce silent infections without extensive tubal pathology after the first inoculation, the $\mathrm{C} 57 \mathrm{BL} / 6 \mathrm{~J}$ mouse strain was chosen for our studies.

For the same reason in our studies $\mathrm{L}_{2}$, a human serovar of $C$. trachomatis was used. As compared to $C$. muridarum, human serovars have been shown to be less virulent in mice (Williams et al., 1981). After vaginal inoculation C. trachomatis human biovars induce a mild infection of the mouse genital tract (Perry et al., 1999). From our results we conclude that using C57BL/6J mice and intravaginal inoculation of a human C. trachomatis strain, high inoculation doses $\left(10^{7}\right.$ IFU) are required to induce an immune response with $\mathrm{IgG}$ antibody formation (Table $\mathrm{I}$ ). This finding is in agreement with other studies using human serovars of $C$. trachomatis (Johansson et al., 1997). However, studies using the C. muridarum agent have shown that much lower concentrations of the microorganism can be used for infection experiments (Perry et al., 1999; Pal et al., 1998).

No data are available in the literature on specific parameters that adequately reflect the changes associated with silent $C$. trachomatis infection of the genital tract in mice. Again, knowledge was derived from studies on acute $C$. trachornatis genital tract infection. It has been shown that genitall tract infection stimulates the immune response in the endometrium, inducing increased influx of inflammatory cells. Based on this, the number of inflammatory cells, and the presence of mitotic and apoptotic cells were scored as parameters for infection. Eventually, the stromal infiltration of inflammatory cells and endometrial atypia appeared to be the parameters specifically related to infection, since those are the parameters increasing with time after inoculation and after re-inoculation. However, the presence of mitosis and apoptosis was not clearly related to infection or re-infection.

We assumed the endometrium in silent Chlamydia infections to respond with increased cell activity, reflected in an increase in mitotic cells. In case of re-infec- 
tion, increased cell activity may result in cell death by apoptosis. Subsequently, apoptosis may induce atypia in the endometrium. Results in mice sacrificed nine weeks after single inoculation showed gross genital tract pathology (i.e. uterine and tubal dilatation) whereas those sacrificed eighteen weeks after inoculation seemed to have recovered. However, stromal inflammatory cells remained present, without the development of atypia in the endometrium. This may suggest a persisting chronic inflammatory process. After re-inoculation, the inflammatory response may be reactivated and finally the endometrium may be unable to recover, resulting in multifocal atypia. To evaluate whether gross genital tract pathology after re-inoculation would persist, a longer follow up period would have been necessary. The results are according to those found in trachoma, in which a primary infection primes the immune system and re-infection induces tissue damage (Grayston et al., 1985). The explanation for this chronicity miglit be that endometrium does not fully recover after a single inoculation, possibly due to the persistence of dormant, but still viable, Chlamydia (Barlow et al., 2001). It may be hypothesised that it is not re-infection with $C$. trachomatis per se, but reactivation of persistent Chllamydia that is able to chronically stimulate the immune responses which are responsible for the development of tubal pathology (Beatty $e t$ al., 1994).

From our C. pnetumoniae pillot study (part B), due to technical problems no major conclusions can be drawn. However, some observations will be discussed. It was postulated that $C$. pneumoniae is able to induce tubal pathology as well. The role of C. pneumoniae in the development of tubal pathology may be explained, by its high inter-species antigen homology with $C$. trachomatis. In case of an infection with a particular Chlamydia species, Chlamydia antigens will result in activation of the immune system, leading to the production of genus-specific and species-specific antibodies. It may be hypothesised that the genus-specific antibody response to $C$. pneamoniae may contribute to the development of tubal pathology.

Although a direct effect of C. pneumoniae on the genital tract might seem unlikely and in any case tmexpected, it has been suggested that $C$. pneumoniae dissemination can occur by circulating infected monocytes and macrophages spreading the microorganism via the blood and / or lymphatic system to almost all organs (Ezzahiri et al., 2002; Gieffers et al., 2001; Maass et al., 2000; Rupp et al., 2005). In mice, the microorganism has been detected by polymerase chain reaction (PCR) in the liver, spleen and lymph nodes following intranasal or intraperitoneal inoculation (Moazed et al., 1997). In accordance with this, $C$. pneumoniae may be postulated to directly affect the genital tract as well.

Summarising our results, the inflammatory response in mice after $C$. pneumoniae intraperitoneal inoculation on the genital tract is obvious. Although no 
major gross or microscopic genital tract pathology was observed in mice three weeks after single $C$. pnewmoniae inoculation, more inflammatory cells were present (table V) than after $C$. trachomatis inoculation (table III, single-3). Furthermore, eighteen weeks after inoculation, inflammatory response and atypia of the endometrium was more evident in $C$. pnetmonide (table VII, single-Cp) compared tó $C$. trachomatis inoculated mice (table III, single-18). Considering re-inoculation ( $\mathrm{Ct}-\mathrm{Cp}$ and $\mathrm{Cp}-\mathrm{Ct}$ ), data on histologic parameters are incomplete. However, whereas only redness was found in mice after single $C$. pnemnoniae inoculation, dilatation of uterine horns and tubes was found in $C$. pnewmoniae / $C$. trachomatis or vice versa re-inoculated mice (table VI). In C. trachomatis re-inoculated mice however (table II, re-inoc), more hydrosalpinges were described as compared to $\mathrm{Cp}-\mathrm{Ct}$ or $\mathrm{Ct}-\mathrm{Cp}$. Since a direct effect of $\mathrm{C}$. preumoniae on the genital tract is rather unexpected, the remarkable inflammatory response might be due to the intraperitoneal route of inoculation. Therefore, in future experiments, intrariasal inoculation should be considered, as this way of inoculation may better mimic the infection course in humans.

In conclusion; part $\mathrm{A}$ of the present study describes a mouse model that mimics the hypothesised course of mild Chlamydia infections in women, i.e. that primary C. trachomatis infections do not result in the development of extensive genital tract pathology. Our results indicate that single intravaginal inoculation of C57BL/6J mice with the human $C$. trachomatis $\mathrm{L}_{2}$ strain induces an infection without extensive pathology, but with a chronic inflammatory cell response. Re-inoculation stimulates this process, finally resulting in the induction of atypia in the endometrium. Changes at the tissue and cellular level were all more evident after re-inoculation, but were also mild. Despite our assumption, that extensive pathology would be found after re-inoculation, only mild genital tract pathology and histologic changes were found. This might be due to various factors in the model. We combined the use of C57BL/6J mice, which have demonstrated only mild disease in earlier studies (De la Maza et al, 1994), with the inoculation of a human C. trathomatis serovar, which has been shown to be less virulent in mice (Tuffrey et al., 1986a, 1986b, 1990). This combination might have led to only mild genital tract pathology after re-inoculation. When using a different strain of mice (e.g. $\mathrm{C} 3 \mathrm{H}$ or $\mathrm{BALB} / \mathrm{c}$ ), which has been shown to be more susceptible to $C$. muridarum (de la Maza et al., 1994), re-inoculation might have led to the induction of more extensive genital tract pathology. Furthermore, increase of the number of inoculations might reinforce the inflammatory response and tissue reaction in the genital tract. Rank and coworkers (1988) demonstrated a short-term immunity to re-infection in guinea pigs after primary inoculation, suggesting that lengthening the time interval between the initial and the re-inoculation might overcome the risk of mice still being immune following the primary inoculation. 


\section{References}

Barlow, $\mathbb{R}$.E., Cooke, I.D., Odukoya, O., Heatley, M.K., Jankins, J, Natryansingh, G, Ramsewak, S.S., Eley, A. (2001) The prevalence of Chamydia trachomatis in fredh tissue specimens from patients with ectopic pregnancy or tubal factor infertility as determined by $P C R$ and in situ bybridisation. J. Med. Microbrol, 10,902-908.

Barron, A.L., White, H.J., Rank, R.G., Solof, B.L., Moses, E.B. (1981) A new anmal model tor the study of Chlawydia trachomatis gental infections of mice with the agent of mouse pneumonitis. I. Infect. Dis, 143, 63-66.

Beatty, W.L., Momison, R.P., Byme, G.I. (1994) Persistent Chamydiae: from cell culture to a paradign for Chlanydial pathogenesis. Mirobiol. Rvv., 58, 686-699.

Brunham, R.C., Kuo, C.C., Chen, W.J. (1985) Systemic Chawydia tradtonatis infection in mice: a comparison of lymfogranuloma venereum and trachoma biovars. Infea. Immun, 48, 78-82.

Brunham, R.C., Peeling, R.W. (1994) Chlamydia todhomatis antigens: role in immunity. Infect. Agents. Dis., 3, 218-233.

Campbell, L.A., Kuo, C-C., Grayston, ] T. (1998) Chany dia phemmonat and cardiovascular disease. Emerg. Infect. Dis., 4, 57-579.

Cotter, T.W., Mirampuri, G.S., Ramsey, K.H., Poulsen, C.E., Byrne, G.I. (1997) Renctivation of Chlamydial genital tract infection in mice. Infect. Lwwun., 65, 2067-2073.

Everett, K.D., Bush, R.M., Anderssen, A.A. (1999) Emended description of the order Chlamydiales, proposal of ParaChlamydaaceae farn. nov, each containing one monotypic genus, revised taxonoray of the family Chlamydiaceae, including a new genus and five new species, and standards for the identification of the organisms. Int J. Syst. Bacteriol., 49,415-440.

Ezzahiri, R., Nelissen-Vrancken, HJ., Kurvers, H.A., Stassen, F.R., Vliegen, I., Grauls, G.E., van Pul, M.M., Kitslaar, P.J, Bruggeman, C.A. (2002) Chlawydophila pneumonide (Chlanydia premonac) accelerates the formation of complex atherosclerotic lesions in Apo E3-Leiden nice. Cardiovasc. Res, 56, 269-76.

Ezzahiri, R., Stassen, F.R., Kurvers, H.A., van Pul, M.M., Kitslaar, P.J., Bruggeman, C.A. (2003) Chamydia pnewrtoniae infection induces an unstable atherosclerotic plaque phenotype in LDL-receptor, ApoE double knockout mice. Eur. I. Vasc. Endovasc, Surg., 26,88-95.

Freidank, H.M. Clad, A., Herr, A.S. Wiedmann-Al-Ahmad, M., Jung, B. (1995) Inmune

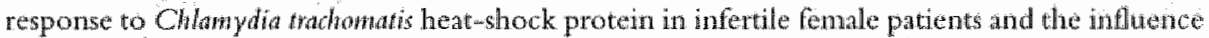
of Chlanydia phetumoniat antibodies. Eus. J. Clin. Microbial. Mnfea., 14, 1063-1069.

Gieffers, J., Füllgral, H., Jahn, J., Kinger, M., Dalhoff, K., Katus, H.A., Solbach, W., Maass, M. (2001) Chanydia pheumoniae infection in circulating human monocytes is refractory to antibiotic treatment. Cikulation, 103, 351-356.

Gijgen, A.P., Land, J.A., Goossens, V.J., Bruggemam, C.A., Evers, J.L.H. (2001) Chlamydia pneumoniae and screening for tubal factor subfertility. Hun. Reprod., 16, 487-491.

Grayston, JT. (2000) Background and current knowledge of Chanydiat phetwoniae and atherosderosis. J. Infect. Dis., 181 (Suppl 3), \$402-\$410.

Grayston, J.T., Gale, J.L., Yeh, L-J, Yang, C-Y. (1972) Parhogenesis and immunology of trachoma. Tran. Assoc. Am. Physicians. 85, 203-211.

Grayston, J.T, Wang, S-P, Yeh, L-J, Kuo, C-C (1985) Importance of reinfection in the pathogenesis of trachoma, Rey. Luferi. Dis., 7, 717-725.

Johansson, M., Schon. K., Ward, M., Lycke, N. (1997) Genital tract infection with Chanydia trachonatis fails to induce protective immunity in gamma intereron receptor-deficient mice despite a strong local imnunoglobulin A response. Infect. Inwmun., 65, 1032-1044. 
Karwonen, M. Twomilehto, J., Pitkänemi, J., Naukkarinen, A., Saikku, P. (1994) Chlamydiz pheumoniad IgG prewalence in South-Western and Eastern Findand in 1982 and 1987. Int, J. Epidem. 23, 1276-184.

Land, J.A., Gysen, A.P. Kessels, A. G.H., Slobbe, M.E.P., Bruggeman, C.A. (2003) Performance of five serological Chlanydia antibody tests in subfertle wonnen. Haw. Reprod, 18, 2621-2627.

Mass, M. Jahn, J., Gieffers, J., Dalhof, K., Katus, H.A, Solbach, W. (2000) Detection of Chlawydia pretwoniate within peripheral blood monocytes of patients with unstable angina or rinyocardial infection. J. Infect. Dis, 181 (Suppl 3), S449-S451.

De la Maza, L.M., Pal S. Khamesipour, A., Peterson, E.M. (1994) Intravaginal inoculation of mice with the Chlamydia trachonatis mouse pneunonitis biovar results in infertility. Infect. Immun., 62, $2094-2097$.

Moazed, T.C., Kua, C.C., Grayston, J.T., Campbell, L.A. (1997) Murine models of Chlamydia phomoniac infection and atherosclerosis. J. Infect. Dis., 175, 883-890.

Monnickendam, M.A., Darougar, S., Treharne, J.D., Tibury, A.M. (1980) Development of chronic conjunctivitis whth scarring and pannus, resembling trachoma, in guinea-pigs. Br. J. Ophohalmol., $64,284-290$

Monno, R., De Vito, D., Losito, G., Sibilio, G., Costi, A.,Fumarola, L, D"Aprile, A., Marcuccio, P. (2002) Chlanydia pneumoniae in community-acquired pneumonia: seven years of experience. J. Heat., 45, 135-138.

Morré, S.A., Lyons, J.M., Ito, J.I. (2000) Murine models of Chlatwydia trachowatis genital tract infection: use of mouse pneumonitis strain versus human strains. Infect. Lwmun, 68, 7209-7211.

Morris, H. Edwards, J., Tiltman, A. et al. (1985) Endometrial lymphoid tissue: an immunohistological study. J. Clin. Pathol, 38,644-652.

Morrison, S.G., and Morrison, R.P. (2000) In situ analysis of the evolution of the primary immune response in murine Chlamydia trachomatis genital tract infection. Infect. Inmun., 68, 2870-2879.

Moss, "T. R., Darougar, S., Woodland, S., Nathan, M., Dines, R.J., Cathrine, V. (1993) Antibodies to Chlamydia species in patients attending a genitourinary clinic and the impact of antibodies to C. presmoniae and $C$. psittaci on the sensitivity and specificity of $C$. trachomatis serology tests. Sex. Transm. Dis., 20, 61-65.

Paavonen, J. and Wolner-Hanssen, P. (1989) Chlamydia trachowtatis: a major threat to reproduction. Hinn. Reprod., 4, 111-124.

Pal, S., Hui, W., Peterson, E.M., de la Maza, L.M. (1998) Factors influencing the induction of infertility in a mouse model of Chamydia tradhomatis ascending genital tract infection. J. Med. Microbiol., 47, 599-605.

Patton, D.L. Kuo, C-C. (1989) Histopathology of C trahowatis salpingitis after primary and repeated reinfections in the nonkey subcutaneous pocket model. J. Reprod. Feril., 85, 647-656.

Patton, D.L., Kuo, C.C., Wang, S.P., Habert, S.A. (1987) Distal twabll obstruction induced by repeated Chlanydia trachowatis salpingeal infections in pig-tailed Macaques. J. Infect. Dis., 155, 1292 1299.

Pattou, D.L., Wolner-Hanssen, P., Cosgrove, S.J., Holmes, K.K. (1990) The effects of Chlamydia trachomatis on the fenale reproductive tract of the Macaca nemestrina after a single tubal challenge following repented cervical inoculations. Obstet. Oynecol., 76, 643-650.

Perry, L.L., Su, H. Feilzer, K., Messer, R., Hughes, S., Whitmire, W., Caldwell, H.D. (1999) Differential sensitivity of distinct Chamyda trabomatis isolates to IFN- $\gamma$-medated inhibition. J Lmmumol., 162, $3541-3548$.

Ramsey, K.H., DeWolfe, J.L., Salyer, R.D. (2000) Disease outcome subsequent to primary and secondary urogenital infection with murine or human biowars of Chlannydia tradomatis. Infect.

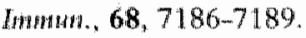


Rank, R.G., Batteiger, B.E., Soderberg, L.S.F. (1988) Susceptibility to reinfection after a primany Chlamydial genital infection. Infect. Imuntm, 56, 2243-2249.

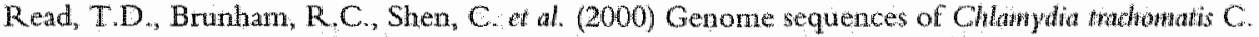
muridarum and Chlamydia pneumomae AR39. Nudenic Acids Res., 28, 1397-1406.

Rupp, J., Koch, M, van Zandebergen, G., Solbach, W., Brandt, E., Maass, M. (2005) Transmission of Chlamydia pneumoniae infection from blood monocytes to wasculat cells in a novel transendothelial migration model. FEMS Microbiol. Letr, 242, 203-208.

Swenson, C.E., Donegan, E., Schachter, J. (1983) Chlawydha trachonatis induced salpingitis in mice. J. Infert. Dis., 148, 1101-1107.

Swenson, C.E. and Schachter, J. (1984) Infertility as a consequence of Chlanydia infection of the upper genital tract in femalle mice. Sex. Transw. Dis, 11, 64-67.

Thejls, 战., Ralm, V.A., Rosen, G., Gnarpe, H. (1987) Correlation between Chlanydia infection and clinical evaluation, vaginal wet smear, and cervical swab test in female adolescents. Ain.J. Obstet. Gynecol., 157, 974-976.

Tuffrey, M., Alexander. F., Inman, C., Ward, M.E. (1990) Correlation of infertility with altered tubal morphology and function in mice with salpingitis induced by a human genital-tract isolate of Chlamydia trachonnatis. J. Reprod. Fertil., 88, 295-305.

Tuffrey, M., Falder, P., Gale, J., Taylor-Robinson, D. (1986a) Salpingitis in mice induced by human strains of Clatanydia trachomatis. Br. J. Exp. Pathol : 67, 605-616.

Tuffrey, M., Falder, P., Gale, J., Quinn, R., Taylor-Robinson, D. (1986b) Infertility in mice infected genitally with a human strain of Chlanydia trachomatis. J. Reprod. Fertil., 78, 251-260.

Tuffrey, M., Taylor-Robinson, D. (1981) Progesterone as a key factor in the development of a mouse model for genital tract infection with Chlawydia trachontatis. FEMS Microbiol. Lett, 12, $111-115$.

Weström, L., Mårdh, P.A. (1975) Effect of acute PID on fertility. Am. J. Ofstet. Gynecol., 121, 703-713.

White, H.J., Rank, B.L., Soloff, B.L., Barron, A.L. (1979) Experimental Chlanydial salpingitis in immunosuppressed guinea pigs infected in the genital tract with the agent of guinea pig inclusion conjunctivitis, Infect. Imwnun, 26,728-735.

Williams, D.M., Schachter, J., Drutz, DJ., Sumaya, C.V. (1981) Pneumoniae dae to Chlamydita trachomatis in the immunocompromised (nude) mouse. J. Infed. Dis, 143, 238-241.

Wong, Y.K., Sucur, J.M. Fall, C.H.D., Orfila, J, Ward, M.E. (1999) The species specificity of the microimmunofluorescence test and comparison with a time resolved fluoroscopic immunoassay for measuring $\mathrm{LgG}$ antibodies against Chlanydia pheswonve. J. Clim, Pathol, 52, 99-102. 


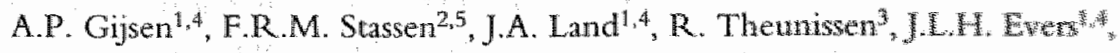
C.A. Bruggeman 2.5

Departments of Obstetrics and Gynaecology ${ }^{1}$, Medical Microbiology $y^{2}$ and Immunology ${ }^{3}$, Research Institute Growth and Developmen (GROW) Cardiovascullar Research Institute Maastricht (CARIM) ${ }^{5}$, Mastricht: the Netherlands 


\section{Introduction}

In the search for markers to be used in screening for tubal factor subfertility, it is important to elucidate its etiology. In this respect, it has been suggested that persistence of $C$. trachomatis infection in the host may be important (Debattista et al., 2003; Stephens, 2003). However mechanisms by which C. trachomatis induces tubal damage have not been determined exactly yet. It has been postulated that the immune response following repeated or chronic exposure to $C$. trachomatis antigens may form the basis for pathology resulting in tissue destruction (Brunham et al., 1985; Beatty et al., 1994a; Mabey et al., 2001). This immune response may either be protective or pathological, depending on the respective contributions of the humoral and cellular immunity. Stimulated by infection, $T$ helper (Th) lymphocytes will respond by following cellular or humoral immune responses, i.e. Th1 cells are involved in cellular immunity and Th2 cells are responsible for humoral immunity. Th1 and Th2 cells each produce distinct cytokines. It is the ability or inability to generate specific cytokines or cytokine patterns in response to a particular infection that will determine the clinical course of the infection, and whether this will result in successful clearance or persistence of the microorganism (Stephens, 2003).

In case of persistence, an autoimmune response has been supposed to underlie the process from persistent $C$. trachomatis infection to tubal pathology, with a central role for antibodies directed against heat shock protein 60 (hsp60) (Domeika et al., 1998). In clinical studies, Chsp60 antibodies, considered as markers of chronic infection, have already been associated with the development of tubal pathology (Toye et al., 1993; Arno et al., 1995; Claman et al., 1997).

Hsp60 is a nember of the heat shock protein family, a group of highly conserved cellular stress proteins, expressed by prokaryotic and eukaryotic cells under physiological conditions or in response to stress (e.g. heat or infection). They participate primarily in mediating intracellular functions, but they are also involved in protecting the cell from adverse effects on cellular metabolism due to stress. Since their amino-acid composition is highly conserved during evolution, hsps of highly divergent organisms are very similar to one another (Neuer et al., 2000). Wath respect to Chlamydia, Chlamydia hsp60 (Chsp60) shares approximately 50\% homology with the human hsp60 (Hhsp60).

Based on this high degree of homology, it has been suggested that antibodies, initially directed against Chsp60 may cross-react with Hhsp60 (Wick et al., 2001). This cross-reactivity may ultimately result in tissue damage when Hhsp60 is translocated to the cell membrane in cases of cellular stress. Such auto-immune mechanism has previously been suggested to be responsible for the adverse effects of chronic $C$. pnetmortiae infections in diseases such as atherosclerosis or arthritis 
(van Eden, 1999; Hannu et al., 1999; Kalayoglu et al., 2002; Schumacher et al., 1999; Wick et al., 2001; Xu et al., 1992 and 1996).

When extrapolating this auto-immune hypothesis to the development of tubal pathology, we postulate that a persistent $C$. trachomatis genital infection may not be directly responsible for the destruction of susceptible epithelial cells (with subsequent tubal damage), but that it induces the expression of Hhsp 60 on the surface of these cells instead. Assuming that repeated or chronic C. trachomatis infection additionally results in the production of Chsp60 antibodies (Beatty et al. 1994a and b), cross-reaction of Chsp60 antibodies with Hhsp60 expressed on tubal epithelial cells may consequently lead to tubal damage. Moreover, the development of tubal pathology might not only be induced by C. trachomatis hsp60 antibodies, but infections with 'antigenic related' microorganisms might also play a role. Because of its high antibody prevalence in subfertile women (Freidank et al., 1995; Gijsen et al., 2001), we postulated C. pneumoniae to be a possible contributor as well.

In the present study we evaluated whether Chlamydia- and mouse hsp60 (Mhsp60) antibodies could be detected in serum following C. trachomatis or C. pneumoniae infection in a mouse model, to evaluate whether auto-immunity, based on cross-reactivity could be the underlying mechanism of tubal pathology.

\section{Materials and methods}

\section{Microorganisms}

C. trachomatis (human serovar $\mathrm{L}_{2}$ ) and C. pnetmoniae (TWAR2043) were cultured in Hep-2C (ATCC CCL-23) monolayers as previously described (Roblin et al, 1992). The concentration of $C$. trachonatis inclusion forming units (IFU) was determined by titration in $\mathrm{Hep}-2$ cells and immunofluorescence staining with monoclonal ancibodies CF2 (Washington Research Foundation, Seattle, Washington, USA) and fluorescein-isothiocyanate-conjugate (FITC)-labeled rabbit anti-mouse conjugate (DAKO F313, Glostrup, Denmark). The concentration of C. pneumoniae IFU was determined by immunofluorescence staining with monocional antibodies RR402 (DAKO 6600, Glostrup, Denmark) and FITC-labeled rabbit anti-mouse conjugate (DAKO F313, Glostrup, Denmark).

\section{Animals}

Specific-pathogen-free (SPF) eight week old female C57BL/6J mice were obtained from Charles River Laboratories (Someren, The Netherlands). They were kept in an isolator-type cage under standard environmental conditions. Mice 
were given subcutaneous injections contaning $2.5 \mathrm{mg}$ of medroxyprogesteronacetate (Anovulin@); Produlab Phama, Raamsdonkveer, The Netherlands) in $100 \mu$ of phosphate buffered saline (PBS) ten and three days prior to inoculation with $C$ irachomath, $C$ pnewmoniae or PBS (control group), to synchronise oestrus (Tuffrey and Taylor-Robinson, 1981). For vaginal noculation the mice were manually restrained and the urine bladder emptied by light rubbing of the abdomen. This was performed to prevent the mice from expelling the inoculum by urinating immediately in response to the inoculation. For $C$. pneumoniae inoctiation mice were fixated manually, and $C$ pneumoniae was injected intraperitoneally as described by Ezzahir and coworkers (2002 and 2003).

Additionally, one group of sera, from mice participating in an atherosclerosis study, was added to the study (kindly provided by R. Ezzahiri, Department of Microbiology, Maastricht, the Netherlands). Consequently, the latter animals' characteristics were different. Seventeen week old SPF C57BL/6J mice were fed an atherogenic diet and injected with 10 monthly intraperitoneal inoculations of $5 \times 10^{7} \mathrm{HU} C$. pnewhoniae.

\section{Experimental design}

First, the presence of Chsp60 and Mhsp60 antibodies was determined in mice inoculated once at an age of 8 weeks with $10^{7}$ IFU C. trachomatis or C. pneumoniae. Mice were sacrificed at three (single-3), nine (single-9) and eighteen (single-18) weeks after inoculation. One mock infected group was included (PBS-control).

Further, sera from mice after intravaginal C. trachomatis and / or intraperitoneal C. pneumoniae re-inoculation were used Sera from three different groups were used: mice inoculated twice with $\mathrm{C}$. trachomatis ( $\mathrm{Ct}-\mathrm{Ct}$ group), mice inoculated with C. trachomatis and re-inoculated with $\mathrm{C}$. premmoniae (Ct-Cp group) and mice inoculated with $C$, pneumoniae and re-inoculated with $C$. trachomatis $(\mathrm{Cp}-\mathrm{Ct}$ group). For details, see legend of table II.

Finally, sera originating from mice that underwent 10 monthly repeated inoculations of $5 \times 10^{7}$ IFU C. pnewmoniae were included (10-Cp). Sera were collected at sacrifice, twenty-five days after the last inoculation. In order to assure that we tised sera from mice that were properly infected, only sera from mice that seroconverted for $C$. trachomatis and / or C. pnemmoniae $\operatorname{IgG}$, as determined by an indirect micro-immunofluorescent antibody technique (C. pneumoniae IgG Micro-IF, Labsystems, Helsinki, Finland), were included. 


\section{Chsp 60 and Mhsp $60 \operatorname{Jg} G$ antibody detection}

Antibodies to Chlamydia and mouse hsp 60 were determined in serum by an 'in-house' ELISA. This experimental assay has been developed in the Department of Immunology and performed according to the following procedure. Recombinant Chlanaydia hsp60 or recombinant mouse hsp60 (Stressgen Bioreagents, Victoria, $\mathrm{BC}$, Canada) were diluted to $5 \mu \mathrm{g} / \mathrm{ml}$ in $100 \mathrm{mM}$ carbonate buffer $\mathrm{pH}$ 9.6, and Maxisorp microtitre plates (NUNC, Roskilde, Denmark) were coated with $50 \mu \mathrm{l}$ per well; wells incubated with $50 \mu$ carbonate buffer only served as blank controls.

After coating overnight at $4^{\circ} \mathrm{C}$, plates were filled with $100 \mu \mathrm{l} /$ well of $1 \%$ BSA in carbonate buffer and incubated overnight at $4{ }^{\circ} \mathrm{C}$ to block remaining binding places. Plates were then washed three times with $0.05 \%$ Tween 20 in PBS pH 7.4 (PBS-T) and incubated for one hour at room temperature with $100 \mu \mathrm{l} /$ well of $0.05 \%$ Tween $20+1 \%$ bovine serum albumin (BSA; Merck, Darmstadt, Germany) in PBS (PBS-T-BSA). Sera were diluted 1/50 in PBS-T-BSA and $50 \mu \mathrm{l}$ of each serum was added in duplicate to both hsp60-coated wells and uncoated control wells; plates were then incubated overnight at $4^{\circ} \mathrm{C}$. After a five-fold wash with $10 \mathrm{mM}$ TRIS pH $8.0+150 \mathrm{mM} \mathrm{NaCl}+0.05 \%$ Tween 20 , plates were incubated with a $1 / 2000$ dilution of an alkaline phosphatase conjugated goat $F(a b){ }_{2}$ anti-mouse IgG Fc (Jackson Laboratories, Pennsylvania, USA) in $100 \mathrm{mM}$ TRIS $+300 \mathrm{mM} \mathrm{NaCl}+0.05 \%$ Tween $20 \mathrm{pH} 8.0$ for 1 hour at $37^{\circ} \mathrm{C}$. After a final five-fold wash with TRIS/NaCl/Tween, $100 \mu$ of NPP/DEA substrate was added. Optical density (OD) was read after 60 minutes at $405 \mathrm{~nm}$. For each serum sample, mean $O D$ value of uncoated wells was subtracted from mean $O D$ value in hsp-coated wells; samples were considered positive if the resulting net OD exceeded 0.1 . Mouse serum samples, strongly seropositive or negative during earlier pilot studies to both Chsp60- and Mhsp60 lgG, served as positive and negative control samples for the test. These samples were added to each microtitre plate. In all cases, the positive control was seropositive indeed and the negative control remained seronegative.

\section{Results}

Table I summarises the results of serum Chsp60 and Mhsp60 IgG antibodies in mice three, nine and eighteen weeks after a single $10^{7}$ IFU $C$. trachomatis or $C$. pneumoniae inoculation. All mock infected mice (PBS-control group) remained seronegative. No antibodies were found in mice three and eighteen weeks after single C. trachomatis inoculation. In only 1 out of 16 mice, Chsp $60 \lg G$ antibodies 


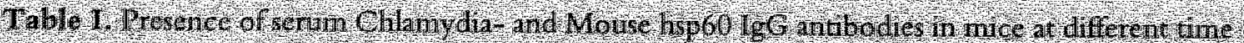

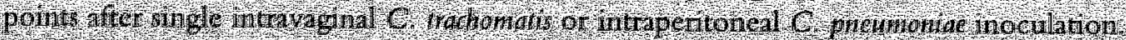

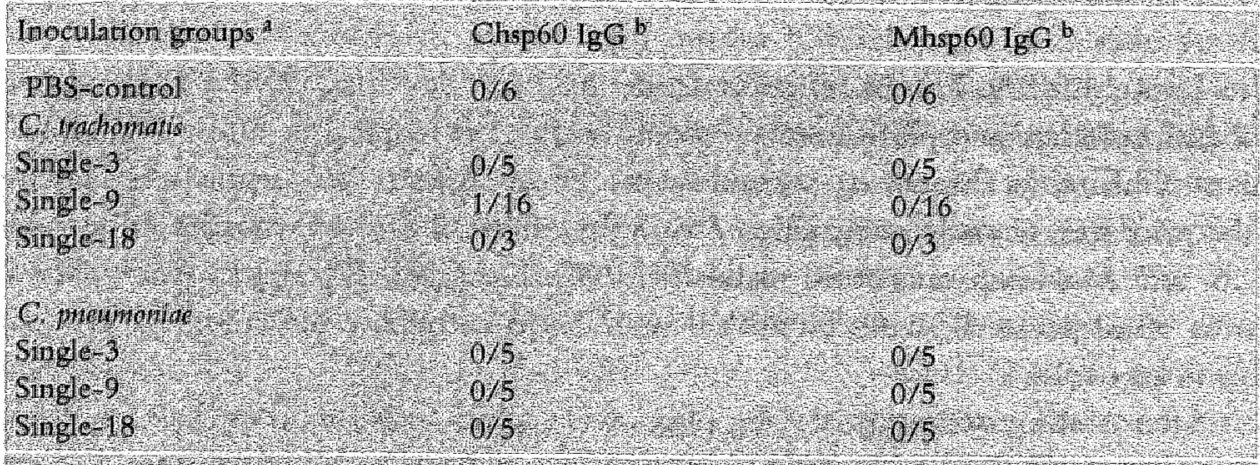

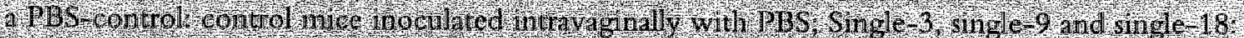

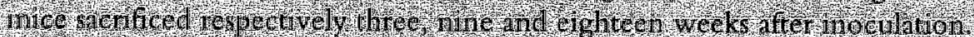

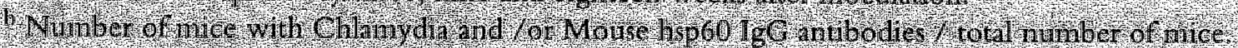

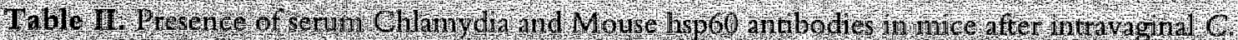

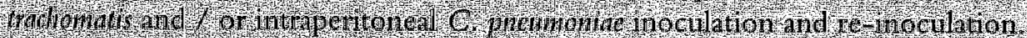

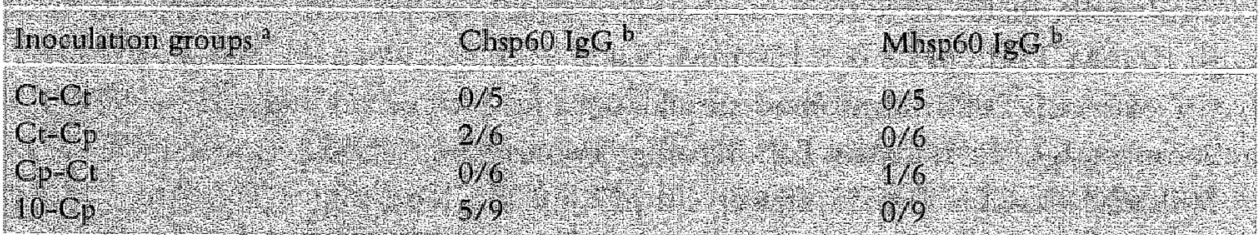

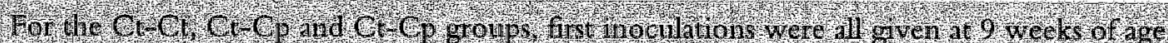

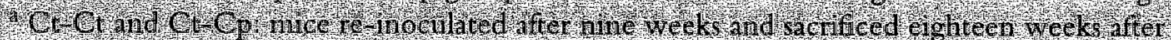

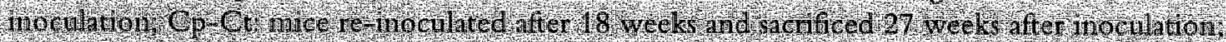

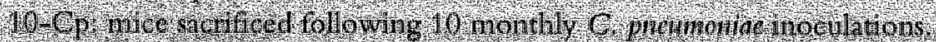

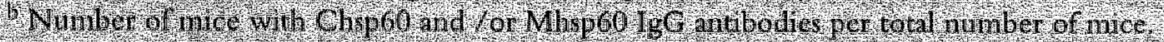

were found nine weeks after $C$. trachomatis inoculation. In none of the $C$. trachomatis inoculated mice serum Mhsp60 antibodies were found.

C. pnewmoniae inoculated mice did not show Chsp60- or Mhsp60 IgG antibodies after a single inoculation.

As shown in table II, serum Chsp60 and Mhsp60 IgG antibody formation in mice after re-inoculation was low: only 2 out of 17 mice showed Chsp60 IgG antibodies and in one mouse Mhsp60 IgG antibodies were found. In the sera from mice adopted from the atherosclerosis study, 5 out of 10 animals showed Chsp60 $\operatorname{lgG}$ antibodies, but no Mhsp60 IgG seroconversion was found. 


\section{Discussion}

In this mouse model we evaluated whether single or repeated $C$. machomatis and / or C. pnewmonine infections resulted in the formation of antibodies directed at Chsp60. Additionally we determined whether this was accompanied by the formation of auto-reactive antibodies, cross-reacting with Mhsp60, which may support the hypothesis that auto-inmune processes contribute to the pathogenesis of Chlarnydia induced tubal pathology. Single inoculation of C57BL/6J mice with either C. trachomatis or C. pnemmoniae resulted in Chsp60 antibody formation in only $3 \%$ of the animals, and no cross-reactive Mhsp60 antibodies could be detected. Re-inoculated mice showed Chsp60 and Mhsp60 antibodies in 12 and $6 \%$ of cases respectively. Frequent re-inoculation, i.e. 10 monthly intraperitoneal C. pneumoniae doses, increased the Chsp60 IgG antibody level to $56 \%$, but also in these mice no Mhsp60 antibodies were detected. Since all mice were $C$. trachomatis and / or C. pneumoniae $\operatorname{lgG}$ seropositive, it can be excluded that these negative results are due to unsuccessful inoculations of the mice. However, we cannot eliminate the possibility that infections had been successfully cleared, and that it was not possible to induce a persistent or chronic infection with the subsequent production of Chsp60 and /or Mhsp60 antibodies in these mice (Brunham and Rey-Ladino, 2005). This may eventually be related to the inherent predisposition of the C57Bl/6J mouse strain to develop a specific immune response, which results in the early eradication of infection (Darville et al., 1997) before chronicity develops and hsp antibodies are formed. Furthermore, it has been demonstrated that this specific mouse strain develops poor immunity against Chlamydia, which may explain the absence of (auto-reactive) antibodies against hsp60 (Huang et al, 2002). This is in contrast to findings by Erkkilä and coworkers (2004), who did show Mhsp60 antibody formation in C57BL/6J mice after repeated intranasal C. pneumoniae infection combined with a cholesterol-enriched diet. Therefore, instead of Mhsp 60 antibodies not being produced, it may as well be that the antibodies, although present, were not detected by our assay. Until now, no commercial assay is available for Chsp60 and Mhsp60 antibody detection in mice. The assay we used is still experimental. It has been developed for human serum. And although this assay has been evaluated thoroughly in experimental settings, it is possible that Mhsp60 antibodies can not be properly detected with the assay. The fact that no Mhsp 60 antibodies could be detected may theoretically be due to the biochemical conformation of the recombinant Msp60 used. It is possible that even small structural differences between the recombinant Mhsp60 and mouse hsp 60 are crucial for recognition, subsequently leading to failure of Mhsp60 $\mathrm{lgG}$ antibody attachment. Finally, as postulated by Stephens (2003), pathogenesis might primarily be based on cellular responses instead of auto-immune reactivity. In this 
hypothesis, Chsp60, produced during (persistent) infection might play a role in the induction of cellular responses rather than auto-immunity (Stephens, 2003).

In conclusion, the results of the pilot studies in our mouse model do not support the contention of auto-immunity, based on cross-reactivity between Mhsp 60 and Chsp60 IgG antibodies, since Chsp60- and Mhsp60 IgG antibody levels, even in frequently re-infected mice, were low or absent. Further studies are needed to assess the relationship, if any, between $C$. trachomatis and $C$. pneumoniae induced immune-mediated pathogenic mechanisms and the development of tubal pathology. 


\section{References}

Arno, JN, Yuan, Y. Cleary, RE, et al (1995) Serologic responses of infertile women to the $60 \mathrm{kD}$ Chlamydial heat shock protein (hsp). Fertil. Strenl., 64, 730-735.

Beatty, W.L., Byrne, G.I Morrison, R.P. (1994a) Repeated and persistent infection with Chlamydia and the development of chronic inflammation and disease. Trends Mowbiol, 2, 94-98.

Beatty, W.L., Morrison, R.P., Byrne, G.I. (1994b) Persistent Chlanydiae: from cell culture to a paradigm for Chlamydial pathogenesis. Micobsul. Rev, 58, 686-699.

Brumham, R.C., Kuo, C.C., Chan, W.J. (1985) Systemic Chlamydia mohomatis infection in nice: a comparison of lymphogranuloma venereum and trachoma biovans. Infect. Immun, 48, 78-82.

Brunham, R.C. and Rey-Ladino, J. (2005) Immunology of Chlanydia infection: implications for a Chlamydia trachomatis vaccine. Nature Reviews, 5, 149-161.

Claman, P., Honey, L., Peeling, R.W., Jessamine, P., Toye, B. (1997) The presence of serum antibody to the chlamydial. heat shock protein (CHSP60) as a diagnostic test for tubal factor subfertility. Fertil. Steril., 67, 501-504.

Darville, T., Andrews, C.W., Laffoon, K.K., Shymasani, W., Kishen, L.R., Rank, R.G. (1997) Mouse strain-dependent variation on the course and outcome of Chlamydial genital tract infection is associated with differences in host response. Infection and Imwwnity, 65, 3065-3073.

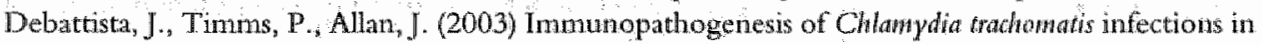
women. Fettil. Steril, 79, 1273-1287

Domeika, M., Domeika, K., Pavonen, J., Mårdh, P.A., Witkin, S.S. (1998) Humoral immune response to conserved epitopes of Chlanydia trachonatis and human $60-\mathrm{kD}$ a heat shock protein in women with pelwic inflammatory disease. J. Infect. Dis, 177, 714-719.

van Eden, W. (1999) Immunity to heat shock proteins and arthritic disorders. Inf. Dis. Obstot. Gymecol, $7,49-54$.

Erkkilä, L., Laitinen, K., Haasio, K., Tïrola, T., Jauhiainen, M., Lehr, H.A., Aalto-Setälä, K., Saikku, P., Leinonen, M. (2004) Atherosderosis, 177, 321-328.

Ezzahiri, R., Nelissen-Vrancken, H.J., Kurvers, H.A., Stassen, F.R., Vliegen, 1., Grauls, G.E., van Pul, M.M., Kitslaar, P.J., Bruggeman, C.A. (2002) Chlanydophila pneumoniae (Chamydia pneswowide) accelerates the formation of complex atherosclerotic lesions in Apo E3-Leiden mice. Cardiovase. Res., 56, 269-76.

Ezzahiri, R., Stassen, F.R., Kurvers, H.A., van Pul, M.M., Kitslaar, P.J., Bruggenan, C.A. (2003) Chlawydia presumonine infection induces an unstable atherosclerotic plaque phenotype in LDL-receptor, ApoE double knockout mice. Eur. J. Was. Endovak. Suk "26, 88-95.

Freidank, H.M., Clad, A., Herr, AS., Wiedmann-AJ-Ahinad, M. Jung, B. (1995) Immune response to Chlamydia trachomatis heat-shock protein in infertile female patients and the influence of Chlamydia pnenswoniae antibodies. Eur. J. Chn. Micobiol. Infoct. 14, 1063-1069

Gijsen, A.P., Land, J.A., Goossens, V.J. Bruggenan, C.A., Evers, J.L.H. (2001) Chlanydia phemoniae and screening for tubal factor subfertility. Hum. Reprod., 16, 487-491.

Hannu, T., Puolakkimen, M., Leirisalo Repo, M. (1999) Chlanydia pmewnoniae as a triggering infection in reactive arthritis. Rhewmatology (Oxford), 38, 411-414.

Huang, J., DeGraves, F.J., Lenz, S.D., Gao, D., Feng, P., Li, D., Schlapp, T., Kaltenboeck, B. (2002) The quantity of nitric oxide released by macrophages regulates Chamydia-induced disease. P.N.A.S., 99, 3914-3919.

Kalayoglu, M.V., Libby, P., Byrne, G.I. (2002) Chlanydia prewmoniae as an emerging risk hetor in cardiovascular disease. JAMA, 288, 2724-2731.

Mabey, D. and Fraser-Hurr, N. (2001) Trachoma. B.M.j, 7306, 218-221. 
$120 \mid$ Chapter?

Nener, A, Spandorfer, S.D., Gialdo, P., Dieterde, S., Rosenwaks, Z, Witkin, S.S. (2000) The role of heat shock proteins in reproduction. Hum. Reptod. Update, $6,149-159$.

Roblin, P.M, Dumonay, W, Hammerschlag, MR. (1992) Use of HEP-2 cells for improved isolation and passage of Chlampha prommonae. I Clin. Microbiol. 30, 1968-1971.

Schumacher, HR, Gerard, H C., Araysis, TK, al (1999) Lower prevalence of Chlamydia pnembnia DNA conpare with Chlanjdid trochomans DNA in synovial tissue of arthritis pactens Athits Rhemnarism, $42,1889-1893$.

Stephens, 1K S (2003) The cellular paradigm of chlamydial pathogenesis. TRENDS Microbiol, 11, 44-51.

Tuffrey, M. Taylor-Robinson, D, (1981) Progesterone as a key factor in the development of a nouse model for genutal tract infection whth Chlawydia evachomatis. FEMS Microbiol. Lett., 12, 111115

Toye, B. Laferriere, C., Claman, Pet al. (1993) Association between the Chlamydial heat shock proten and tubal infertility. J Infect. Dis, 168, 1236-1240.

Wick, $G$, Perschinka, H, Millonig, $G$. (2001) Atherosclerosis as an autoimmune disease an update. TRENDS Imwนm, 22, 665-669.

Xu, Q. Dierriech, H., Steiner, H.J., Gown, A.M., Schoel, B., Mikuz, G., Kaufmann, S.H.E, Wick, G. (1992) Induction of arteriosclerosis in nomocholesterolemic rabbits by immunization with heat shock protein 65. Arterioder. Thromb., 12, 789-799.

$\mathrm{Xu}, \mathrm{Q}$. and Wick, $\mathrm{G},(1996)$ The role of heat shock proteins in ptotection and pathophysiology of the arterial wall. Mol. Med. Today, $2,372-379$. 


\section{eneral Discussion}

\section{C. trachomatis course of infection}

C. trachomatis is a major cause of sexually transmitted urogenital tract infection in men and women. Manifestations and consequences affect woman's health more than man's. Infection in women starts with invasion of the endocervical epithelium with $C$. trachomatis elementary bodies. From this point onwards the infection may run a symptomatic or an asymptomatic course. In the majority of cases infections remain asymptomatic (Peipert, 2003), and are therefore left untreated, which may enable the organism to ascend into the upper genital tract causing pelvic inflammatory disease (PID). PID may either resolve spontaneously, progress to symptomatic PID, or lead to asymptomatic (silent) PID with a risk of developing late sequelae. In this latter case patients suffering from late sequelae may eventually present with chronic pelvic pain, ectopic pregnancy or subfertility (Wiesenfeld et al., 2002). Figure I schematically present the various symptomatic and asymptomatic courses of $C$ itrachomatis genital tract infection and possible clinical manifestations.

In this general discussion, topics that have contributed to the current understanding and approach of asymptomatic C. trachomatis infections and its late sequelae will be highlighted, using figure I for guidance. More specifically, attention will be paid to screening for tubal factor subfertility by serum Chlamydia Antibody Testing (CAT), as this is the main subject of the present thesis. Finally, the most important findings of the present investigations will be summarised.

\section{Spontaneous clearance}

Although data on the natural course of $C$. trachomatis infections are rather poor, it has been shown that cervical infections may resolve spontaneously (Golden et al, 2000; Brunham and Rey-Ladino; 2005). Previous studies showed spontaneous clearance rates between $16-50 \%$, with $7-18 \%$ development of symptomatic PID 
$1221^{\text {Chapten } 8}$




(McCormack et al., 1979; Rahm et al, 1986). However, those studies concerned only small patient groups and used conventional and rather insensitive $C$. trachomatis detection systems. Morré and coworkers (2002) studied thirty women with a $C$. trachomatis positive urine sample in a cohort based nested case-control study $(\mathbf{n}=744$ women). Urine specimens at one, six and twelve months were analysed for the presence of $C$. trachomatis-DNA, and questionnaires, concerning demographic and sexual behaviour variables and questions on self-reported urogenital complaints, were completed The findings of this study showed that, without using antibiotics, almost half of the asymptomatic $C$. trachomatis infections in women cleared during one year of follow-up, and that none of the untreated $C$. trachomatis positive women developed symptomatic PID. Molano and coworkers (2005) performed a 5-year follow-up analysis of asymptomatic C. trachomatis-positive women. They retrospectively used clinical specimens (i.e. cervical smears) for polymerase chain reaction analyses (PCR) and questionnaire data of women originally participating in a study on the natural course of human papillomavinus infection in relation to cervical intraepithelial neoplasia. In accordance with Morré and coworkers, approximately $46 \%$ of the infections were persistent at 1 year. In $18 \%$ infections persisted at 2 years of follow-up, and in $94 \%$ of the women, $C$. trachornatis infections had cleared spontaneously without causing complaints at 4 years of follow-up.

\section{Microorganism related factors associated with infection outcome}

Whether C. trachonatis leads to symptomatic or asymptomatic infection, and whether infection leads to sequelae might be due to various factors. Among those, serovar specific properties have been suggested, based on variation in the major outer membrane protein. First, in the earlier described study of Molano on sponta neous clearance, differences in rate of clearance were found between serovars (Molano et al., 2005). Serovars were grouped on the basis of amino acid similarity: group $B$ (serovars $B, D$ and $E$ ), group $C$ (serovars $H, I, J$ and $K$ ) and an intermediate group (serovars $F$ and $G$ ). Of the serovars identified in single-serovar infections, $35 \%$ belonged to group $\mathrm{B}, 29 \%$ to group $\mathrm{C}$ and $36 \%$ to the intermediate group. The most common serovars identified were D, E, F and $G$. The rate of clearance was lower for serovars of groups $B$ and $C$ than for serovars of the intermediate group. The authors suggested this higher rate of persistence of groups $\mathrm{B}$ and $\mathrm{C}$ serovars to be due to an ability to escape the host immune response (Mollano et al., 2005).

The association between serovars and clinical manifestation of cervical infection has been studied by several groups (Persson et al., 1993; Workowski ef al., 
1994, Dean et al., 1995, van de Lar et a., 1996). None of them found an association between specific clinical manifestations and certain serovars or genotypes of serovars, suggesting no serovar specific differences in virulence. Van Duynhoven and coworkers (1998) however, were the first to suggest an association between C. trahomatis genotypes and patients' self reported symptoms. In women, genotypes of the $F$ and $G$ groups seemed to cause more complaints of lower abdominal pain. Sign upon examination (such as easily induced bleeding of the cervix; cervical ectopy and mucopunalent discharge) were not associated with any $C$. trachomals genotype. However, the study concemed a small number of symptomatic women, and before these C. trachomatis genotypes can serve as prognostic indicators for complicated infections of the upper genital tract, the association needs to be confimed in larger studies. To some extent, the association is supported by a study in 33 women with cervical or endometrial infections. Variants of genotype F were associated with PID and presence of plasma cells and neutrophils in the endometrium (Dean et al.; 1995).

To determine whether certain $C$. thachomatis serovars are preferentially associated with a symptomatic or an asymptomatic course of infection, $C$. trachomatis serovar distributions were analysed in symptomatic and asymptomatic nales and females (Morré et $a /, 2000$ ). The most prevalent serovars (D, E and F), comprising $73 \%$ of the $C$. trachomatis serovars, showed no association with either a symptomatic or asymptomatic course of infection. However, differences were found for the less frequent $C$. trachomatis serovars: serovar $G$ a was associated with dysuria in men, serovar la was detected only in asymptomatically infected persons. Furthermore, serovar $\mathrm{K}$ was associated with the specific clinical symptom of abnormal vaginal discharge in women (Morré et al., 2000).

Taken together, some associations were detected, although the observed inconsistencies in reported results warrant further investigation to establish whether a causal relationship exists between serovar and virulence.

\section{Host related factors associated with infection outcome}

Host variation might also play an important role in the susceptibility for $C$. trachomatis infection and in the outcome of an infection. The use of human leucocyte antigen (HLA) typing revealed that PID was related to specific HLA types (Cohen et al., 2000 and 2003; Ness et al., 2004). Differences in HLA types may be responsible for the fact that not all women with previous $C$. trachomatis infections develop late sequelae such as tubal pathology. For example, the balance between the $T$ helper $\mathbb{1}$ (Th) $\mathbb{1}$ and Th 2 immune response, characterized by interferon (IFN)- $\gamma$ or interleukin (IL) 10 secretion respectively, has been suggested to be 
controlled by epitopes selected by the HLA class II molecules. An association of the cellular immune response to Chamyda hsp 60 (Chsp60), HLA class II alleles and $1 \mathrm{~L}-10$ promoter genotypes was revealed in patients with $\mathrm{C}$. trachomatis tubal factor subfertility (Kimmunen et al., 2002). Cohen and coworkers (2003) studied the presence of certain HLA class II alleles and polymorphisms in selected cytokine genes and compared the results among tubal factor subfertility patients with and without $C$. trachomatis antibodies. They found that two class II alleles were detected less commonly in sero-positive than in sero-negative women, and suggested that these alleles may induce an immunologically mediated mechanism of protection against $C$. trachowatis infection, or alternatively increase the risk for tubal scarring due to another cause.

Morré and Lyons and coworkers (2003 and 2004 a) investigated polymorphisms in a gene encoding for Toll like receptor 4 function, a receptor supposed to play an important role in $C$. trachomatis infection outcome. Their study did not confirm any over-or under-expression of polymorphisms of the gene in women with or without tubal pathology. Furthemore they investigated the role of IL-1B and IL-1 receptor antagonist gene polymorphisms in tubal pathology, and the presence of these gene polymorphisms in $C$. trachomatis $\lg G$ positive women with and without tubal pathology. Although the $\mathrm{IL}_{\mathrm{L}}-1$ gene cluster has been linked to inflammatory and infectious diseases, their data suggested that specific $1 \mathrm{~L}-1$. gene polymorphisms are not associated with tubal pathology or with the development of C. trachomati-based post-infectious sequelae (Murillo et al, 2003).

The host genetic background may still be an additional variable influencing the susceptibility to and the course of $\mathrm{C}$. trachomatis infection, but so far there is little evidence to support this.

\section{Screening for asymptomatic C. trachomatis cervicitis}

Since the majority of $C$. trachomatis cervicites remains asymptomatic, these infections are left unrecognised and hence untreated; unless screening is being performed. Community based screening programs for asymptomatic $C$. trachomatis infections have been the subject of interest of several large-scale studies. The aforementioned study by Morté and coworkers (2002) on spontaneous clearance of microorganisms, suggested that the eventual clinical complication rate of asymptomatic $C$. irachomatis infections might be much lower than the previously published 2-20\% (Paavonen et al., 1998; Weström et al., 1992). As a consequence, their study questions the usefulness of screming programmes, since the $C$. trachomatis prevalence above which screening may be cost effective; might be much higher than the $3.9 \%$ calculated by Paavonen and coworkers (1998). 
Recently, three studies on cost-effectweniess of screening women for asymptomatic $C$ trachomatis infections were reviewed (van Valkengoed et al, 2004). In all three studies, the decision models are based on assumptions about the risk of complications (1.e. expected complication rates). The expected rate for developing PUD varied from 15 to $80 \%$ (symptomatic and as ymptomatic PID). For toubal infertility, ectopic pregnancy, and chronic pelvic pain after an asymptomatic Chamydia infection the expected rates were $10-20 \%, 5-25 \%$ and $18-30 \%$ respectively. In addition, the probability of complications of $\mathrm{C}$. rachomatis was calculated based on avallable registration data and data from several studies (i.e. observed complication rates). The observed complication rates were $0.43 \%$ clinical PID, $0.02 \%$ tubal infertility and $0.07 \%$ ectopic pregnancy. For all complications of $C$. trachwatis, the expected complication rates are higher than the observed conplication rates. Therefore, our curtent estimate of the complication rates after asymptomatic C. trachomatis infection is likely to be too high. The effect of overestimation is potentially the largest in populations with a low prevalence, and the currently assumed cost savings associated with screening may disappear when using more realistic estimates for complications.

In accordance with the Dutch Institute for Health Care Improvement revised guideline (Bleker ef al, 2003), community based screening for asymptomatic $C$. trachomatis infections has been designated for Amsterdam, a high-risk area, since it was calculated to be cost effective there. For other parts of the country, prevalence studiles should be performed first. Until these studies will be available, according to the same guideline, risk groups eligible for screening on $C$. trachowatis infection in the Netherlands include: partners of C. trachomatis-positive persons, visitors of clinics for sexually transmitted diseases, women who will undergo an induced abortion, mothers of newborns with conjunctivitis or pneumonitis, young persons of Surinam or Antillean descent, young women with new sexual relationships and individuals whose history indicates risky sexual behaviour.

\section{Persistence of C. trachomatis infection and clinical implications for subfertility patients}

The ability of $C$. trachowatis to persist in the genital tract is becoming increasingly evident (Beatty et al, 1994b and 1995). This persistence is characterised by incomplete Chlanydia replication and the formation of atypical reticulate bodies (RBs), which are unable to differentiate into infectious progeny (Beatty ef al., 1994a; Koebler et al., 1997). The duration of persistence in vivo is not known, but recent evidence suggests that organisms may persist for as long as 5 years in the genitall tract (Dean et al., 2000). 


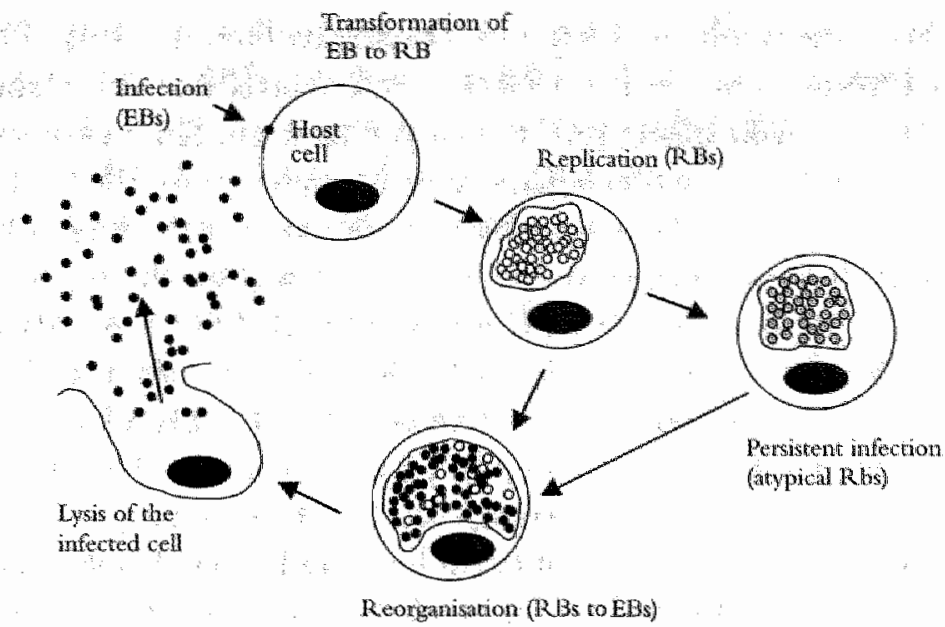

Figure I. Revised Chlamydia developmental cycle of infection and replication. EB is elementary body and RB is reticulate body. Persistent Chlamydia infection is characterised by incomplete Chlamydia replication and the formation of atypical RBs.

The ability of C. trachomatis to become "reactivated" from a persistent state has been demonstrated in both mice (Cotter et al., 1997), humans (Forsey et al., 1990) and in vitro (Beatty et al., 1993). The aberrant forms again recover the shape of normal $\mathbb{R B s}$ and replication may resume. The mechanism leading to persistence and the capacity to enter into a reversible latent form have not been fully defined in vivo. Figure II schematically depicts a revised C. trachomatis life cycle in which persistence of $C$. trachomatis is incorporated.

The ability of $C$. trachomatis to persist may have clinical relevance for subfertility patients. Since most of these patients will undergo uterine instrumentaition as part of their fertility workup, they are, in case of an active or persistent $C$. trachomatis endocervical infection, at risk for induction of an ascending infection. Different intervention strategies have been proposed for the prevention of ascending infections by uterine instrumentation. In chapter 5 of the present thesis we discuss screening for endocervical $C$. trachowatis infections in subfertility patients before uterine instrumentation. We argue that endocervical PCR screening is inappropriate since not all persisting Chlamydia infections can be identified in cervical samples. Because of these "false negative" PCR results, selective treatment of only positive cases will not suffice. Furthermore, screening by CAT is unsuitable as well, since it will only determine previous exposure to the organism, without providing information as to whether viable Chlamydia will be actually present (Thomas et al., 2000). Furthermore, negative CAT does not exclude C. trachomatis cervical infection, since cervical infections only rarely cause 
a rise in Chlamydia serum antibody titre (Taylor-Robinson, 1997). Thus, up to now, no adequate non-invasive screening test is available for identifying all patients with Chlamydia in any part of their genital tracts. Since iatrogenic spread of Chlamydia in subfertile women has severe consequences for the preservation of their fertility, clinical guidelines conceming precautions in subfertile women undergoing uterine instrumentation are essential. Based on the theoretical arguments of inadequate screening possibilities, we proposed that prophylactic antibiotics (i.e. azithromycin in a single oral dose, 12 hours before the planned procedure) should replace endocervical screening for $C$. trachomatis and treatment of positive cases only (chapter 5 ). This policy has been criticized by others (Witkin et al, 2002; Ng et al., 2002), postulating that the universal prophylaxis approach might contribute to the development of antibiotic resistance (Somani et al., 2000). Reports from the literature indicate that antibiotics may not eliminate Chlamydia from all host cells in vitro (Dreses-Werringloer et al., 2001), in macaques (Patton et al., 1997) and in humans (Bragina et al., 2001). In patients with treated Chlamydia infections, atypical small intracellular inclusions have been found, suggesting that antibiotics may induce persistence by modulating the microorganism, rendering it less susceptible to antibiotics. These observations deserve further exploration, since they question the principles and efficacy of treatment of acute as well as chronic Chlamydia infections.

\section{Screening for tubal factor subfertility}

In case spontaneous clearance of infection has not occurred and C. trachomatis infection has been able to ascend from the cervix into the upper genital tract, asymptomatic (silent) PID may occur, with the risk of inducing tubal pathology. The best available standard for diagnosing tubal pathology as a late sequel of $C$. trachomatis infection is direct visualization of the pelvic organs at laparoscopy and dye testing, a technique that is invasive, costly, and that worldwide has limited availability. Because it was noted that the development of tubal pathology was associated with $C$. trachonatis IgG antibody formation, CAT was developed as an inexpensive and non-invasive technique for distinguishing patients at high risk for tubal factor subfertility.

The micro-immunofluorescence (MIF) test, widely used for CAT, has several limitations. Since in the MIF test the number of antigens has been reduced, or only one broadly reacting antigen is used, there is lack of species-specificity, and unintended cross-reactivity with C. pnetwoniae antibodies in the MIF may occur, vesulting in false positive CAT results. Moreover, the test is time consuming and inter-observer and inter-laboratory variabilities exist. In order to overcome the 
clinical limitations of MIF, enzyme-linked immuno sorbent assays (ELISA) have been developed as a standardized and less labour-intensive altemative.

In chapter 4 a comparison is presented of five commercially available tests (MIF Biomerietix, MIF Labsystems, ELISA Labsystems, pELISA Medac, ELISA Savyon) in respect of their accuracy to predict tubal pathology. The results showed that there still is no single outstanding screening test for tubal pathology in subfertile women. Although ELISAs have been claimed to be highly sensitive and specific, they are not superior to MIF in predicting tubal factor subfertility. In all but one test (pELISA Medac), a cross-reaction was found with $C$. pneumoniae antibodies. Significant differences were found between the distributions of $C$. pneumoniae antibodies in the CAT positive and CAT negative patients when CAT was performed by MIF Biomerieux, MIF Labsystems, ELISA Labsystems or ELISA Savyon. These results suggest cross-reactivity with $C$. pneumoniae as a cause for false positive CAT results and confirm our previous findings (chapter 3), suggesting an additive role of $C$. pnenmoniae in the development of tubal pathology. However, after enlargement of the cohort and using a logistic regression model, additive determination of $\mathrm{IgG}$ antibodies to $C$. pnesmoniae did not improve the predictive value of $C$. trachomatis $\operatorname{IgG}$ antibody testing in screening for tubal factor subfertility. The odds ratio (OR) of screening by $C$. trachomatis IgG only was 13.9 and an OR of 15.4 was found for the combination of $C$. trachortatis IgG and C. pneumoniae IgG (den Hartog et al, 2004).

Besides false positive CAT results, also false negative CAT were found, in which ELISAs tended to have more false negative results than MIF (chapter 4). The more general hypothesis that false negative CAT results may be due to disappearance of $\operatorname{IgG}$ antibodies between infection and fertility investigation 10-15 years later could be refuted (chapter 2). In patients with an initial CAT $>32$ by MIF, a specific decline in IgG antibody titres (defined as a decline of at least two titre steps) was found in only $18 \%$, and in no patient did IgG titres become undetectable in 5 years. With ELISA, in chapter 2 used as a validation of MIF, signal / cut-off values did not decrease.

Also, the specific synthetic peptides used in the species-specific ELISA could be responsible for false negative test results. These peptides are derived from the variable domain region of the major outer membrane of $C$. tractiomatis. These highly specific epitopes may not be able to be recognized by all serotypes involved in $C$. trachomatis infection, and therefore cause false negative results (Bas et al., 2001).

Finally, besides assay-related factors as a cause for false positive and false negative CAT results, the aforementioned serotype-related factors and genetic factors in the host may play a role as well. Host genetic factors may be responsible for the fact that not all patients with $C$. trachomatis antibodies develop tubal pathology (causing false positive CAT) (Kinnunen et al., 2002). Variants of serotypes (Morré 
et al., 1998) as well as mutations in the position within MOMP (Dean et al., 2000) have been described, through which a test may not be able to detect the specific antibodies (causing false negative CAT).

In conclusion, there is still no outstanding screening test for tubal pathology in subfertile women, for which several reasons are held responsible. For the improvement of screening for $C$ trachomatis induced tubal pathology, IgG testing as an indicator of previous $C$. trachomatis infection should be combined with, or even replaced by, markers more specifically related to the inmunopathology.

\section{Immunopathogenesis of C. trachomatis induced tubal pathology}

In the present thesis we studied some of the clinical limitations of CAT. In order to develop more accurate tests for the prediction of tubal pathology, future research should focus on the immunopathology of silent $C$. trachomatis infections:

The flow chart in figure III attempts to provide a simple model of $C$. trachomatis invasion, the interplay between cellular and humoral immunity, infection and pathology. Progression along a particular pathway is determined by the immune response, which in turn is determined by a range of both host and pathogen factors as described earlier in this chapter. The exact mechanism by which changing cytokine patterns influence a particular immune pathway, i.e. shift away from balance in favour of either Th1 or Th2, is yet to be resolved (Debattista et al., 2003). Because of the asymptomatic course of infection these interactions are difficult to study in humans. Therefore, a mouse model has been developed. (chapter 6).

Since it has become increasingly evident that for development of tubal pathology chronic infection, by repeated or persisting C. trachomatis infection, is necessary, we focussed on single and repeated C. trachonatis vaginall inoculation of female C57BL/6] mice. Despite our hypothesis that extensive tubal pathology will be found after re-inoculation, only mild genital tract pathology and histological changes were encountered. Nevertheless, some findings are worth mentioning. Single intravaginal inoculation induced an infection without extensive pathology, but with an inflammatory cell response in the endometrium. Stromal inflammatory cells remained present, suggesting a persisting chronic inflammatory process. Re-inoculation stimulated the process, finally resulting in the induction of atypia of the endometrium. Based on these data, we suggested that re-inoculation might (re)activate the inflammatory response. Eventually, in the mouse, the endometrium may be unable to recover, resulting in pathology of the upper genital tract. 
Crochondin cervical antection

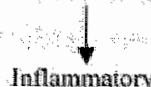

ropponsin

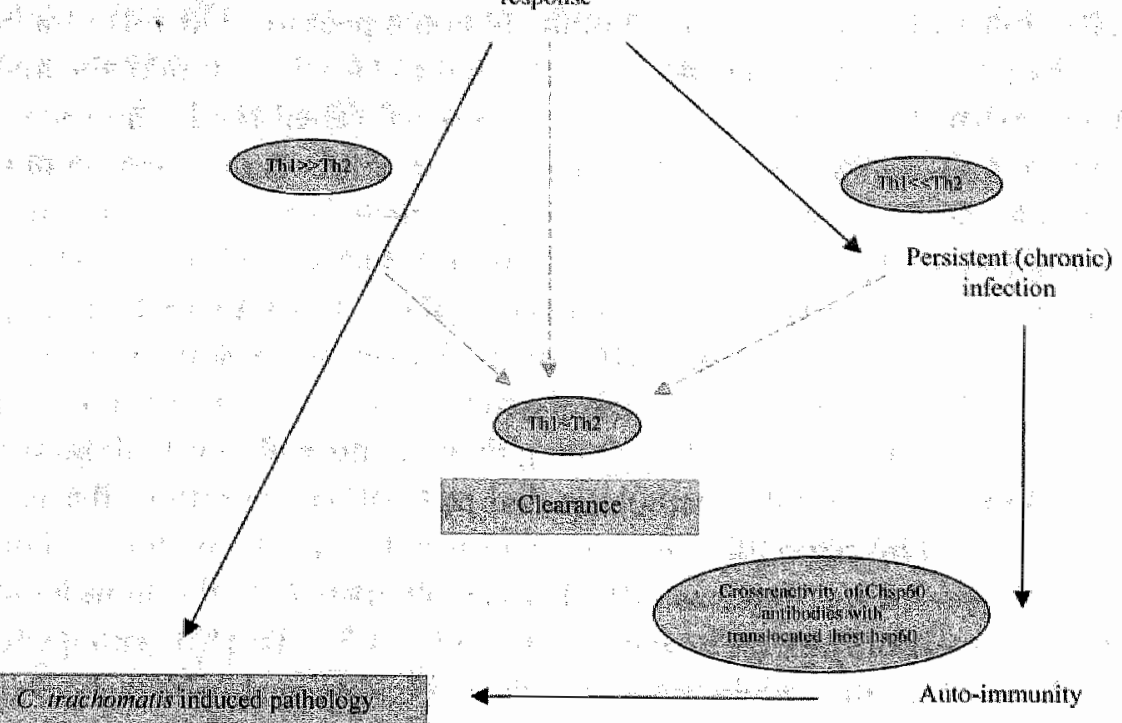

Figure III. Postulated immunopathogenesis of C. trachomatis infection (adapted from Debattista et al. 2003)

An auto-immune response based on hsp60 antibody cross-reactivity has been hypothesised to underlie the evolvement from $C$. trachomatis infection to tubal pathology (Domeika er al., 1998). In chapter 7 we evaluated whether single or repetitive C. trachomatis and / or C. pneumoniae infections resulted in the formation of Chsp60 antibodies, and additionally whether this was accompanied by the formation of auto-reactive antibodies (mouse hsp60 (Mhsp60) antibodies). In our study we found that Chsp60 and Mhsp60 antibody levels were low, even in frequently infected mice. The results therefore did not support the hypothesis of auto-immunity, based on cross reactivity of Chsp60 and Mhsp60 IgG antibodies, being the underlying mechanism of tubal pathology induction, at least in this mouse model. In summary, in the present model no extensive tubal pathology was found, and neither could auto-immunity due to hsp60 IgG antibody cross-reactivity be demonstrated.

In reference to figure III, host related immune factors might play a role in $C$. trachomatis infection outcome, i.e. the inherent predisposition of a mouse strain to develop a certain immune response. Since C57BL/6J mice are known to predominantly conduct a Th1 response (Darville et al., 1997), resolution of infection may 
have occurred before chronicity and the formation of hsp antibodies and auto-immunity could develop. Lyons and coworkers (2004b) compared two immunologically different strains of mice, Th1 inherent C57BL/6J mice and $B A L B / c$ mice with inherent Th2 immune response polarity. The role of inherent Th1/Th 2 polarity bias on the course of infection and on the nature of the immune response to female genital tract infection was studied. Their results showed significant differences among the mouse strains. Once established, the duration of infection was longer in C57BL/6J mice. However, their level of bacterial shedding during infection was less, and assessments of quantitative and qualitative cellular and humoral responses to infection showed stronger Th1 type immune response in $\mathrm{C} 57 \mathrm{BL} / 6 \mathrm{~J}$ compared to $\mathrm{BALB} / \mathrm{c}$ mice. However, regardless of inherent Th1/Th2 polarity, a significant level of acquired immunity to re-infection was induced in both mouse strains. Combining these results with our findings suggests that, in order to study tubal pathology due to persistent infection, the use of a predominantly Th2 responding mouse strain may have to be preferred. Furthermore, as reviewed by Stephens (2003), as an alternative to the immunological paradigm for Chlamydia pathogenesis, it might rather be that pathogenesis is primarily based on the cellular responses elicited by mucosal epithelial cells, their secretion of chemokines and growth factors, and secondarily their interaction with the adaptive immune system.

In conclusion, attention should be paid to improvement of the mouse model focussing on the influence of the various factors. As is the case with human $C$. trachomatis genital infection, both host and microorganism related factors play a role (i.e. differences in mouse strains and serovars), and complicate the development of a useful model. However, a suitable model would ultimately provide opportunities to study the individual factors involved in the inflammatory response to infection and re-infection and the role of different serovars and host immunogenetic factors in the etiology of tubal factor subfertility.

\section{Recent insights in serological screening for tubal factor subfertility}

Elucidating the etiology of $C$. trachomatis induced tubal pathology may provide insights that could lead to the development of new markers that could subsequently be introduced in screening for tubal factor subfertility. Persistent exposure to $C$. trachonatis may result in a chronic inflammatory response and increase the risk of tubal damage. Although $\operatorname{IgG}$ antibodies are markers of a previous infection, they may not reflect a persistent chronic inflammation properly. Recent studies have focussed on anti-lipopolysaccharide (LPS) antibodies, Chsp60 antibodies, C. 
trachontatic $\operatorname{IgA}$ antibodies, and C-reactive protein (CRP), assuming these factors to more specifically reflect persistent infection.

There is a high interspecies homology in the outer membrane protein LPS between Chlamydia species. Although it is known that genus-specific anti-LPS-antibodies increase rapidly in the early phase of infections, in case of infection with $C$. trachomatis and re-infection with a particular Chlamydia species or endogenous "reactivation", a chronic inflammatory response may be induced leading to the continuous production of anti-LPS-antibodies. In this perspective, anti-LPS-antibodies were hypothesised to serve as a marker for chronic inflammation. Anti-LPS antibodies were found significantly more often in women with distal tubal pathology as compared to women without distal tubal pathology. However, the presence of anti-LPS antibodies was no independent predictor for tubal disease (den Hartog ef al., 2004).

Chsp60 has been postulated to play an important role in chronic inflammatory processes, immune responses and in the development of tubal pathology (Domeika et al., 1998; Witkin et al, 1998), and antibody responses to Chsp60 may signal chronically persistent or repeated infection. In small series, Chsp60 antibodies, considered as markers for chronic infection, have already been associated with the development of tubal pathology (Toye et al., 1993; Arno et al., 1995; Claman et al., 1997). Although the studies were performed in small patient groups, a Chsp60 antibody test showed sensitivities of $44-76 \%$ and specificities of $81-92 \%$ for detecting tubal factor subfertility. When the tests were used in combination with $C$. trachomatis IgG antibodies by MIF, sensitivity and specificity of Chsp60 antibody testing showed even more promising results (70-92\% and $70-93 \%$ respectively) (Freidank et al, 1995; Claman et al, 1997). When both the MIF for C. trachomatis IgG and Chsp60 test were used, Freidank and coworkers (1995) reported a positive likelihood ratio of 10 and a negative likelihood ratio of 0.32 , suggesting the combination of C. trachomatis $\operatorname{IgG}$ and Chsp60 to be a promising marker for predicting C. trachomatis induced tubal factor subfertility. In a cohort of 313 women, den Hartog and coworkers (2005) studied whether Chsp60 antibodies, C: trachomatis IgA antibodies or elevated CRP, alone or in combinations, could identify tubal pathology in subfertile women better than currently used $C$. trachomatis IgG antibodies. C. trachomatis IgG antibody testing remained the best single predictor for tubal pathology. For Chsp60 antibodies, an OR of 5.9 was found, which is significantly lower than the OR of 13.9 for C. trachomatis IgG antibodies. This lower OR may be explained by cross-reactivity with $C$. pneumonide, being highly prevalent in subfertile women. The same held true for $C$. trachomatis IgA antibodies. Although associated with chronic inflammation and infection in studies considering C. pneumoniae and cardiovascular diseases (Falck et al., 2002), IgA antibodies did not prove to be adequate predictive markers for 
tubal factor subfertility (OR 6. 1). A forward stepwise logistic regression analysis revealed that only adding the CRP-test significantly improved the diagnostic performance of the $\mathrm{C}$. Irachowatis IgG test (OR 39.7) (den Hartog et al, 2005).

In considering asymptomatic $C$. rachowatis infection as a chronic disease, similarities may be drawn with the pathogenesis of other chronic diseases in which inflammatory processes play a role. Over the past few years, the association of chronic C. pneumonial infection with wascular diseases, if atherosclerosis and its complications, has become apparent (Leinonen et al, 2002, Libby et al, 2002a en b). An obsenwation that has generated interest is that slightly elevated CRP levels represent a strong predictor of myocardial infarction, stroke and vascular death (Ridker et at, 2001a en b; 2002). Further studies suggest that CRP may not onlly be an inflammatory marker of atherosclerosis but also a mediator of the disease, because it contributes to lesion formation, plaque rupture, and coronary thrombosis by interacting with and altering the endothelial cell phenotype (Wang et al., 2003. Bisoendial el al, 2005). Extrapolating these findings to the development of tubal pathology, it was found that measuring $C$. trachomatis $\operatorname{IgG}$ antibodies (markers of a previous infection) in combination with CRP (a marker of the course of the infection) seems to identify a subset of subfertile women with the highest risk of persistent infections and distal tubal pathology (den Hartog et al. $2005)$

In summary, the most important findings of the present study are:

- A decline in IgG antibody titre over time is not a significant cause of false negative Chlamydia antibody test (CAT) results (chapter 2).

- The prevalence of $C$. pneumoniae antibodies in subfertility patients is $75 \%$ (chapter 3):

- The prevalence of $C$ pnewnoniae antibodies did not differ between patients with and without tubal pathology (chapter 3).

- C. pneumoniat antibodies, due to cross-reactivity, may be the cause of false positive CAT results (chapter 3 ).

- Tubal pathology is more common in patients who have both antibodies to $C$. irachonatis and C. prewmoniae (chapter 3).

- In screening for tubal factor subfertility, significant differences in predictive value exist between different commercially avalable MIF and ELISA tests (chapter 4).

- Combining two CAT tests does not improve the predictive value of CAT (chapter 4).

- In subfertile women undergoing uterine instrumentation, prophylactic antibiotics should replace endocervical screening for $C$. trachomatis and treatment of positive cases only (chapter 5). 
- Single intravaginal inoculation of $\mathrm{C} 57 \mathrm{BL} / 6 \mathrm{~J}$ mice with the human $\mathrm{C}$. trachomatis $\mathrm{L}_{2}$ strain induces an infection without extensive pathology, but with a chronic inflammatory cell response in the endometrium (chapter 6).

- Re-inoculation of $\mathrm{C} 57 \mathrm{BL} / 6 \mathrm{~J}$ mice stimulates the inflammatory process, finally resulting in the induction of atypia of the endometrium (chapter 6).

- No extensive genital tract pathology and histologic changes are found in the C57BL/6J mouse, possibly due to various factors in the model (chapter 6).

- The results in our mouse model do not support the contention of auto-immunity, based on cross-reactivity between Mhsp60 and Chsp60 IgG antibodies, since Chsp60- and Mhsp60 IgG antibody levels, even in frequently re-infected mice, were low or absent (chapter 7). 


\section{References}

Arno, J N. Yan, Y, Cleary, RE et al (1995) Serologic responses of infertile women to the $60 \mathrm{kD}$ Chlamydial heat shock protein (hsp) Fertil steril, 64, 730-735.

Bas, S. Muzzin, P. Ninet, B., Bornant, J E, Scieux, C, Vicher, T L (2001) Chlanyda serology: comparative diagnostic value of inmunoblotting, micromnnunofluorescence test, immunoassays using different recombinant proteins as antigens. J. Clin. Micobiol, 39, 1368-1377.

Beatty, WL L, Bytne, GI, Morrison, R.P. (1993) Morphologic and antigenic characterization of interferon-y-mediated persistent $C_{\text {a }}$ trachomatis infection in vitro. Proc. Natl. Acad. Sai. USA, 90, $3998-4002$.

Beatry, W.L., Morrison, R.P., Byme, G.I. (1994a) Persistent Chlamydiae from cell culture to a paradign for Chlanydial pathogenesis. Wicrobiol. Rev, 58, 686-699.

Beatty, W.L., Byrne, G.I., Morrison, R.P. (1994b) Repeated and persistent infection with Chlamydia and the development of chronic inflammation and disease. Trends Microbiol, 2, 94-98.

Beatty, W., Morrison, R., Byme, G.I. (1995) Reactivation of persistent C. trachomatis infection in cell culture. Infect. Immun., 63, 199-205.

Bisoendial , R.J., Kastelein, J.J, Levels, J.H., Zwagina, J.J, wan den Bogaard, B., Reitsma, P.H., Meijers, J.C., Hartman, D., Levi, M., Stroes, E.S. (2005) Activation of inflammation and coagulation after infusion of $\mathrm{C}$-reactive protein in humans. Circ Res., 7, 714-716.

Bleker, OP., wan der Meijden, W.I., Wittenberg, J., van Bergen, J.E.A.M., Boeke, A.J.P., van Doornum, G.J.J., Henquet, C.J.M., Galama, J.M.D., Postma, M.J., Prins, J.M., van Voorst Vader, P.C. (2003) CBO richtlijn'Seksueel overdragbare aandoeningen en herpes neonatorum" (herziening). NTVG, 147,695-699.

Bragina, E.Y., Gomberg, M.A., Dmitriev, G.A. (2001) Electron microscopic evidence of persistent chlamydial infection following treatment. $J E A D V, 15,405-409$.

Brunham, R.C. and Rey-Ladino, J. (2005) Immunology of Chlamydia infection: implications for a Chlanydia trachomatis vaccine. Nature Reviews, 5, 149-161.

Claman, P., Honey, L., Peeling, R.W., Jessamine, P., Toye, B. (1997) The presence of serum antibody to the chlanydial heat shock protein (CHSP60) as a diagnostic test for tubal factor subfertility. Fertil. Steril, 67, 501-504.

Cohen, C.R., Sinei, S.S., Bukusi, E.A., Bwayo, J.J., Holmes, K.K., Brunharn, R.C. (2000) Human leucocyte class $\sqrt{11} \mathrm{DQ}$ alleles associated with Chamydia trachomatis tubal infertility. Obstet. Gynecol., 95, 72-7\%.

Cohen, C.R., Guctur, J., Rukaria, R., Sinei, S.S., Gaur, L.K., Brunham, R.C. (2003) Immunogenetic correlates for Chamyclia trachomatis-associated tubal infertility. Obster. Gynecol., 101, 438-444.

Cotter, T.W., Miranpuri, G.S., Ramey, K.H. (1997) Reactivation of chlamydial genital tract infection in mice. Infect. Inmmu, 65, 2067-2073.

Darville, T., Andrews, C.W., Laffoon, K.K., Shymasani, W., Küshen, L.R., Rank, R.G. (1997) Mouse strain-dependent variation on the course and outcome of Chlamydial genital tract infection is associated with differences in hose response. Infection and Immunity, 65, 3065-3073.

Dean, D., Oudens, E., Bolan, G., Padian, N., Schachter, J. (1995) Major outer membrane protein variants of Chlamydia trachomatis are associated with severe upper genital tract infections and histopathology in San Francisco. J. Inffect. Dis., 172, 1013-1022.

Dean, D., Suchland, R., Stanm, W. (2000) Evidence for long-term cervical persistence of C. trachomatis by ompl genotyping. J. Infect. Dis, 182, 909-916. 
Debattista, J., Timams, P., Allan, J. (2003) Immunopathogenesis of Chlanydia trathontatis nfertions in women. Fentll Steril, 79, 1273-1287.

Den Hartog, JE, Land, JA, Stassen, F.R.M, Slobbe-van Drunen, M.E.P, Kessels, A.G.H., Bruggeman, CA. (2004) The role of Chlanydia genus-specific and species-specitic IgG antibody testing in predicting tubal disease in subfertile women. Hum. Reprod, 19, 1380-1384.

Den Hartog, J.E., Land, J.A., Stassen, F.R.M., Kessels, A.G.H., Bruggeman, C.A. (2005) Serological markers of persistent $C$. tmachomatis infections in women with tubal factor subfertility. Hwh. Reprod., 20, $986-990$.

Domeika, M., Domeika, K., Pavonen, J., Mărdh; P.A., Witkin, S.S. (1998) Humonal immune tesponse to conserved epitopes of Chlamydia trachomatis and human $60-\mathrm{kDa}$ heat shock protein in women with pelvic inflammatory disease. J. Infect. Dis., 177, 714-719.

Dreses-Werringloer, U.; Padubrin, I., Zeidler; H., Köhler, L. (2001) Effects of azithronycin and rifampicin on Chlanydia trachomatis infection in vitro. Antimorob. Agents Chewother, 45, 3001-3008.

van Duynhoven, Y.T.H.P., Ossewarde, J.M., Derksen-Nawrocki, R.P., van der Meijden, W.I., van de Laar, M.J.W. (1998) Chlamydia trachomatis genotypes: correlation witl clinical manifestations of infection and patients" characteristics. Clin. Infect. Dis, 26, 314-322.

Falck, G., Gnarpe, J., Hansson, L.O., Svärdsudd, K., Gnarpe, H. (2002) Conparison of individuals with and without specific IgA antibodies to Chlamydia pneumonize. Respiratory morbidity and the metabolic syndrome. Chest, $122,1587-1593$.

Forsey, J.P., Caul, E.O., Paul, I.D., Hull, M.G.R. (1990) Chlanydia trachomatis, tubal disease and the incidence of symptomatic and asymptomatic infection following hysterosalpingography. Hum, Reprod, 5, 444-447.

Freidank, H.M., Clad, A., Herr, A.S., Wiedmann-Al-Ahmad, M., Jung, B. (1995) Immune response to Chlamydia trachomatis lreat-shock protein in infertile femalle patients and the influence of Chlamydia pneumoniae antibodies. Eur. J. Clin. Microbiol. Infect, 14, 1063-1069.

Golden, M.R., Schillinger, J.A., Markowitz, L., St Louis, M.E. (2000) Duration of untreated genital infections with Chlamydia trachomatis. A review of the literature. Sex. Transm. Dis., 27, 329-337.

Kinumen, A.H., Surcel, H-M., Lehtinen, M., Karhukorpi, J., Tiitinem, A, Halttunen, M., Bloigu, A., Morrison, R.P., Karttunen, R., Paavonen, J. (2002) HLA DQ alleles and interleukin-10 polymorphism associated with Chlamyida trachonatss-related tubal factor infentily: a case-control study. Hum. Reprod., 17, 2073-2078.

Koehler, L., Nettehbreker, E., Hudson, A.P., Ott, N., Genard, H.C., Brangan, P. ., Schunacher, H.R., Drommer, W., Zeidler, H. (1997) Ultrastructural and molecular analyses of the persistence of $\mathrm{C}$. trachowatis (serovar K) in human monocytes. Michb. Paihog, 22, 133-142.

van de Laar, M.J.W., Lan, J, van Duyphowen, Y.T.H.P. et al. (1996) Differences in clinical manifestations of genital chalmydial infections related to serovars. Genitourin. Med., 72, 261-265.

Leinonen, M., Saikku, P. (2002) Evidence for infectious agents in cardiovascullar disease and atherosclerosis. Lancet Inyect. Dis., 2, 11-17.

Libby, P, Ridker, P.M., Maseri, A. (2002a) Inflammation and atherosclerosis. Circulation, 105, $1135-1143$.

Libby, P, (2002b) Inflammation and atherosclerosis. Nature, 420, 868-874.

Lyons, J.M., den Hartog, J., Ouburg, S., Land, J.A, Bruggeman, C.A., Pleijster, J., Ito, J.1., Peòa, A.S. Morré, S.A. (2004a) The role of the toll-like receptor 4 in Chlanydia trachomatis female genital tract infection: the knockout mouse and human candidate gene approaches. In thesis: An integrated approach to the study of Chlanydia trachomatis infection of the fermale genital tract, $81-89$. 
Lyons, J.M., Morre, S.A., Brown, L.P. Peòa, A.S., Ito, Il. I. (2004b) Comparision of Chlanydu trachomatis genital tract infection in different strains of female mice. In thesis: An integrated approach to the study of Chanydia trachomatis infection of the female genital mact, 136-146.

MeComack, W.M. Alpert, S. McComb, D.E., Nichols, R.L. Senine, D.Z., Zinner, S.H. (1979) Fiften-month follow-up study of women infected with Chlawyda trachomatis. N. Eng. If. Med, $300,123-125$

Molano, M. Meijer, C.L.M, Weiderpass, E, Arslan, A., Posso, H., Fanceschi, S, Ronderos, M., Munoz, N, yan den Brule, A.J.C. (2005) The natural course of Chlamydia trachomatis infection in asymptonatic Colonbian women: a 5-year follow-tup study. Inf. Dis., $191,907-916$.

Morté, S.A. Ossewande, JM, Lan, J., van Doomum, G.J.J., Walboomers, J.M.M., MacLaren, D.M. Meijer, C.J.L.M. van den Brule, A.J.C. (1998). Serotyping and genoryping of genital Chlamydia trachomatis isolates teveal variants of serovar $B$ a $G$ and $J$ as confirmed by ompl nucleotide sequence analysis. J. Clin. Microbiol, $36,345-351$.

Morré, S.A., Rozendaal, L, wan Valkengoed, I.G.M., Boeke, A.J.P., van Voorst Vader, P.C.,

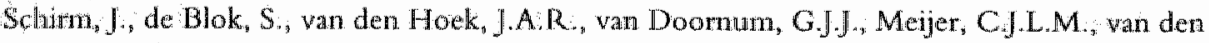
Brule, A.J.C. (2000) Urogenital Chlamydia trachomatis serovars in men and women with a symptonatic or asymptomatic infection: an associacion with clinical manifestations? I. Clin. Microbiol, 38, 2292-2296.

Morré, S.A, den Brule, A.J.C., Rozendal, L., Boeke, A.J.P.; Voorhorst, F.J, de Blok, S. Meijer, C.J.L.M. (2002) The natural course of asymptomatic Chlamydia tradhomatis infections: $45 \%$ clearance and no development of clinical PID after one-year follow-up. Int J. STDEAIDS, 13 (Suppl, 2), $12-18$.

Morré, S.A., Murillo, L.S., Bruggeman, C.A., Peña, A.S. (2003) The role that the functional Asp299Gly polymorphism in the Toll-like receptor-4 gene plays in susceptibility to Chlanydia trachomakis associated tubal infertility. J. Infed. Dis., 187, 341-342.

Murillo, L.S., Land, J.A., Pleiister, J, Bruggeman, C.A., Perna, A.S., Morré, S.A (2003) Interleukin-1B $(I J-1 B)$ and interleukin-1 receptor antagonist $(I L-1 R N)$ gene polymorphisns are not associated with tubal pathology and Chamydia trachomatis-related tubal factor subfertility. Hum. Reppod, 18, 2309-2314.

Ness, R.B., Brunhan R.C., Shen C., Bass, D.C. (2004) Associations among human leucocyte antigen (HLA) class II DQ wariants, bacterial sexually transmitted diseases, endometritis, and tertility among women with clinically pelvic inflammatory disease. Sex. Trats. Dis., 31, 301-304.

Nig, E.H.Y., Ngat, C.S.W., Ho, P.C. (2002) Chlamydia trachomatis in infertile women undergoing uterine instrumentation: screten or treat. Hum. Reprod, 17, 2215.

Paavonen, J., Puolakkainen, M., Paukku, M., Sintonen, H. (1998) Cost-benefit analysis of first-void urine Chlamydia trachomatis screening program Obstet. Gynecol, 92, 292-298.

Patton, D.L., Cosgroove Sweeney, Y., Bohannon, N.J., Clank, A.M., Hughes, J.P., Cappuccio, A., Campbell, L.A.s Stanm, W.E. (1997) Effects of Doxycycline and anti-inflammatory agents on experimentally induced chlamydial upper genital tract infection in female macaques. J. Infert. Dis. $175,648-654$.

Peipert, J.F. (2003) Clinical practice. Genitall clalamydial infections. N, Eng. J. Med., 349, $2424-2430$.

Persson, K., Osser, S. (1993) Lack of evidence of a relationship between genital symptoms, cervicitis and salpingitis and difterent serovars of Chlamydia trachonntis Eur. J. Clim. Mirobiol. Infect. Dis., 12, 195-199.

Rahmi V.A., Velshein, J., Gleerup, A., Gnarpe, H., Rosen, G. (1986) Asymptomatic caniage of Chlamydiat trachomatis: a study of 109 teenage girls. Eur. J. Sex. Transm. Dis., 3, 91-94. 
Ridker, P.M:, Stampfer, M.J., Rifai, N. (2001a) Novel risk factors for systemic wherosclerosis: a comparison of C-reactive protein, fibrinogen, homocysteine, lipoprotein(a), and standard cholesterol screening as predictors of peripheral arterial disease. JAMA, 285, $2481-2485$.

Ridker, P:M. (2001b) High-sensitivity C-reactive protein: potential adjunct for global risk assessment in the primary prevention of cardiovascular disease. Circulation, $103,1813-1818$.

Ridker, P.M., Rifai, N., Rose, L. et al. (2002) Comparison of C-neactive protein snd low-density lipoprotein cholesterol levels in the prediction of first cardiovascular events. N. Eng. J. Med. $347,1557-1565$

Somani, J.. Bhallar, V.B., Workowski, K.A., Farshy, C.E., Black, C.M. (2000) Multiple drug-resistant Chlamydia trachomatis associated with clinical freatment fallure. J Infort. Dis. $181,1421-1427$.

Taylor-Robinson, D. (1997) Evaluation and comparison of tests to diagnose Chamydia trachomatis genital infections. Hum. Reprod., 12 (Suppl. 2), 113-120.

Thomas, K., Coughlin, L., Mannion, P.T., Haddad, N.G. (2000) The value of Cliamydia trachomatis antibody testing as part of routine infertility investigations. Ham. Reprod., 15 , $1079-1082$.

Toye, B.; Laferrière, C., Claman, P., Jessamine, P., Peeling, R. (1993) Association between antibody to the chlamydial heat shock protein and tubal infertility. J. Infect. Dis. 168, 1236-1240.

Van Valkengoed, I.G.M., Morré, S.A., van den Brule, A.J.C., Meijer, C.J.L.M., Bonter, L.M., Boeke, A.J.P. (2004) Overestination of complication tates in evaluations of Chlanidia trachomatis screening programmesimplications for cost-effectiveness analyses. lint I. Epil., 33, 416-425.

Wang, C-H., Li, S-H., Weisel, R.D., Fedak, P.W.M., Dumont, A.S., Szmitko, P., Li, R-KK., Mickle, D.A.G. Verma, S. (2003) C-reactive protein upregulates angiotensin type 1 receptors in vascular smooth muscle. Circulation, 107, 1783-1790.

Weström, L., Joesoef, R., Reynolds, G., Hadgu, A. Tompson, S.E. (1992) Pelvic infammatory disease and fertility. A cohort study of 1844 women with laparoscopically verified disease and 657 control women with normal laparoscopic results. Sex. Trawsin. Dis, 19, 185-192.

Wiesenfeld, H.C., Hillier, S.L., Krohn, M.A., Amortegui, A.J., Heine, R.P., Landers, D.V., Sweet, R.L. (2002) Lower genital tract infection and endometritis: insight into subclinical pelvic intlammatory disease. Obstet. Ginecol, 100, 456-463.

Witkin, S.S., Askienazy-Elbhat, M., Heriry-Suchet, J., Belarch-Allat, J., Tort-Cnimbach, J, Sarjdine, K. (1998) Circulating antibodies to a conserwed epitope of the Chlamydia trachomatis $60 \mathrm{kDa}$ heat shock protein (hsp60) in infertile couples and its rellationship to antibodics to $C$. trachowatis sarface antigens and the Escherichia coli and human hap60. Hom. Reprod., 13, $1175 \% 1179$.

Witkin, S. S. and Linhares, I.M. (2002) Chlanydia trachomatis in subfertile wonken undergoing uterine instrumentation. An alternative to direct microbial testing or propliylactie antibiotic treatment. Hum. Reprod, 17, 1938-1941.

Workowski, K.A., Stevens, C.E., Suchland, R.J et a. (1994) Clinical mamifestations of genital infection due to Chlanydia trachomatis in women: differences related to serovars. Chin. Infer. Dis., $19,756-760$. 


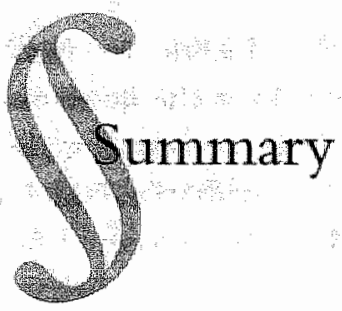

The present thesis focussed on the role of Chlamydia (C.) rachonatis antibody testing (CAT) in screening for tubal factor subfertility. CAT was developed as an inexpensive and non-invasive technique for distinguishing high-risk patients from those with a low risk for tubal factor subfertility due to silent $C$. trachomatis nifection. Ideally, based on the results of CAT, high-risk patients would be subjected to diagnostic testing (i.e. laparoscopy) while additional testing of tubal patency could be postponed in low-risk patients. The clinical significance of CAT, however, has its limitations due to false negative and false positive results.

The aim of the current study was to elucidate factors that have been hypothesised as a cause of limiting the predictive value of CAT. Moreover, also factors that have been suggested to improve the predictive value of CAT were studied. To obtain more insight in C: trachomatis induced tubal pathology a mouse model was developed.

In chapter 1, the literature on the microorganism $C$. trachomatis and the way it induces infection has been reviewed Furthermore, the pathogenesis, the immune response, and its role in the development of tubal pathology were described. Subsequently, the epidemiology, the clinical manifestations of female $C$ : wachomatis genital tract infection and the need for screening programmes were discussed. An overview of the available diagnostic tests was given and screening for tubal factor subfertility was reviewed.

In chapter 2 , it was postulated that $\operatorname{lgG}$ antibodies might decline over time after $C$. trachomatis infection. In view of the time span between primary $C$. trachomatis infection in adolescence and fertility work-up in adulthood, decline of C. trachomatis IgG antibodies over time as a potential cause of false negative CAT results was studied. A number of 39 women with an initial titre of $\geq 64$ were restudied serologically after $4-7$ years. The initial and a new serum sample were tested for $C$. trachomatis $\operatorname{IgG}$ antibodies using a micro-immunofluorescence assay (MIF). A species-specific enzyme-linked immunosorbent assay (ELISA) was used to validate the MIF test results. All patients filled out a questionnaire to determine risk factors for renewed C. trachomatis infection between the initial and second serum sample. Although seven of the 39 patients (18.0\%) showed a significant decline in $\operatorname{IgG}$ antibodies by MIF over a period of $4-7$ years, $\operatorname{IgG}$ antibodies never 
became undetectable. In the $7 / 39$ patients who showed a decline by MIF, signal/cut-off values by ELISA did not decrease. From the results of the questionnaire, it was concluded that $C$. trachomatis re-infection appeared to be no major cause of persistence of Chlamydia IgG antibody titres in the subfertile women studied. We concluded that a decline of $\operatorname{IgG}$ antibodies did occur, but could not be considered as a significant cause of false negative results.

In chapter 3 , the role of $C$. pneunoniae antibodies, as a potential cause of false positive CAT results due to cross-reactivity with C. trachomatis antibodies in the MIF test, has been evaliuated.

In 240 subfertile women serologic data were compared to laparoscopy findings.

The prevalence of C. pneumoniae antibodies using ELISA was $75 \%$ and did not differ between patients with and without tubal pathology.

C. pnemmoniae antibodies were found in $87 \%$ of women with a positive MIF test $(\geq 32)$, and in $66 \%$ with a negative MIF test $(p<0.0005)$. Similar percentages were found when using ELISA instead of MIF for the detection of C. trachomatis antibodies, i.e. $87 \%$ of $C$. trachomatis positive women versus $69 \%$ of $C$. trachomatis negative women had C. pneumoniae antibodies ( $<<0.0005)$.

Patients without tubal factor subfertility but a positive MIF test (i.e. false positive CAT result) showed C. pnewmoniae antibodies more frequently than patients without tubal factor subfertility and a negative MIF test (true negative CAT result), indicating that $C$. pneumoniae is a major contributor of false positive CAT results by MIF. Remarkably, tubal pathology was more common in patients who had antibodies to both $C$. trachomatis and $C$. pneumomiae, supporting the contention that C. pneumoniae may be involved in Chlamydia upper genital tract infections and/or subsequent tubal damage.

Chapter 4 describes a comparison of five commercially available CAT tests (MIF Biomerieux, MIF Labsystems, ELISA Labsystems; pELISA Medac, ELISA Savyon) in respect of their accuracy in predicting tubal pathology was performed. In a prospectively collected cohort of 315 subfertile women results of the five CAT tests were correlated to findings at laparoscopy. Furthermore it was evaluated whether combinations of tests could improve the predictive value of CAT. Of all tests evaluated, MIF Labsystems had the single best diagnostic performance (OR 15.7), and among the three ELISA tests; pELISA Medac performed best (OR 8.2). Stepwise logistic regression analysis showed that the performance of MIF Labsystems could not be improved by adding a second test. Furthermore, except for pELISA Medac, significant cross-reactivity with $C$. pneumoniae antibodies was found in all tests.

Chapter 5 deals with screening of endocervical C. trachomatis infections in subfertility patients. Most of these patients will undergo uterine instrumentation as part of their fertility work-up. They are, in case of an active or dormant $C$. 
trachowatis endocervical infection or colonization, considered at risk for ascending infection. Since endocervical PCR screening may not identify all dormant $C$. trachomatis, and CAT will only determine previons exposure to the organism, without providing information as to whether Chlamydia is actually present, no adequate non-invasive screening test for genital tract infection is available. Based on these theoretical arguments, we argue that prophylactic antibiotics (i.e. azithromycin in a single oral dose, 12 hours before the planned procedure) should replace endocervical screening for $C$. trachomatis and selective treatment of positive cases only.

In chapter 6, the development of a mouse model was described, to study the largely unknown pathogenesis of tubal factor subfertility after silent $C$. trachomatis infections. It was hypothesised that primary C. trachomatis infection would not result in extensive genital tract pathology, and that only subsequent $C$. trachomatis re-infection would induce tubal disease. Therefore, female $\mathrm{C} 57 \mathrm{BL} / 6 \mathrm{~J}$ mice were inoculated intravaginally with human $C$. trachomatis serovar $\mathrm{L}_{2}$. Mice were sacrificed at regular intervals, three, nine and eighteen weeks after inoculation, and the development of histopathologic changes and tissue damage in the genital tract was studied. One group of mice was submitted to re-inoculation to investigate the effect of re-infection on the development of genital tract pathology. Furhtermore, to explore whether $\mathrm{C}$. pneumoniae wouls contribute to the development of $\mathrm{C}$. trachomatis induced tubal pathology, a pilot study with C. pneumoniae was performed. The results indicated that single intravaginal inoculation of $\mathrm{C} 57 \mathrm{Bl} / 6 \mathrm{~J}$ mice with the human $\mathrm{C}$. trachomatis $\mathrm{L}_{2}$ strain induces an infection without extensive pathology, but with a chronic inflammatory cell response. Re-inoculation stimulated the process, finally resulting in the induction of atypia of the endometrium. Changes at the tissue and cellular level were all more evident after re-inoculation. Despite our assumption that extensive pathology would be found after re-inoculation, only mild genital tract pathology and histologic changes were found. Various factors in the model that might be held responsible for the findings, e.g. the use of $\mathrm{C} 57 \mathrm{~B} 1 / 6 \mathrm{~J}$ mice and inoculation with a human C. trachomatis strain, were discussed.

In chapter 7, it was postulated that auto-immunity, based on cross-reaction of Chlamydia hsp60 (Chsp60) antibodies with human hsp60 expressed on tubal epithelial cells during persistence of infection, might be the underlying mechanism of tubal pathology. We evaluated in a mouse model whether Chsp60 and mouse hsp60 antibodies could be detected in serum following $C$. trachomatis and $C$. pneumoniae infection. The results of our pilot studies did not support the hypothesis of auto-immunity, since Chsp60 and mouse hsp60 antibody levels, even in frequently inoculated mice, were low. We recognize however the limitations of our model. 
In chapter 8 topics that have contributed to our current understanding and approach of asymptomatic $C$. trachomatis infections and its late sequelae were highlighted. In this context, the results of the present studies were discussed more specifically and the most important findings were summarised. 


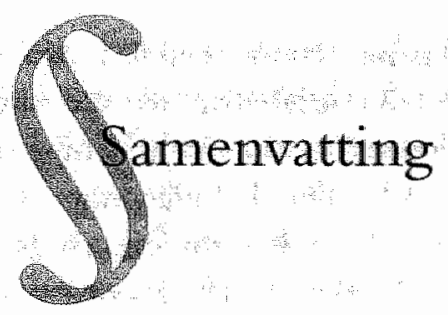

De best beschikbare standaard voor het diagnostiseren van tubapathologie ten gevolge van Chlamydia (C.). trachomatis infectie is de laparoscopie met tubatesten. Daar dit een invasief en duur onderzoek is, is het niet geschikt voor het screenen van groepen patiënten. Als screeningstest voor tubapathologie wordt binnen het oriënterend fertiliteitsonderzoek de Chlamydia IgG antilichaam titer (CAT) bepaling gebruikt, met als doel patiënten met een hoog risico op tubapathologie ten gevolge van $C$. trachomatis infectie te onderscheiden van die met een laag risico. Idealiter zouden patiënten at risk voor tubapathologie vroeg in het fertiliteitsonderzoek invasieve diagnostiek kunnen ondergaan (laparoscopie met tubatesten), terwijl dit in patiënten met een laag risico kan worden uitgesteld en het fertiliteitsonderzoek zich meer kan richten op andere oorzaken en behandeling van de subfertiliteit. Helaas zijn de klinische resultaten met betrekking tot het voorspellen van tubapathologie teleurstellend door het voorkomen van zowel fout-positieve als fout-negatieve CAT uitslagen.

Het huidige onderzoek richtte zich op factoren waarvan gesuggereerd wordt dat ze mogelijk verantwoordelijk zouden kunnen zijn voor de beperkte voorspellende waarde van CAT. Vervolgens werden mogelijkheden voor verbétering van de voorspellende waarde van CAT onderzocht. In het laatste deel van het proefschrift wordt aandacht besteed aan de ontwikkeling van een muismodel, daar een beter begrip van de pathogenese noodzakelijk is voor het ontwikkelen van een accurate screeningstest voor tubapathologie ten gevolge van asymptomatische $C$. trachomatis infecties.

Hoofdstuk 1 betreft een literatuuroverzicht over het micro-organisme $C$. trachomatis en het infectieverloop. Aan bod komen de pathogenese, de immuunrespons en de rol hiervan in de ontwikkeling van tubapathologie. Verder wordt aandacht besteed aan de epidemiologie, het klinische beeld, en de noodzaak van screeningsprogramma's. Er wordt een overzicht gegeven van de beschikbare diagnostische tests en screeningstests voor tubapathologie. De doelstellingen van het proefschrift worden uiteengezet.

Een mogelijke verklaring voor het voorkomen van fout-negatieve CAT is het dalen van titers in de tijdsperiode tussen de oorspronkelijke infectie en het fertili- 
teitsonderzoek. In hoofdstuk 2 bestudeerden we 39 patienten met een CAT $\geq 64$ ten tijde wan hun fertiliteitsonderzoek. Bij hen werd 4 jaar later opnieuw serum afgenomen, werd een vragenlijst afgenomen om het nsico van een her-infectie in de tussentiggende periode in te schaten. CAT net behulp van een micro-immunoflurescence test (MIF) werd uitgevoerd op het initiele en het nieuwe serummonster. Ter validatie wan de MIF test werd tevens een species-specifieke ELISA verricht. Zeven van de $39(18 \%)$ patienten toonden een significante afname van IgG antilichamen (minimaal twee titerstappen). Seroconversie van positief naar negatief werd slechts bij ển patiënt aangetoond. De ELISA resultaten voor deze groep toonden geen daling van IgG antistoffen. Uit de resultaten van de vragenlijst kon worden geconcludeend dat het voórkomen van risicofactoren woon her-infectie gelijk was woor patienten met en patiënten zonder titer daling. Afname van de $\operatorname{IgC}$ antilicham titer $1 \mathrm{jkt}$ derhalve geen bielangrijke oorzaak voor fout-negatieve CAT uitslagen te zijn.

In hoofdstuk 3 onderzochten we de rol van C. phewnoniae als potentiele oorzaak voor het voorkomen van fout-positieve CAT uitslagen. Fout-positieve CAT kunnen het gevolg zijn van kruisreactie in de MIF test tussen C. trachomatis en andere species, bijw. C. pnewmoniae: In een groep van 240 patiënten werden serologische data vergeleken met de laparoscopische bevindingen. De prevalentie van C. pnewnonine $\operatorname{Ig} G$ antistoffen bedroeg $75 \%$, en was vergelijkbaar voor patiënten met en zonder tubapathologie.

Van de patiënten met een positieve MIF test $(232)$ was $87 \%$ C. pnewmoniae IgG positief, versus $66 \%$ wan de patiẻnten met een negatieve MIF test $(p<0.0005$ ). Wanneer de ELISA werd gebrukt voor het aantonen van $C$ machowatis IgG waren de cijfers respectievelijk $87 \%$ van de $\mathrm{C}$. trachomatis positieve patienten versus $69 \%$ wan de $C$. trachowatis megatieve patiënten $(p<0.0005)$. In de groep patienten zonder tubapathologie mat een positieve MIF test ("fout-positieve" CAT) werden relatief vaker $C$. pwenmonide $\mathrm{IgG}$ antistoffen angetrofren dan in de groep patienten zonder tubapathologie an een negatieve MIF test "terecht negatieve" CAT). Kruisteactie in de MIF tussen $C$. trachomatis en $C$. pneumoniac speelt dus een rol bij het voórkomen van fout-positieve CAT uitslagen. Opvallend was dat tubapathologie vaker voorkwam bij patiënten met zowel $\mathrm{G}$. trachomatis $\lg \mathrm{G}$ en $\mathrm{C}$. phewmonace $\operatorname{IgC}$ antistoffen, implicerend dat C. pnewmoniae een rol zou kunnen spelen in het ontstain wan C. rachomatis gerelateerde tubapathologie.

Hoofdstuk 4 beschrijft de voorspellende waarde van CAT voor vijf comnercieel beschikbare tests (MIF Biomericux, MIF Labsystems, ELISA Labsystems, pELISA Medac, ELISA Savyon). In een prospectief verzameld cohort van 315 patiënten werden de resultaten van de vijf tests gecorreleerd aan de bevindingen bij laparoscopie. Verder werd onderzocht of een verbetering van de voorspellende waarde mogelijk was door het combineren van een of meer tests. MIF labsystems 
bleek superieur aan de andere 4 tests (OR 15.7), en van de drie ELISA's, kwam pELISA van MEDAC als beste test naar voren. Logistisclie regressie analyse toonde geen verbetering van predictieve warde door het combineren van twee tests. In alle tests, behalve in PELISA wan MEDAC, werd een significante kruis-reactiviteit met $C$. pneumoniae antistoffen gevonden.

Hoofdstuk 5 beschrijft screening van endocervicale $C$. trachomatis infecties bij subfertiliteitspatiënten. Als onderdeel van het fertiliteitsonderzoek of -behandieling vindt frequent intra-uteriene instrumentatie plaats. De aanwezigheid van actieve danwel persisterende endocervicale $C$. trachomatis infecties vormen derhalve een risicofactor woor het ontstaan van opstijgende infecties. Endocervicale PCR screening detecteert met name actieve infectie, waardoor een persisterende infectie mogelijk niet wordt onderkend en CAT toont eerdere expositie aan C. trachomatis, zonder informatie over de actuele aanwezigheid van $C$. trachomatis in de endocervix. Er is geen adequate non-invasieve screeningstest voor de aanwezigheid van persisterende infectie in de tractus genitalis. Gebaseerd op deze theoretische argumenten, adviseren we profylactische antibiotica (eenmalig azythromycine, 12 uur voor de geplande ingreep) voor elke subfertiele patiënte voorafgaand aan intra-uteriene instrumentatie, in plaats van endocervicale $C$. trachomatis screening en behandeling van de patiënten met een positieve test uitslag.

In hoofdstuk 6 beschrijven we de ontwikkeling van een muismodel, ter bestudering van het nog grotendeels onbekende ontstaan van tubapathologie ten gevolge van $C$. trachomatis. Er werd verondersteld dat uitgebreide tubapathologie niet ontstaat in aansluiting aan een primaire (subklinische) C. trachomatis infectie, maar dat met name herhaalde infecties kunnen leiden tot uitgesproken afwijkingen. Vrouwelijke C57BL/6J muizen werden intravaginaal geïnoculeerd met de humane $C$. trachomatis L2 stam. Intervalsgewijs werden dieren opgeofferd en de histopathologische veranderingen en weefselschade in de tractus genitalis bestudeerd. Een groep muizen onderging een tweede inoculatie om het effect van her-infectie op het ontstaan van tubapathologie te evalueren. Tevens werd een pilot-studie verricht waarin de eventuele bijdrage van C. pneumoniae aan C. trachowatis-geinduceerde pathologie werd bestudeerd. Enkelvoudige intravaginale inoculatie van $\mathrm{C} 57 \mathrm{BL} / 6 \mathrm{~J}$ muizen met humane $C$. trachonatis $\mathrm{L} 2$ induceerde een infectie zonder uitgebreide tubapathologie, maar met een chronische ontstekingsreactie. Re-inoculatie stimuleerde dat proces, uiteindelijk leidend tot atypie van het endometrium. Afwijkingen op weefsel- alsmede cellulair niveau waren meer uitgesproken na her-inoculatie, alhoewel uitgebreide tractus genitalis pathologie niet werd waargenomen. Diverse factoren, mogelijk verantwoordelijk voor de milde bevindingen werden bediscussieerd.

Hoofdstuk 7 vooronderstelt dat auto-immuniteit, gebaseerd op kruis-reactiviteit van Chlamydia hsp60 (Chsp60) antistoffen met humaan hsp60, ten grondslag 
zou kunnen liggen aan het ontstaan van tubapathologie. In een muismodel werden in aansluiting aan infectie met $C$. trachomatis en / of C. pneumoniae Chsp60 en muis hsp60 (mhsp60) antistoffen bepaald. De resultaten ondersteunden de hypothese niet, daar slechts sporadisch Chsp60 en mhsp60 antistoffen konden worden aangetoond.

In hoofdstuk 8 worden onderwerpen beschreven die bijdragen aan ons huidige begrip en de benadering van asymptomatische $C$. trachowatis infecties en de late gevolgen ervan. In deze context bediscussieerden we de resultaten van de gepresenteerde studies. De belangrijkste bevindingen van het onderzoek werden samengevat. 


\section{ankwoord}

\section{Het is af.}

Het antwoord op de vraag die de afgelopen jaren vele malen de opening vormde van oppervlakkige, diepgaande, goede en minder goede gesptekken. ledereen met wie ik deze gesprekken voerde wil ik bedanken voor de net aflatende belangstelling en het vertrouwen dat ze door het vaak meermalen stellen van die vragg getoond hebben. Met name wil ik hen bedanken die hebben meegeholpen bij de realisatie van dit proefschrift.

Professor Evers, telkens als ik ne afvroeg wiens idee het "tien-jaren plan IVF-arts / promotieonderzoek / Gynaecologie opleiding" ook alweer was, lad u weinig woorden nodig. .. Heel hartelijk dank voor de geboden kansen, uw bijstaring en ansporing op de juiste momenten.

Professor Bruggeman, beste Cathrien, al sinds het prille begin van het onderzoekstraject hebben we gebruik genaakt van je expertise over het onbegrijpelijke gedrag van Chlamydia. Je menselijke benadering, en je net aflatende vertrouwen in het uiteindelijke resultaat hebben me meermalen van weerhouden de kaft er maar af te laten.

Jolande Land, mijn onderzoek begon met een op het eerste oog eenvoudige database, die gedurende het onderzoek wan steeds grotere watarde bleek Dankzij jouw onuitputtelijke inzet is het Chlamydia-onderzoek inmiddels uitgegroeid tot een gedegen onderzoeksgroep met enthousiaste mensen uit verschillende disciplines en meerdere klinieken. Dank voor de mogelijkheid als eerste promovendus te participeren binnen deze groep.

Vakgroep Medische Microbiologie, analisten en onderzockers, Gert Grauls, Marjon Gijbels, Frank Stassen en medewerkers proefdierlaboratorium. Dank voor jullie hulp en geduld bij het uitleggen van allerlei laboratorium en dier-experimentele vaardigheden, de vele MIF's en ELISA's, het snijden en kleuren van de coupes, de discussies over de ruwe resultaten. Het feit dat iedereen gemakkelijk benaderbaar was, maakte dat ik me thuis voelde in een voor mij volstrekt vreemde werkomgeving.

Fons Kessels, je snelle inzicht in mijn allerminst gestructureerde spreadsheets en onderzoeksresultaten en thet in no time toepassen van de juiste statistische toetsen 
op die data zijn bijzondere gaven. De statistiek zố uitleggen, dat een gewone clinicus als ik er mee uit de voeten $k a n$, een zo mogelijk nog grotere!

IVF-team, lieve Germaine, Laurence, Carla, Ceciel, Josien, Edith en alle anderen: heel veel plezier heb $\mathrm{k}$ gehad in het samen draaiend houden van de uit zijn kluten gewassen IVF-afdeling. Op de meest cruciale momenten hielden jullie me met beide benen op de grond met gesprekken over zaken die niets met wetenschappelijk onderzoek, maar alles met het leven te maken hadden. Heel hartelijk bedankt woor all jullie steun en vriendschap.

Lieve Jacques, twaalf jaar geleden in Uppsala hadden we niet het geringste vermoeden dat we vrijwel onze hele opleiding samen zouden gaan doorlopen. Van collega's werden we maatjes, trotseerden we weer en wind om op de meest onmogelijke tijdstippen, via toeristische routes de files omzeilend, aan onze opleidingseisen te voldoen. Inmiddels zijn we beiden bijna gynaecoloog, een doel dat jarenilang mijlenver weg leek.

Lieve Janneke, ik bewonder je overgave en de koelbloedigheid waarmee je het onderzoek hebt overgenomen en richting gegeven. Ik ben blij dat je, als voorproefje op je eigen promotie, me vandaag terzijde wilt staan Laat je nog even niet afleiden door alle nieuwe uitdagingen in de kliniek, veel succes met de latste loodjes!

Heenlense maatschap Gynaecologie en collegae assistent gynaecologen, op het dieptepunt van mijn motivatie had ik me geen betere start van de opleiding kumnen wensen. Op een degelijke fundering is het stevig bouwen.

Lieve pap en mam, en Ruud, heel waak was het bijna af, soms kwan het nooit meer af, nu is het echt af! Bedankt voor jullie onvoorwaardelijke liefde, steun en belangstelling.

Lieve Wilbert, het feit dat ik jou ontmoette in een tijd waarin mijn gedachten grotendeels bestonden uit het afionden van dit boekje is (volgens jou) voorbestemd geweest. Bedankt dat we ondanks je eigen drukke bezigheden steeds weer tijd, steun, hulp, geduld, gezelligheid, lach en liefde kunnen delen. Hakuna matata, er komen nóg betere tijden! 


\section{urriculum vitae}

Tanja Gijsen werd op 8 november 1971 te Nederweert geboren. In 1990 voltooide zij het VWO aan de Philips van Horne Scholengemeenschap te Weert, waarna zij startte met de studie Geneeskunde aan de Universiteit Maastricht. Na het artsexamen in juni 1997 werkte zij als Assistent Geneeskundige Niet in Opleiding op de afdeling Gynaecologie van het Elkerliek ziekenhuis te Helmond. Vervolgens werkte zij wan mei 1998 tot april 2002 als IVF-arts in het Academisch Ziekenhuis in Maastricht. Naast het klinisch werk op de IVF-afdeling, werd gestart met het onderzoek beschreven in dit proefschrift. Het onderzoek werd uitgevoerd binnen het onderzoeksinstituut Groei en Ontwikkeling (GROW), afdeling Obstetrie en Gynaecologie (begeleider: prof. dr. J.L.H. Evers) en de afdeling Medische Microbiologie (begeleider: prof. dr. C.A. Bruggeman). Vanaf april 2002 is zij in opleiding tot gynaecoloog. De opleiding werd gestart in het Atrium Medisch Centrum te Heerlen (opleider dr. F.J.M.E. Roumen) en vanaf april 2005 vervolgd in het Academisch ziekenhuis te Maastricht (opleider prof. dr. J.L.H. Evers). 